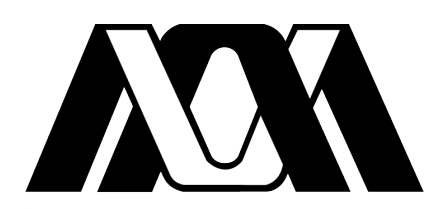

Casa abierta al tiempo

UNIVERSIDAD AUTÓNOMA METROPOLITANA

UNIDAD IZTAPALAPA

DIVISIÓN CIENCIAS BÁSICAS E INGENIERÍAINGENIERÍA BIOMÉDICA

\title{
Efecto del Polipirrol/Yodo como tratamiento \\ de la lesión de médula espinal de ratas \\ evaluado mediante imágenes \\ de difusión por resonancia magnética in vivo
}

Tesis que presenta

Rodrigo Mondragón Lozano

Para obtener el grado de Doctor en Ciencias

(Ingeniería Biomédica)

Directores de tesis:

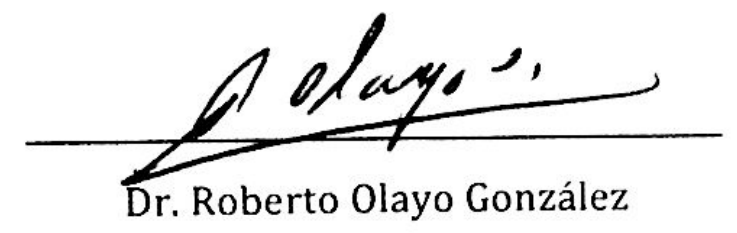

Dr. Roberto Olayo González

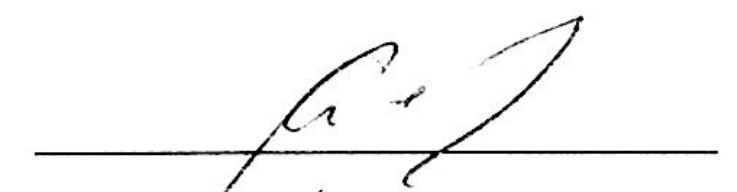

Dra. María de los Ángeles Araceli Díaz Ruiz

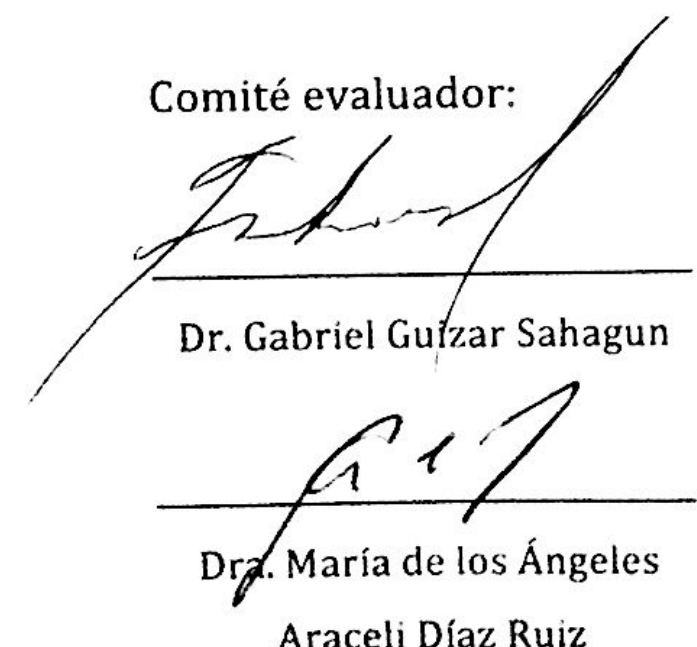

Araceli Díaz Ruiz

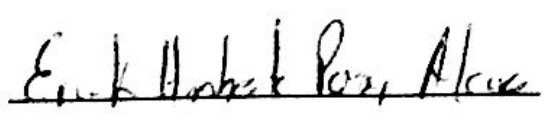

Dr. Erick Humberto Pasaye

Alcaráz

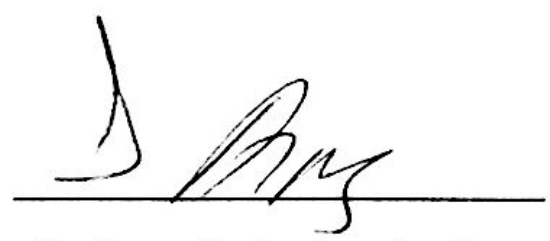

Dr. Joaquín Azpiroz Leehan

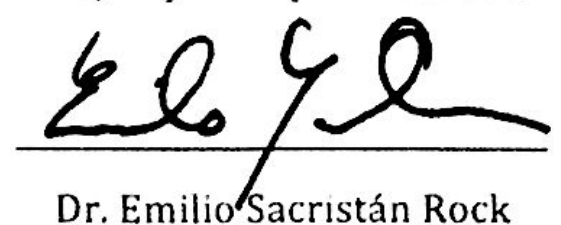

Dr. Emilio Sacristán Rock

México, Junio 2014 


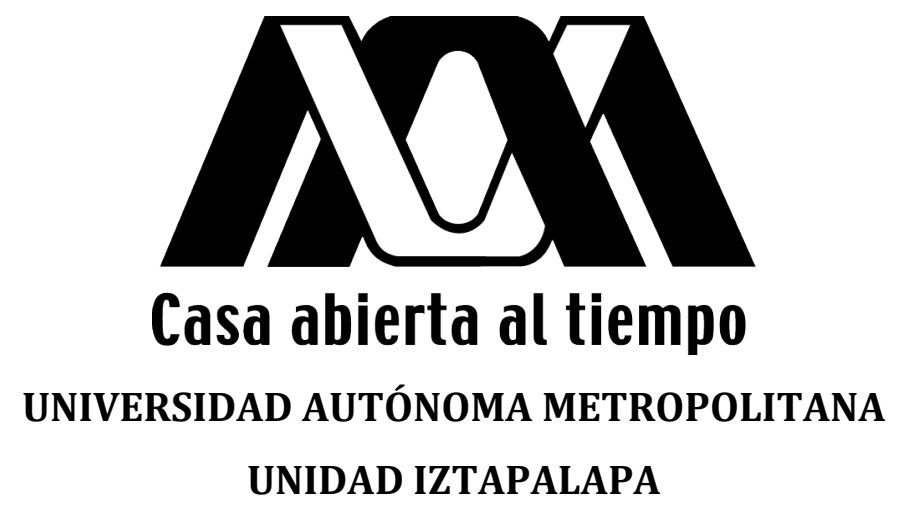

DIVISIÓN CIENCIAS BÁSICAS E INGENIERÍA

INGENIERÍA BIOMÉDICA

Efecto del Polipirrol/Yodo como tratamiento de la lesión de médula espinal de ratas evaluado mediante imágenes de difusión por resonancia magnética in vivo

\section{Rodrigo Mondragón Lozano}

Directores de tesis: 


\section{Agradecimientos}

Este trabajo se realizó gracias al apoyo de:

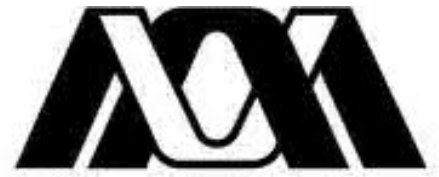

Casa abierta al tiempo
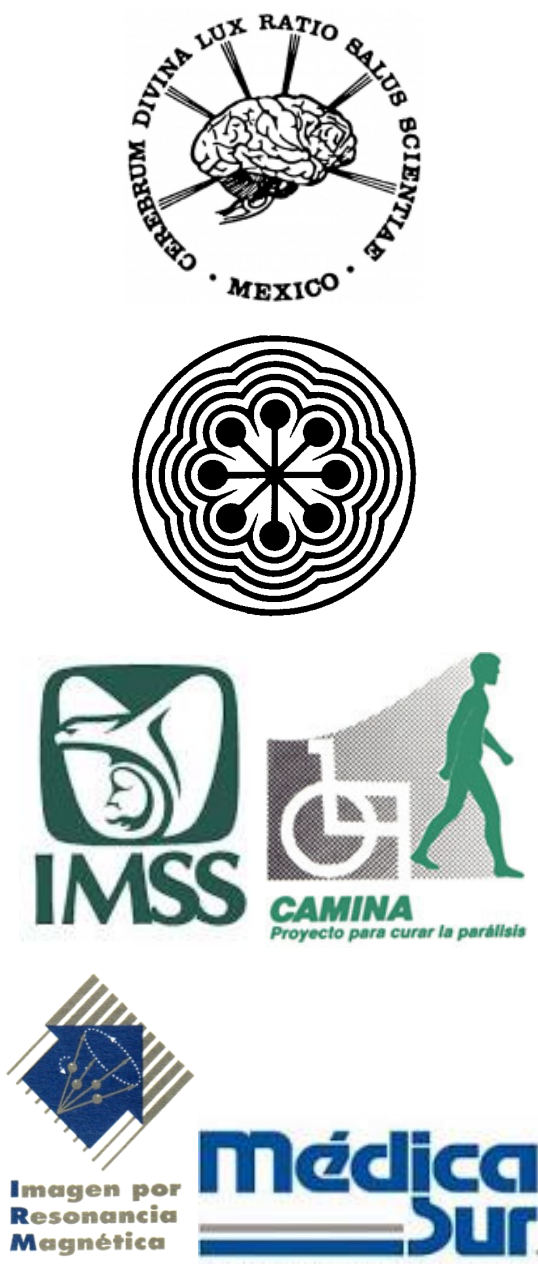

Macuética

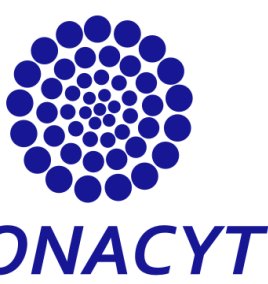

CONACYT

Consejo Nacional de Ciencia y Tecnología
Universidad Autónoma Metropolitana

Dr. Roberto Olayo González

Dr. Juan Morales Corona

Instituto Nacional de Neurología y Neurocirugía

Dra. María de los Ángeles Araceli Díaz Ruiz

Dr. Camilio Ríos Castañeda

Instituto Nacional de Investigaciones Nucleares

Dra. Guadalupe Olayo González

Dr. Guillermo Cruz Cruz

Instituto Mexicano del Seguro Social/Proyecto CAMINA A. C. Dra. Hermelinda Salgado Ceballos

Imagen por Resonancia magnética/Fundación Medica Sur Dr. Ernesto Roldan Valadez

\section{Consejo Nacional de Ciencia y Tecnología}

Programa de becas para estudios de posgrado: 172223 


\section{Contenido}

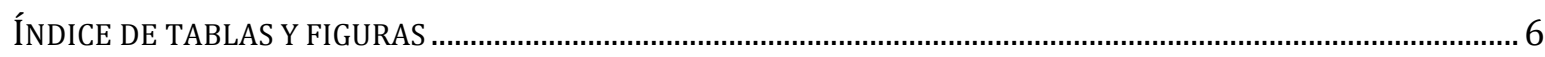

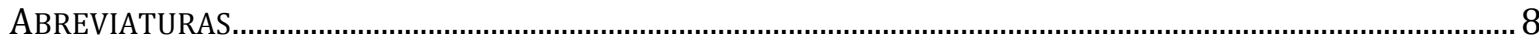

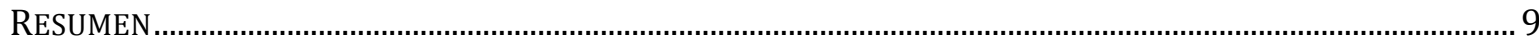

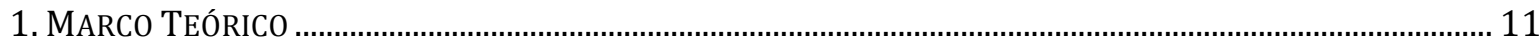

1.1. Anatomía y función de la médula espinal .............................................................................................13

1.2. Epidemiología y fisiopatología de la lesión traumática de la médula espinal ...................................... 15

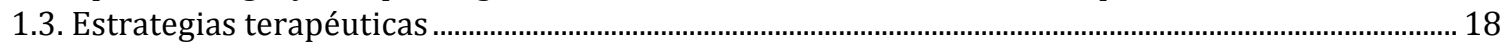

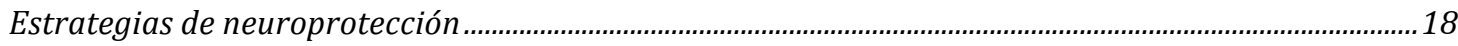

Estrategias de neuroregeneración.......................................................................................................................20

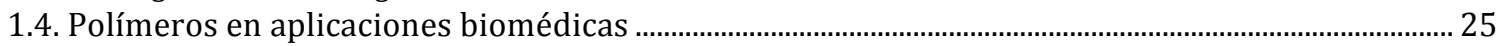

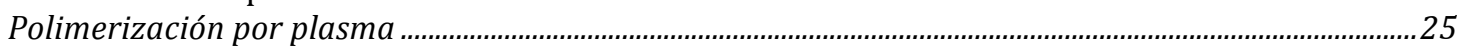

Ventajas:

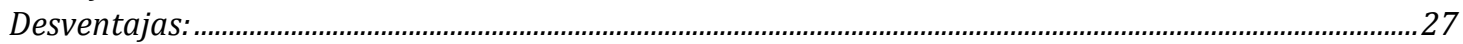

Polímeros por plasma en aplicaciones biomédicas ......................................................................................27

1.5. Evaluación de la lesión de la médula espinal en modelos experimentales ...........................................2 27

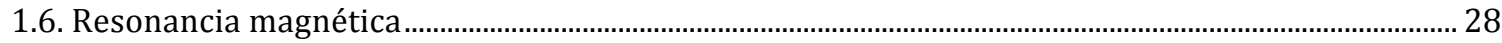

Difusión por Resonancia Magnética....................................................................................................................32

Uso de la Resonancia magnética en lesiones de la médula espinal..................................................................36

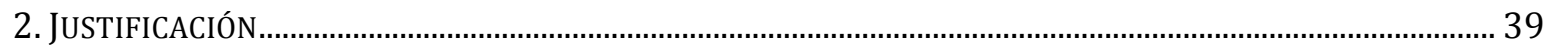

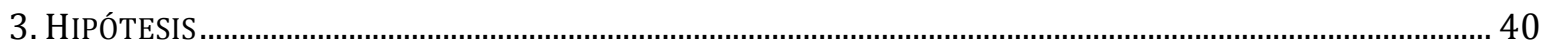

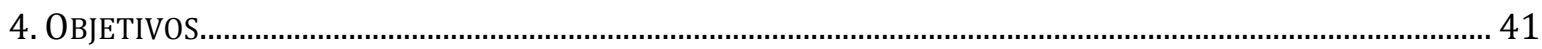

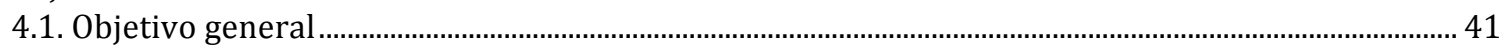

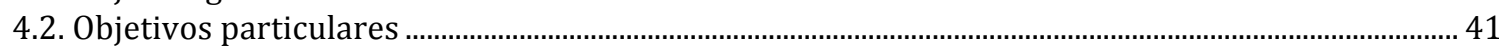

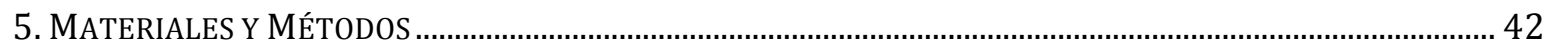

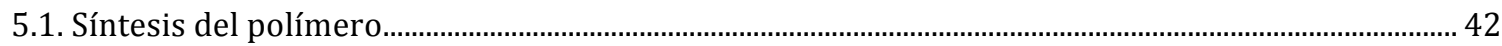

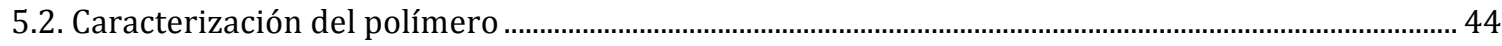

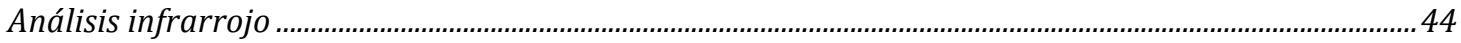

Descripción morfológica y análisis elemental ……..........................................................................................44

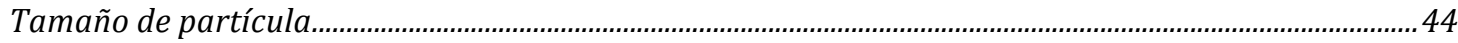

5.3. Elaboración del tratamiento con Polipirrol/Yodo ....................................................................................... 44

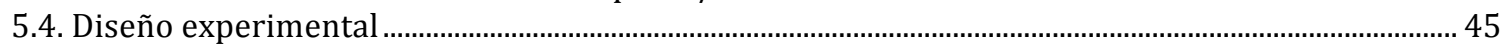

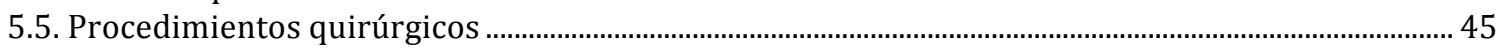

Lesión por contusión de la médula espinal y administración de tratamiento...............................................45

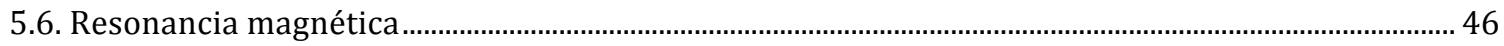

Diseño y construcción de dispositivo de fijación ...............................................................................................4

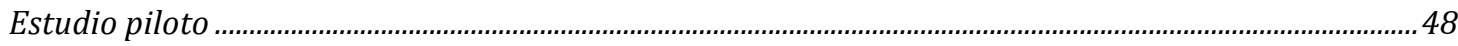

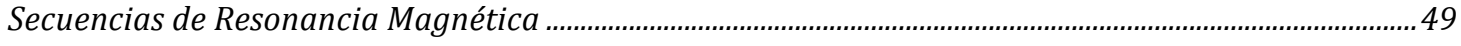

Post-procesamiento de imágenes y medición de parámetros............................................................................50

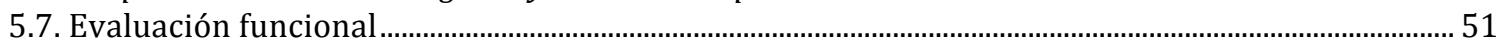

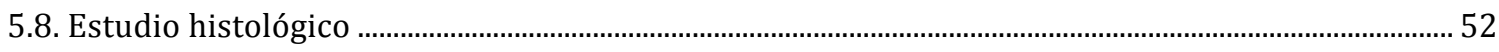

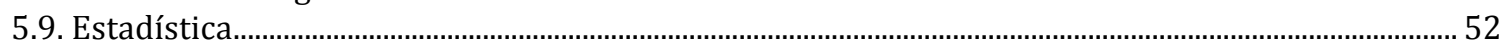

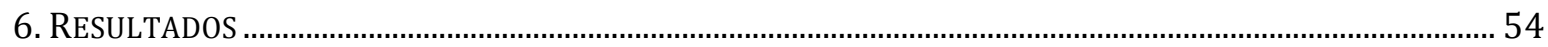

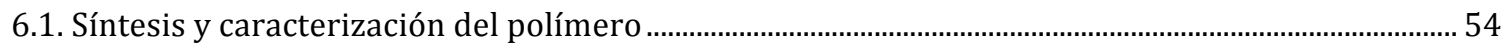

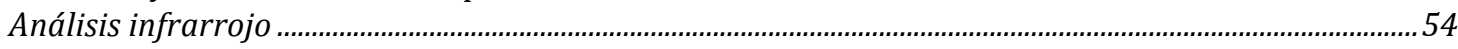

Descripción morfológica y análisis elemental …………................................................................................55 


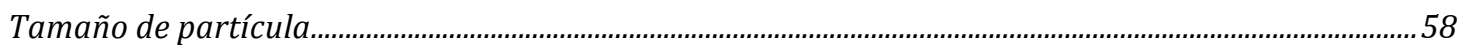

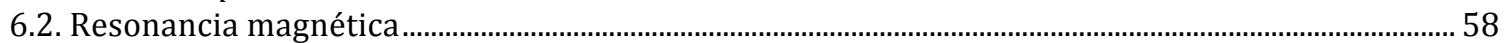

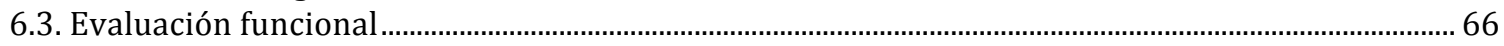

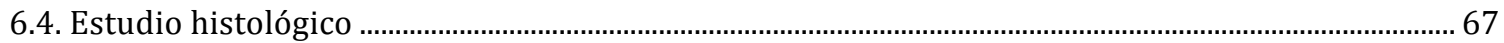

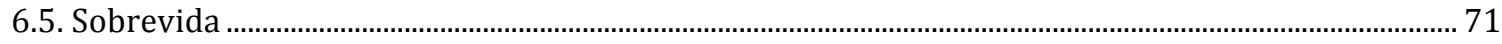

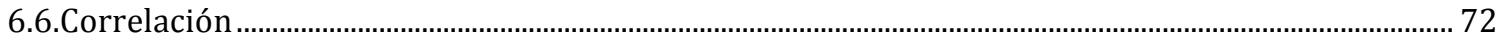

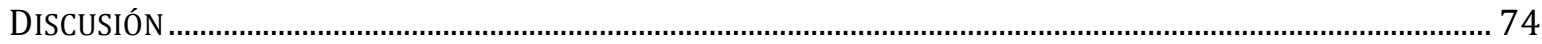

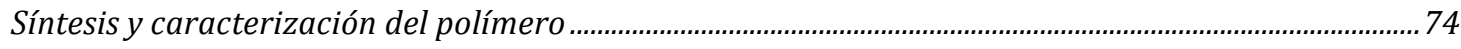

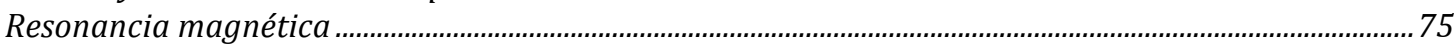

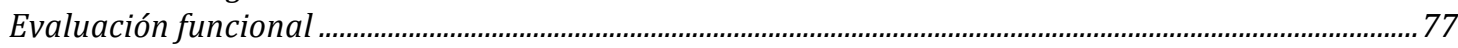

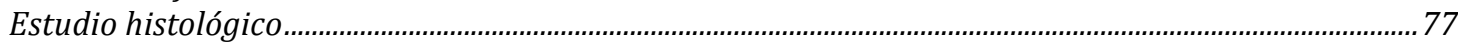

CONCLUSIONES ................................................................................................................................. 79

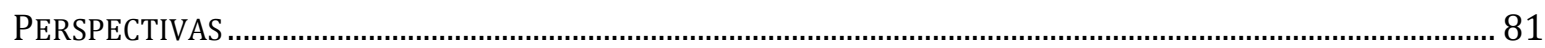

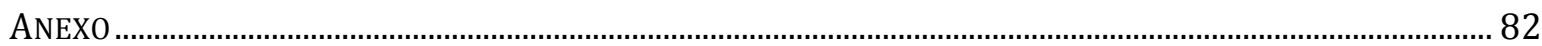

A. Reglamento de la ley general de salud en materia de investigación para la salud .............................. 82

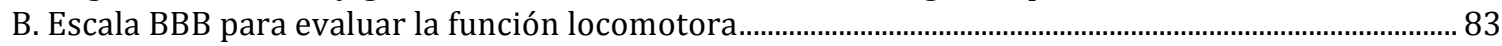

C. Procedimiento de tinción. Método de Hematoxilina y Eosina de Harris ..................................................85

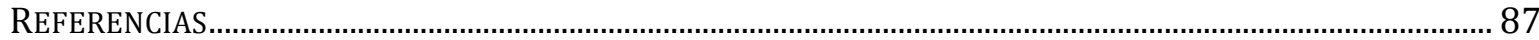




\section{Índice de tablas y figuras}

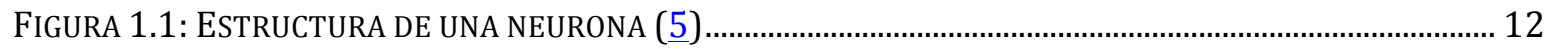

FIGURA 1.2: ESTRUCTURA DE LA MÉDULA ESPINAL (1) ……................................................................... 13

FIGURA 1.3: CORTE TRANSVERSAL DE LAS PRINCIPALES VÍAS LARGAS DE FIBRAS NERVIOSAS DE LA MÉDULA

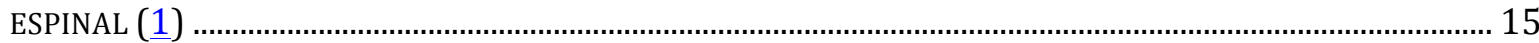

FIGURA 1.4: PRINCIPALES EVENTOS DE DAÑO SECUNDARIO DESPUÉS DE UNA LESIÓN TRAUMÁTICA DE LA

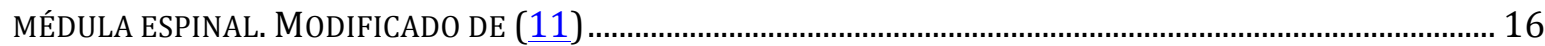

FIGURA 1.5: ESQUEMA DEL PROCESO DE RESONANCIA MAGNÉTICA. CONJUNTO DE NÚCLEOS EN AUSENCIA DE UN CAMPO MAGNÉTICO, GIRAN ALREDEDOR DE SU EJE EN DIRECCIONES ALEATORIAS (A). EN PRESENCIA DE UN CAMPO MAGNÉTICO LOS NÚCLEOS SE ALINEAN DE FORMA PARALELA AL CAMPO (B). PULSO DE RF (C). CAMBIA LA DIRECCIÓN DE LA MAGNETIZACIÓN A UN PLANO TRANSVERSAL AL CAMPO MAGNÉTICO B $_{0}$ (D). 29

FIGURA 1.6: RELAJACIÓN LONGITUDINAL: DECAIMIENTO DE LA MAGNETIZACIÓN TRANSVERSAL Y AUMENTO DE LA MAGNETIZACIÓN EN EL EJE Z DEBIDO A LA INTERACCIÓN DE LOS NÚCLEOS CON EL ENTORNO (A). LA PÉRDIDA DE FASE DE PRECESIÓN DE LOS NÚCLEOS PROVOCA LA PÉRDIDA DE LA MAGNETIZACIÓN

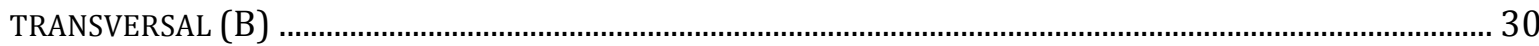

FIGURA 1.7: DECAIMIENTO DE INDUCCIÓN LIBRE (FID). ES PROPORCIONAL A LA CANTIDAD DE MAGNETIZACIÓN TRANSVERSAL GENERADO POR EL PULSO DE RF ................................................................. 31

FIGURA 1.8: ESQUEMA DE DIFUSIÓN LIBRE Y RESTRINGIDA............................................................................ 34

TABLA 5.1: PARÁMETROS DEL REACTOR DE PLASMA PARA LA SÍNTESIS DEL POLÍMERO ................................. 42

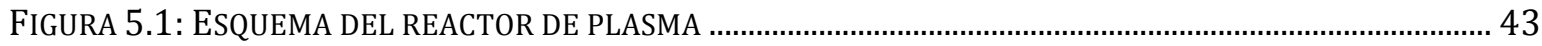

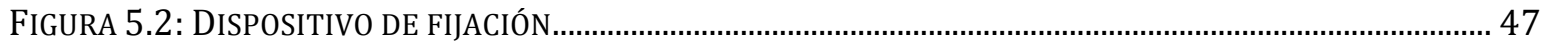

FIGURA 5.3: ESQUEMA DE DISPOSITIVO DE FIJACIÓN .................................................................................. 48

FIGURA 5.4: (A) ESQUEMA DE COLOCACIÓN DE LA RATA EN EL SISTEMA DE FIJACIÓN Y BOBINA, (B) UBICACIÓN DENTRO DE LA BOBINA DE LA MUÑECA EN CUADRATURA (MAYO CLINIC, MODELO BC-10, ROCHESTER, MN) CON EL DISPOSITIVO DE FIJACIÓN, (C) ESCÁNER CLÍNICO DE MR 3T (SiGNA HDXT, GE

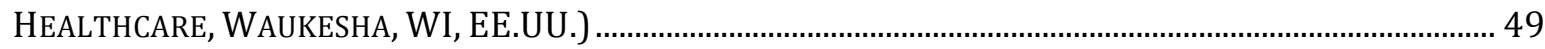

TABLA 5.2: PARÁMETROS DE LAS SECUENCIAS DE RESONANCIA MAGNÉTICA …............................................... 50

FIGURA 5.5: REPRESENTACIÓN ESQUEMÁTICA DE LA LOCALIZACIÓN DE LOS ROIS (IZQUIERDA) Y EJEMPLOS DE LA SECUENCIAS EMPLEADAS PARA LA MEDICIÓN DE PARÁMETROS (DERECHA). LÍNEAS VERDES, REFERENCIA DEL NIVEL DE LOS CORTES. MODIFICADO DE (102) ….............................................................. 51

FIGURA 6.1: ESPECTROS INFRARROJOS DE PPYI SINTETIZADO POR PLASMA A 80 W DURANTE 240 MIN.... 55

FiguRA 6.2: MiCROGRAFías SEM DE PPy/I. (A) SUPERFICIE DE LA PELÍCULA 2500X, (B) PERFIL DE LA PELÍ́CULA 2000X, (C) PARTíCULAS RESULTANTES DESPUÉS DE MOLER LA PELÍCULA 1000X....................... 56

TABLA 6.1: COMPOSICIÓN ELEMENTAL Y RELACIÓN ATÓMICA DEL PPY/I ……................................................. 57

FIGURA 6.3: IMÁGENES REPRESENTATIVAS SAGITALES T1 DE RESONANCIA MAGNÉTICA IN VIVO DE LA MÉDULA ESPINAL DE RATA (GRUPo CONTROL). (A) RATA SANA. (B) RATA UNA SEMANA DESPUÉS LA LESIÓN. (C) RATA CUATRO SEMANAS DESPUÉS DE LA LESIÓN. (D) RATA OCHO SEMANAS DESPUÉS DE LESIÓN. LAS FLECHAS INDICAN NIVEL DE LESIÓN. ................................................................................................. 59 
FIGURA 6.4: IMÁGENES REPRESENTATIVAS SAGITALES T2 DE RESONANCIA MAGNÉTICA IN VIVO DE LA MÉDULA ESPINAL DE RATA (GRUPO CONTROL). (A) RATA SANA. (B) RATA UNA SEMANA DESPUÉS DE LA LESIÓN. (C) RATA CUATRO SEMANAS DESPUÉS DE LA LESIÓN. (D) RATA OCHO SEMANAS DESPUÉS DE LESIÓN. FLECHAS INDICAN NIVEL DE LESIÓN. 60

FIGURA 6.5: SECUENCIAS IN VIVO DE RESONANCIA MAGNÉTICA DE TENSOR DIFUSIÓN DTI, DWI, Y T2MAP ANTES Y DESPUÉS DE LA LESIÓN POR CONTUSIÓN MODERADA DE LA MÉDULA ESPINAL DE RATAS (GRUPO CONTROL). (A Y B): CORTE AXIAL DTI, EN NIVEL VERTEBRAL T10 SE OBSERVAN DIFERENCIAS EN LA INTENSIDAD DE LA SEÑAL ENTRE LA MÉDULA ESPINAL PREVIO A LA LESIÓN (A) Y LA ZONA DE LESIÓN 1 SEMANA DESPUÉS DE LA CONTUSIÓN (B). (C Y D): CORTE SAGITAL DWI DE LA MÉDULA ESPINAL DE RATA SANA (C), LA FLECHA INDICA EL LUGAR DE LA CONTUSIÓN UNA SEMANA DESPUÉS DE LA LESIÓN (D). (E Y F) IMÁGENES SAGITALES T2MAP DE UNA RATA SANA (E) Y SE MUESTRAN LOS CAMBIOS SUTILES EN LOS TIEMPOS DE RELAJACIÓN EN EL SITIO DE LA LESIÓN MEDULAR. LAS FLECHAS (B, D Y F) MUESTRAN EL SITIO DE LESIÓN 1 SEMANA DESPUÉS.

FIGURA 6.6: GRÁFICA DE T2MAP. (A)NIVEL CERVICAL, (B)NIVEL LESIÓN. LOS VALORES ESTÁN EXPRESADOS COMO MEDIAS \pm E.E. ( $N=4$ POR GRUPO). ANÁLISIS DE ANOVA DE MEDIDAS REPETIDAS SEGUIDO DE PRUEBA DE DUNNETT. ${ }^{*} \mathrm{P}<0.05$. 62

FIGURA 6.7: GRÁFICA DE ADC. (A)NIVEL CERVICAL, (B)NIVEL LESIÓN. LOS VALORES ESTÁN EXPRESADOS COMO MEDIAS \pm E.E. ( $=4$ POR GRUPO). ANÁLISIS DE ANOVA DE MEDIDAS REPETIDAS SEGUIDO DE PRUEBA DE DUNNETT. ${ }^{*} \mathrm{P}<0.05$ 64

FIGURA 6.8: GRÁFICA DE FA. (A)NiVEL CERVICAL, (B)NIVEL LESIÓN. LOS VALORES ESTÁN EXPRESADOS COMO MEDIAS \pm E.E. ( $N=4$ POR GRUPO). ANÁLISIS DE ANOVA DE MEDIDAS REPETIDAS SEGUIDO DE PRUEBA DE DUNNETT. ${ }^{*} \mathrm{P}<0.05$

FIGURA 6.9: GRÁFICA DE LA RECUPERACIÓN MOTORA EVALUADA CON LA ESCALA BBB. LOS RESULTADOS ESTÁN EXPRESADOS COMO MEDIAS \pm E.E. ( $\mathrm{N}=4$ POR GRUPO). ANOVA DE MEDIDAS REPETIDAS SEGUIDA DE LA PRUEBA DE DUNNETT. *DIFERENCIA SIGNIFICATIVA AL COMPARAR CON EL GRUPO CONTROL P<0.05 .. 67

FIGURA 6.10: IMÁGENES REPRESENTATIVAS DE CORTES HISTOLÓGICOS LONGITUDINALES DE LA MÉDULA ESPINAL 8 SEMANAS DESPUÉS DE LA LESIÓN. TÉCNICA HISTOLÓGICA HEMATOXILINA EOSINA. (A) CONTROL, (B) Vehículo, (C) Polímero. 68

FIGURA 6.11: IMÁGENES COMPARATIVAS DE RESONANCIA MAGNÉTICA E HISTOLOGÍA DE RATA OCHO SEMANAS DESPUÉS DE LA LESIÓN POR CONTUSIÓN MODERADA DE LA MÉDULA ESPINAL (GRUPO CONTROL).

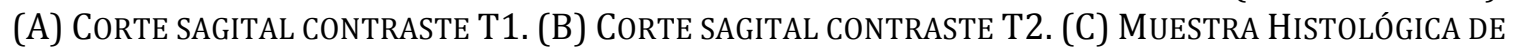
MÉDULA ESPINAL EN LA ZONA DE LESIÓN, TÉCNICA HISTOLÓGICA HEMATOXILINA EOSINA. FLECHAS INDICAN ZONA DE LESIÓN.

FIGURA 6.12: GRÁFICA DEL ANÁLISIS DE TEJIDO PRESERVADO. LOS RESULTADOS ESTÁN EXPRESADOS COMO MEDIAS \pm E.E. (8 SEMANAS DESPUÉS DE LA LESIÓN, N=4 POR GRUPO). ANOVA DE UNA VÍA SEGUIDA DE PRUEBA DE DUNNETT. * $\mathrm{P}<0.05$.

FIGURA 6.13: DIAGRAMAS DE DISPERSIÓN DE PARÁMETROS DE MR RELAXOMETRÍA T2 (T2MAP), COEFICIENTE DE DIFUSIÓN APARENTE (ADC) Y ANISOTROPÍA FRACCIONAL (FA) VS ESCALA FUNCIONAL (BBB) Y TEJIDO PRESERVADO. CORRELACIÓN SPEARMAN, 8 SEMANAS DESPUÉS DE LA LESIÓN. 


\section{Abreviaturas}

\begin{tabular}{|c|c|}
\hline PPy/I & Polipirrol/Yodo \\
\hline IR & Infrarrojo \\
\hline BBB & Basso, Beattie y Bresnahan \\
\hline T2MAP & Relaxometria T2 \\
\hline ADC & Coeficiente de Difusión Aparente \\
\hline FA & Anisotropía Fraccional \\
\hline MR & Resonancia Magnética \\
\hline $3 \mathrm{~T}$ & 3 Tesla \\
\hline TE & Tiempo de Eco \\
\hline TR & Tiempo de Repetición \\
\hline FOV & Campo de Visión \\
\hline T1 & Relajación Longitudinal \\
\hline T2 & Relajación Transversal \\
\hline DWI & Imágenes Ponderadas en Difusión \\
\hline DTI & Imágenes de Tensor de Difusión \\
\hline SPGR & Spoiled Gradient Echo \\
\hline ROI & Región de Interés \\
\hline LTME & Lesión Traumática de la Médula Espinal \\
\hline PT & Patas Traseras \\
\hline PD & Patas Delanteras \\
\hline $\mathbf{R F}$ & Radiofrecuencia \\
\hline SEM & Microscopio Electrónico de Barrido \\
\hline SN & Sistema Nervioso \\
\hline SNC & Sistema Nervioso Central \\
\hline SNP & Sistema Nervioso Periférico \\
\hline
\end{tabular}




\section{Resumen}

Introducción: La lesión traumática de la médula espinal (LTME) es un padecimiento que provoca un daño irreversible que induce la pérdida de la función motora, sensitiva y autónoma. Actualmente no se cuenta con una estrategia terapéutica efectiva para restablecer la función neurológica perdida, debido a la complejidad para revertir los mecanismos fisiopatológicos que se desencadenan. Se ha demostrado que los implantes de polímero semiconductor después de una lesión por sección completa de la médula espinal, promueven la preservación del tejido nervioso y la recuperación funcional en ratas. Por otra parte, la evaluación de los tratamientos propuestos se realiza a través del monitoreo de escalas cualitativas de la calidad de marcha o de forma cualitativa mediante el análisis del tejido nervioso post mortem. La Resonancia Magnética (MR por sus siglas en inglés) es la herramienta más adecuada para el estudio longitudinal no invasivo en animales de experimentación en lesión de médula espinal. Las imágenes convencionales de MR de la médula espinal permiten registrar una descripción cualitativa de la evolución de la patología y dar seguimiento en tratamientos experimentales, además, la difusión por MR permite realizar mediciones cuantitativas de parámetros directamente relacionados con el estado fisiopatológico de la médula espinal. Los estudios en roedores descritos hasta el momento que emplean MR in vivo, utilizan sistemas de alto campo destinados a la investigación en combinación con antenas de superficie o implantadas que logran una alta resolución espacial. Sin embargo, la disponibilidad de estos equipos es limitada. A diferencia de estos sistemas, los equipos clínicos de MR son de mayor acceso y cuentan con secuencias que permiten la comparación directa de los resultados entre roedores y humanos.

Objetivo: Evaluar el efecto neuroprotector y promotor de la recuperación funcional del PPy/I sintetizado por plasma como tratamiento en un modelo de lesión por contusión moderada de la médula espinal de ratas mediante la monitorización in vivo de parámetros de difusión por resonancia magnética empleando un equipo clínico de 3 Tesla.

Materiales y Métodos: Se realizó un estudio experimental aleatorizado, doble ciego y controlado con placebo, para evaluar el efecto de una suspensión elaborada de Polipirrol/Yodo administrada 48 horas después de una lesión por contusión moderada de la médula espinal en ratas. Los animales se dividieron en tres grupos experimentales: Grupo Control, animales con lesión por contusión moderada de la médula espinal; Grupo Vehículo, lesión por contusión moderada de la médula espinal más $30 \mu$ de solución salina; Grupo Polímero: lesión por contusión moderada más $30 \mu \mathrm{l}$ de suspensión en solución salina de PPy/I. Para monitorizar el estado de la médula espinal se realizaron secuencias de imágenes por MR y se tomaron mediciones 
a nivel cervical y torácica: Sag T1 y T2 y T2MAP para medir los tiempos de relajación T2, y de difusión y tensor de difusión para medir los parámetros de coeficiente de difusión aparente (ADC) y anisotropía fraccional (FA) respectivamente, estas secuencias se realizaron previo al modelo de lesión para conocer el estado normal de la médula espinal y posteriormente 1, 4 y 8 semanas, paralelamente se llevaron a cabo evaluaciones de la calidad de la marcha con la escala $\mathrm{BBB}$, al término de este tiempo los animales fueron sacrificados para realizarles un estudio histológico y evaluar la cantidad de tejido nervioso preservado.

Resultados: Los parámetros de MR de relaxometría T2 no mostraron diferencias entre los grupos en ninguno de los dos niveles (cervical y torácico), pero si un incremento en los valores a lo largo del estudio a nivel torácico, el parámetro ADC mostro diferencia significativa en comparación con el grupo control a nivel torácico, mientras que a nivel cervical no se observaron diferencias significativas a lo largo del estudio ni entre los grupos. El valor FA mostro diferencias estadísticas significativas a nivel torácico entre el grupo polímero al ser contrastado con el grupo control y sin diferencias significativas a nivel cervical. Los resultados mostraron que los animales del grupo polímero tuvieron una mayor recuperación funcional al ser evaluados con la escala BBB y comparados con el grupo control. El grupo polímero se observó una mayor cantidad de tejido preservado presentando una diferencia significativa al comparar contra el grupo control. Se observó que la evaluación funcional y la cantidad de tejido preservado muestran una correlación positiva con la FA y un asociación inversa con el ADC.

Conclusiones: Este es el primer estudio en el que se prueba el PPy/I sintetizado por plasma como tratamiento administrado in situ en un modelo semicronico de lesión por contusión moderada de la médula espinal de ratas. El empleo de un escáner clínico de MR en combinación con una antena de muñeca y un sistema de fijación permite obtener imágenes de modelos animales de LTME donde es posible identificar el sitio de lesión, así como obtener secuencias de difusión y medir parámetros como T2MAP, ADC, FA de forma muy reproducible que son sensibles a los cambios después de un modelo de lesión y evaluar posibles tratamientos. Los parámetros de difusión (ADC y FA) resultaron tener valor pronostico al presentar correlaciones con las técnicas experimentales empleadas para determinar el estado funcional y anatómico de la médula espinal (escala BBB y tejido preservado). El PPy/I mejora de manera significativa la función motora en los animales, este implante tiene un efecto neuroprotector al disminuir la cantidad de tejido dañado y presenta una menor respuesta inflamatoria cuando se compara con el grupo control. 


\section{Marco Teórico}

El sistema nervioso es una red de tejido especializado, que se encarga de coordinar las funciones más especializadas del organismo y desempeña 3 funciones principales: 1) función sensitiva, 2) función integradora, y 3) función motora. Se divide en Sistema nervioso central (SNC), que a su vez está compuesto por el encéfalo y la médula espinal, y sistema nervioso periférico (SNP). $(\underline{1}, \underline{2})$

El Sistema Nervioso (SN) se compone de dos tipos de células básicas; las neuronas, y las células de sostén y aislantes: 1) las neuronas, que realizan todas las funciones especializadas, como recibir e integrar en forma simultánea estímulos provenientes de varias fuentes, traducir el estímulo en una diferencia de carga eléctrica entre las superficies de sus membranas, propagar esta diferencia de potencial, traducir la señal eléctrica en mensajeros químicos y llevar estos mensajeros a células efectoras $(\underline{3}, \underline{4})$ (Figura 1.1). La neurona está constituida principalmente por cuatro regiones. a) Cuerpo celular: A partir de él se desprenden múltiples prolongaciones ramificadas que constituyen las principales áreas receptoras de la neurona. En esta región se encuentra el núcleo y gran cantidad de organelos. Brinda gran parte de la nutrición de la célula. b) Dendritas: Prolongaciones ramificadas del cuerpo celular. La mayoría de las señales que la neurona va a transmitir ingresan por las dendritas que suelen recibir señales de puntos de contacto con otras neuronas. Cada uno de estos se denomina sinapsis. c) Axón: Prolongación que abandona el soma de la neurona, suele denominarse fibra nerviosa. Llevan las señales nerviosas a la neurona siguiente. d) Sinapsis: Todos los axones presentan muchas ramificaciones cerca de sus terminaciones, en el extremo de cada una de esas terminaciones existe una terminación axónica especializada (terminación presináptica), que descansa sobre la superficie de la membrana de una dendrita o del soma de otra neurona; se tiene así un punto de contacto, denominado sinapsis, a través del cual se pueden transmitir las señales de una neurona a la siguiente. 


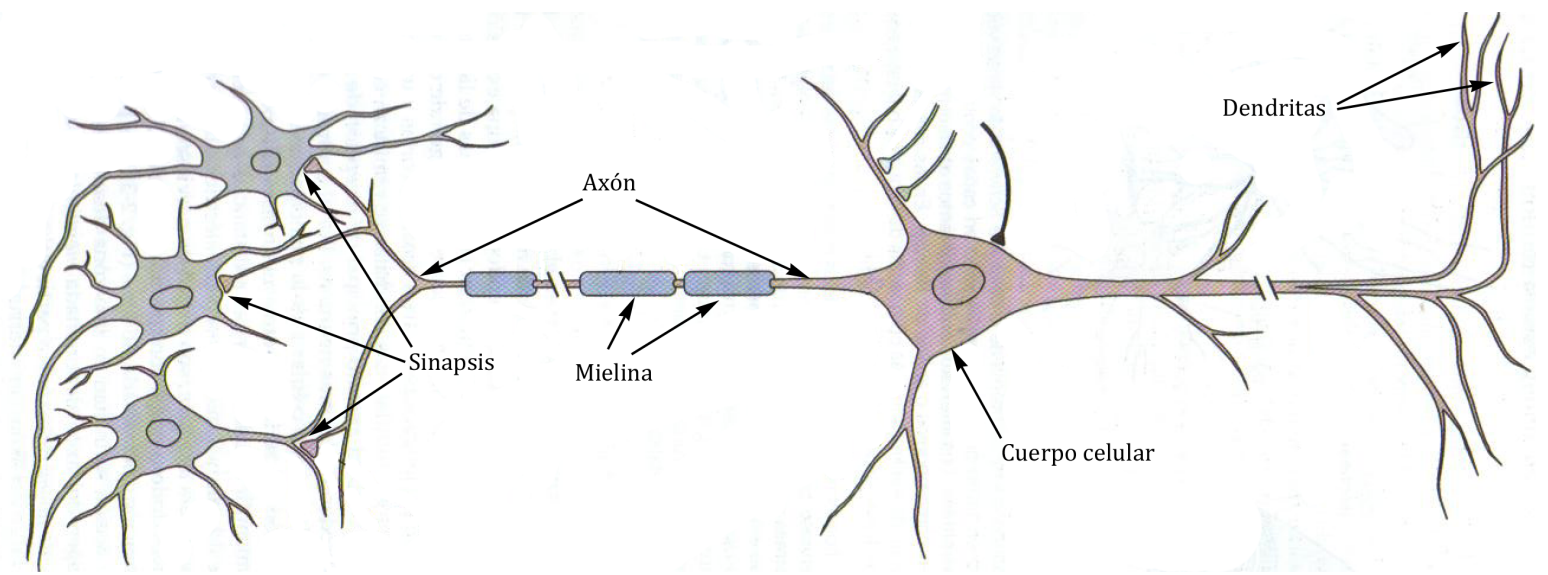

Figura 1.1: Estructura de una neurona (ㅁ)

2) Células de sostén y aislantes: Son células que mantienen a las neuronas en su lugar y evitan la diseminación de las señales por otras neuronas. En el SNC ambos tipos se denominan en conjunto neuroglia, los oligodendrocitos (células aislantes) son capaces de recubrir de mielina a varios axones, mientras que en el SNP se denominan células de Schwann y una sola célula es responsable de proveer de mielina a un solo axón. Otras células de la neuroglía en el SNC y en el SNP son la astroglía, encargada de múltiples funciones, entre ellas la regulación de diversos sustratos y precursores para la síntesis de citocinas, y neurotransmisores, están involucradas en el metabolismo neuronal y nutrición de las neuronas la microglía, cumplen la función de responder como células inflamatorias cuando existe un estímulo traumático o infeccioso sintetizando citocinas. (1) El SNC, está ubicado en un plano profundo del organismo, rodeado y protegido por hueso. Consiste del cerebro dentro del cráneo y la médula espinal que se extiende por el conducto vertebral hasta aproximadamente la primera o segunda vértebras lumbares. El cerebro es la principal área integradora del SN. La medula espinal desempeña dos funciones; sirve como conducto para muchas vías nerviosas que van y vienen del encéfalo, y como área integradora para muchas actividades nerviosas subconscientes. 


\subsection{Anatomía y función de la médula espinal}

Existen 3 membranas que rodean a la médula espinal: la duramadre, la aracnoides y la piamadre. La duramadre es la más externa, es una cubierta tubular fibrosa y resistente. El espacio epidural separa a la duramadre de la columna vertebral, contiene tejido areolar laxo y plexos venosos. El espacio subdural es un espacio estrecho entre la duramadre y aracnoides subyacente. La aracnoides es una membrana transparente delgada, separada de la piamadre por el espacio subaracnoideo que contiene el líquido cefalorraquídeo. La piamadre se adosa íntimamente a la médula espinal. (Figura 1.2) (1)

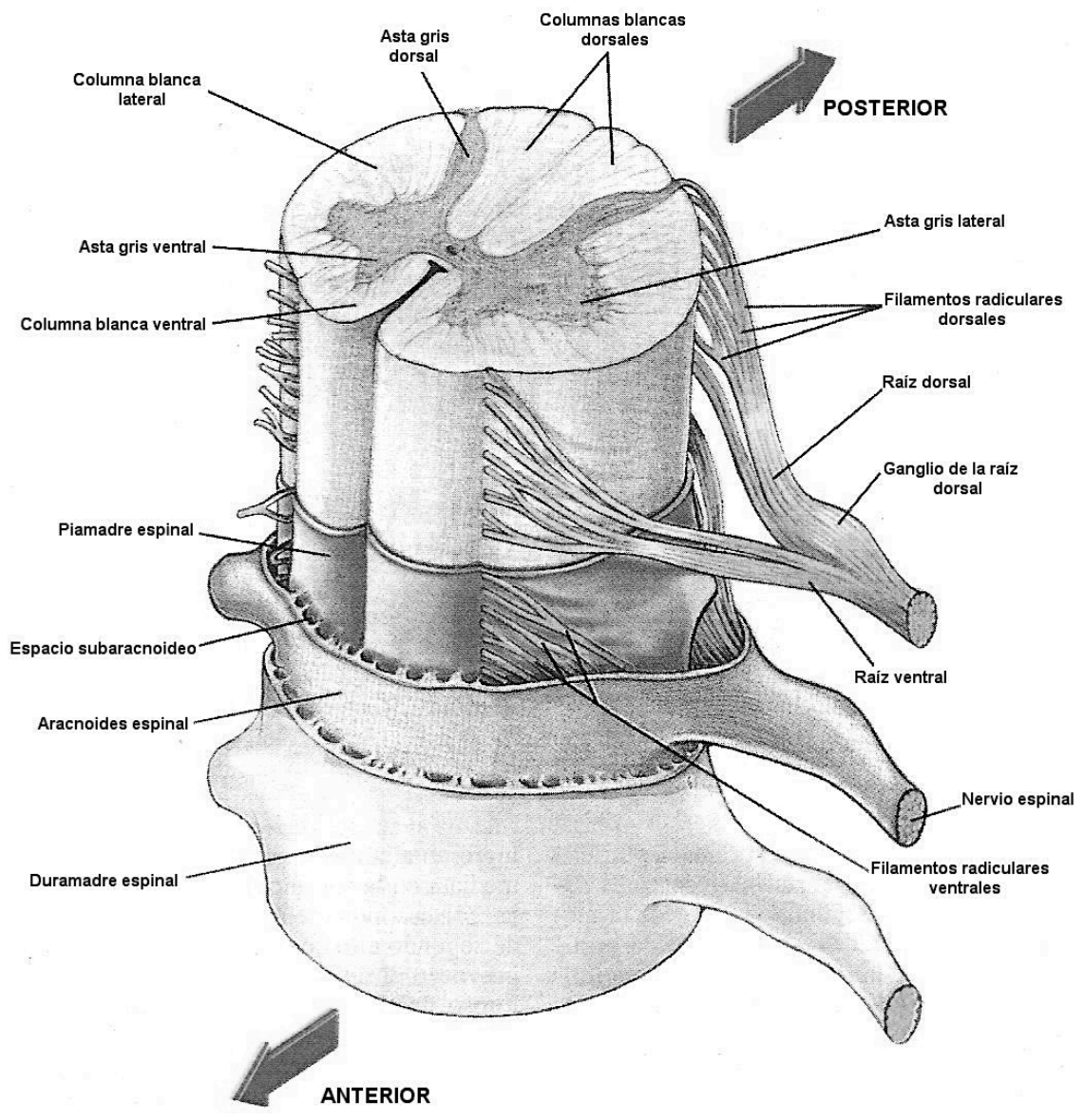

Figura 1.2: Estructura de la médula espinal (1)

El encéfalo y la médula espinal están compuestos por áreas de sustancia gris y áreas de sustancia blanca, mientras que en el cerebro la sustancia blanca es más profunda. Si se observa en sección transversal la médula espinal se aprecia que contiene una masa 
de sustancia gris en forma de H rodeada por sustancia blanca. La sustancia gris está constituida por dos mitades simétricas unidas en la línea media por una conexión transversal (comisura), de sustancia gris, a través de la cual corre un pequeño conducto central. La columna gris anterior (asta anterior) está delante del conducto central y contiene las células que dan origen a las fibras de las raíces ventrales. La columna lateral contiene células preganglionares del sistema nervioso autónomo. La columna gris posterior (asta posterior) es una columna larga y delgada que llega casi hasta el surco colateral posterior. Está cubierto por una masa en forma de media luna, de tejido translúcido, que contiene células nerviosas. La formación reticular es una red de prolongaciones que se extienden dentro del cordón lateral situado entre los cordones anterior y posterior. La forma, cantidad y aspecto de la sustancia gris varía a diferentes niveles. La sustancia gris de la médula espinal puede ser dividida en 2 componentes principales: motor y sensitivo. La parte motora comprende a las columnas anterior y lateral y da origen a las raíces anteriores. Contiene el asta anterior con motoneuronas que inervan a la musculatura estriada voluntaria. Las células de la columna lateral dan origen a fibras preganglionares del sistema nervioso autónomo, torácico y lumbosacro las cuales abandonan la médula espinal con las raíces anteriores. Figura 1.3. (므)

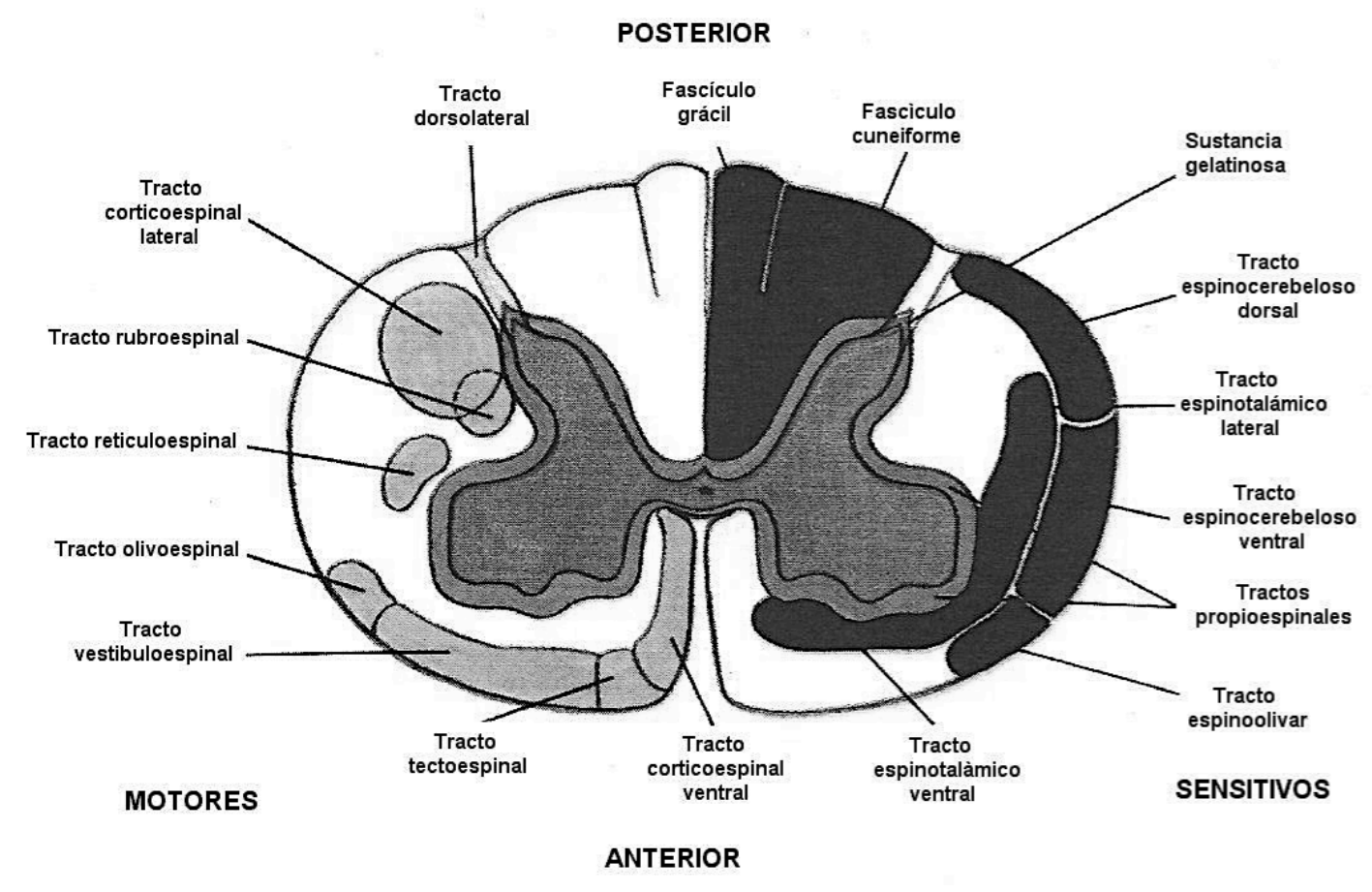


Figura 1.3: Corte transversal de las principales vías largas de fibras nerviosas de la médula espinal (1)

\subsection{Epidemiología y fisiopatología de la lesión traumática de la médula espinal}

Cuando se produce una Lesión Traumática de la Médula Espinal (LTME), se presenta una pérdida de la función nerviosa (motora, sensitiva y autonómica) por debajo del nivel de la lesión, que puede ser parcial o total, dependiendo de la severidad del trauma.

Datos epidemiológicos han estimado una incidencia anual de 40 nuevos casos por millón de habitantes o 12,000 nuevos casos al año en Estados Unidos con una frecuencia mayor en hombres (80\%). La edad promedio es de 28.7 años y las principales causas son los accidentes automovilísticos (41.3\%) seguida de las caídas, los actos de violencia (principalmente disparos) y finalmente actividades deportivas. La proporción de lesiones causadas por accidentes deportivos ha disminuido en los últimos años mientras las lesiones causadas por caídas han aumentado. (ㄱ)

Cuando se presenta una lesión de la médula espinal se desencadena una serie de eventos autodestructivos denominados mecanismos secundarios de lesión. El daño inicial se ubica en el epicentro de la lesión e induce un proceso de isquemia e inflamación que provoca muerte neuronal primaria, (Figura 1.4). Con el tiempo, la lesión se extiende produciendo muerte neuronal en forma secundaria, que acaba con más neuronas que la lesión primaria.(ㅁ)

Tras el traumatismo, se destruye la barrera hematoencefálica y se produce daño a los vasos sanguíneos locales de la sustancia gris y la sustancia blanca, produciendo hemorragias y causando isquemia, anoxia e hipoglucemia, con esto las células sanguíneas invaden el área lesionada generando edema.(99)

El tejido que no fue dañado cambia a un metabolismo oxidativo originando acidosis láctica. Las células nerviosas dañadas responden con una serie de descargas de potenciales de acción. Estos potenciales se acompañan de desregulación iónica, se

pierde el potencial de membrana y se despolarizan las neuronas y células gliales, debido a esto se liberan aminoácidos excitatorios al espacio extracelular.(10) 


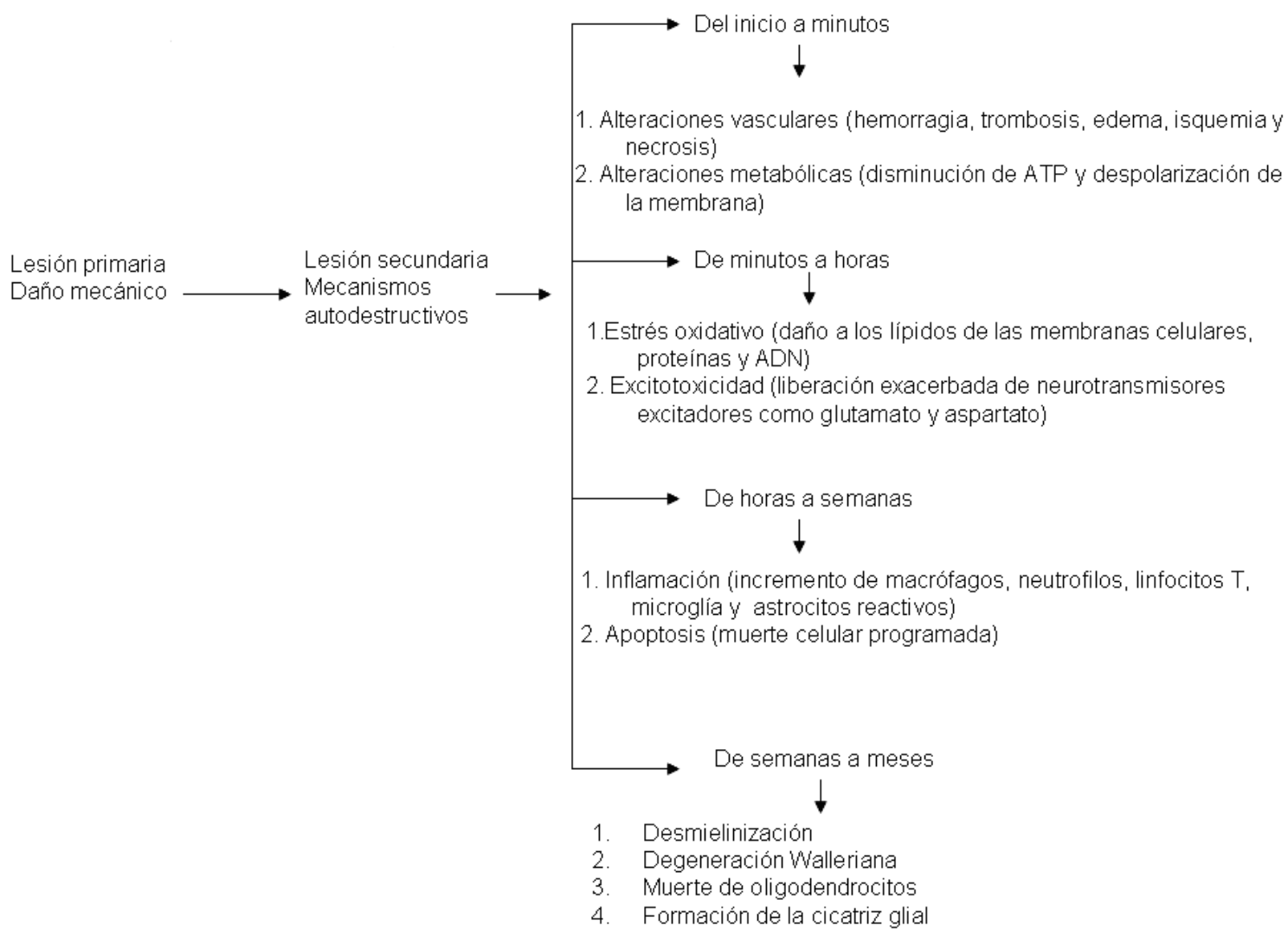

Figura 1.4: Principales eventos de daño secundario después de una lesión traumática de la médula espinal. Modificado de (11)

La despolarización incrementa la concentración de sodio $(\mathrm{Na}+)$ y calcio $(\mathrm{Ca} 2+)$, disminuye la concentración de potasio $(\mathrm{K}+)$ intracelular y esto perturba la excitabilidad y la transmisión sináptica. El calcio es crucial ya que regula la permeabilidad para el sodio y potasio durante la excitación neuronal, controla la actividad de muchas enzimas y el almacenamiento de neurotransmisores en las vesículas sinápticas.

En situaciones normales las terminales axonicas presinápticas liberan pequeñas cantidades de neurotransmisores excitadores como el glutamato, que se une a sus receptores en las neuronas postsinápticas, promoviendo el impulso nervioso, pero en condiciones de daño, la liberación se lleva a cabo de manera masiva y descontrolada como consecuencia de la falla energética, este evento promueve la muerte celular, se conoce como excitotoxicidad. 
La excitotoxicidad favorece la formación de radicales libres que atacan las membranas y otros componentes celulares generando más muerte neuronal en la vecindad. Así también, los oligodendrocitos, células responsables de la producción de mielina en el sistema nervioso central son dañados por estos mecanismos. La destrucción de oligodendrocitos propicia la destrucción de los axones no comprometidos por el trauma inicial, que se desmielinizan y en consecuencia son incapaces de conducir de manera adecuada el impulso nervioso después de la lesión. (12)

Otro de los eventos de daño secundario es el estrés oxidativo, que se ha descrito como el desbalance en la producción de especies reactivas de oxígeno y de nitrógeno y la baja capacidad de las defensas antioxidantes para contrarrestarlos. Existen diversos mecanismos por los cuales se incrementa la producción de radicales libres entre estos podemos mencionar, la activación de sintasa del óxido nítrico tanto constitutiva como inducible, la activación de la hemooxigenasa y el daño mitocondrial que lleva al desacople de la cadena transportadora de electrones, etc. Durante este evento se daña las biomoléculas (ácidos grasos de las membranas, ADN y proteínas) llevando a la célula a la muerte (13)

La respuesta inflamatoria es otro de los eventos de daño secundario que es el responsable del deterioro al tejido adyacente, que se establece desde las primeras horas después de sucedido el traumatismo. Una gran cantidad de células inflamatorias (neutrofilos, basófilos y esosinófilos) están presentes en el tejido nervioso; la mieloperoxidasa, una enzima específica de neutrófilos se activa para producir ácido hipocloroso dañando las biomoléculas del tejido y favoreciendo la muerte celular programada.(14)

La apoptosis se presenta en un plazo de horas y dura hasta semanas después del evento de lesión primaria, es un mecanismo fisiológico regulado a nivel genético y con participación activa de la propia célula, en el SNC puede afectar tanto a neuronas como a células de gliales y aunque el mecanismo por el cual se desencadena aún permanece desconocido, parece ser que puede ser inducida por factores exógenos, como el glutámico, los iones calcio o los radicales libres, así como por factores proteicos, o incluso como consecuencia de sustancias excretadas por algunas células, como pueden ser ciertas citoquinas o el óxido nítrico. (15) 
Por último tanto en la fase aguda como en la fase crónica después de la LTME se observa la muerte celular por apoptosis en ambas direcciones (anterógrada y retrógrada), se alteran receptores y canales iónicos en la expresión y en los niveles de activación, se produce cicatrización e inmovilización de la columna sobre todo en lesiones penetrantes; la desmielinización produce déficit del impulso nervioso, los macrófagos fagocíticos desaparecen del área lesionada y dejan un quiste carente de células rodeada de glía reactiva, y se continúa con la presencia de cavidades llenas de líquido que producen espasticidad y alteraciones sensoriales. Cerca de los axones preservados se presenta una respuesta regenerativa de crecimiento lateral en las prolongaciones, pero no van más allá de $1 \mathrm{~mm}$; los circuitos neuronales se encuentran alterados debido a los cambios en estímulos inhibitorios y excitatorios de entrada. En

muchos tipos de células se desarrolla hiperexcitabilidad permanente, lo que se traduce en los síndromes de dolor neuropático crónico. $(\underline{16}, \underline{17})$

\subsection{Estrategias terapéuticas}

Actualmente no se cuenta con ninguna estrategia terapéutica efectiva para restablecer la función neurológica normal, debido a la complejidad para regular los mecanismos de daño secundario, así como a la baja capacidad de regeneración espontánea que se observa en el SNC.

Las estrategias terapéuticas actuales están enfocadas a proteger a las células nerviosas sobrevivientes después de la lesión (neuroprotección), en la recuperación de las pérdidas (neuroregeneración) y restablecimiento en las funciones perdidas.

\section{Estrategias de neuroprotección}

Se ha propuesto una gran variedad de estrategias terapéuticas (farmacológicas, administración de diversos factores tróficos, etcétera) enfocadas a detener los mecanismos fisiopatológicos desencadenados en la etapa aguda de la lesión.

- Reducción de edema y de producción de radicales libres

La preocupación inmediata es la estabilización a través de la hemostasia y estabilización de la columna vertebral para evitar nuevos traumas. Una de las 
estrategias centrales de tratamiento agudo es la reducción del edema y/o la respuesta inflamatoria con corticosteroides, la más exitosa ha sido la metilprednisolona, (18) que actúa como antioxidante, inhibe la respuesta inflamatoria, y actúa como inmunosupresor $(19,20)$ pero puede agravar la necrosis neuronal, debido a esto, un potente inhibidor de la peroxidación lipídica como el tirilazad mesilato (lazaroide) ha demostrado ser un neuroprotector que tiene menos efectos secundarios que la metilprednisolona. (21) Otros fármacos con propiedades antioxidantes son la ciclosporina A, EPC-K1, que es un diéster fosfato vinculado con vitaminas E y C (inhibe la activación de leucocitos y disminuye la lipoperoxidación), la melatonina y altas dosis de naloxona han demostrado cierta eficacia en ensayos clínicos (22).

\section{- Inhibición de excitotoxicidad}

Diferentes modelos de LTME han indicado que los antagonistas del receptor de glutamato pueden ser útiles las estrategias terapéuticas, los antagonistas de receptores NMDA y no-NMDA [(Dizocilpina (MK-801) NBQX, riluzol], pues inhiben la excitotoxicidad y la apoptosis $(23,24)$. La producción de óxido nítrico contribuyente a la muerte de células nerviosas, el tratamiento previo con $\mathrm{N}^{\mathrm{G}}$-nitro-L-arginina metil éster (L-NAME) ha demostrado mejorar la morfología celular (25). Así también, la activación de receptores A1 de adenosina, ya sea por activación de adenosina o por agonista selectivo de receptores en un sitio específico (26).

- Reducción de inflamación

La inflamación es un mecanismo de reparación endógeno, pero, se ha demostrado que la cascada inflamatoria produce varias vías de degradación, como la vía de la prostaglandina. Agentes antiinflamatorios se han utilizado con cierto éxito. Evidencia reciente sugiere que la mieloperoxidasa, una enzima producida y liberada por los neutrófilos, es de especial importancia en la difusión de daño tisular, la dapsona es un inhibidor irreversible de esta enzima (27). Administración de la citocina antiinflamatoria IL-10, a pesar de la mejora en el comportamiento del aparato locomotor que se registró (preservando la materia gris) (28) se ha retraído su uso (29). Inhibidores de la ciclooxigenasa (COX)-2 han demostrado neuroprotección (푸) en modelos de lesión por contusión. La hipotermia, ya sea medular o sistémica, proporciona protección a células nerviosas, disminuye la muerte celular y reduce la 
inflamación. El mecanismo puede estar relacionado con la inhibición en el aumento de las concentraciones extracelulares de aminoácidos excitatorios. (31)

\section{- Inhibición de apoptosis}

Un enfoque consiste en la inhibición de caspasas, pues se cree que desempeñan un importante papel como mediador de la apoptosis $(\underline{32}, \underline{33})$. Otra estrategia que ha recibido atención por su papel en la degradación celular, tanto en la necrosis como en la apoptosis es la calpaina. Calpainas son activadas por $\mathrm{Ca}^{2+}$ por lo que juegan un papel importante en la degradación del citoesqueleto en células dañadas. Así, los inhibidores de la calpaina podrían reducir o retrasar la apoptosis (22). Por último, la administración exógena de neurotrofinas ha sido considerada útil para el rescate de las células que han perdido apoyo trófico debido a la muerte de las proyecciones de las neuronas, inervación del objetivo, u oligodendrocitos. Las neurotrofinas se han administrado con cierto éxito, incluyen el factor de crecimiento del nervio, factor neurotrófico derivado de las células gliales, factor neurotrófico ciliar, el factor de crecimiento de fibroblastos, y factor neurotrófico derivado del cerebro. (34-37)

\section{Estrategias de neuroregeneración}

Después de producirse una LTME se observa pobre regeneración espontánea. Se sabe que existen diversos eventos que contribuyen con este proceso, como la cicatriz glial, la inhibición de la remielinización, la propia muerte celular y la producción insuficiente de factores de crecimiento que permitan la regeneración axonal. (38)

- Desmielinización y déficit de conducción

Se sabe que, con lesiones neuronales, se presenta un incremento en los potenciales de acción que se produce a causa de la liberación masiva de neurotransmisores. Esta liberación masiva, junto con los cambios iónicos, puede resultar en la muerte de las células nerviosas. La estrategia de inhibición depende de los canales de $\mathrm{Na}^{+}$, pues proporcionan la base iónica del potencial de acción. El bloqueador de los canales de $\mathrm{Na}^{+}$tetrodotoxina ha demostrado un rescate de tejido nervioso y proporciona un ambiente más adecuado para la recuperación (39). En este sentido, es importante señalar que muchos de los axones son desmielinizados como resultado del daño secundario. El empleo de un bloqueador de los canales de $\mathrm{K}^{+}$mediados por voltaje, 4- 
aminopiridina se basa en que estos quedan expuestos internodalmante como resultado de la desmielinización, esto altera considerablemente las propiedades de conducción en los axones sobrevivientes (쑤).

Otra estrategia para la desmielinización es el trasplante de células que pueden producir nueva mielina y restablecer el déficit de conducción. Células que se han ensayado con cierto éxito en modelos animales incluyen: células del bulbo olfativo, oligodendrocitos, y las células de Schwann. (ㅁ)

\section{- Regeneración axonal}

Las células nerviosas tienen la capacidad intrínseca necesaria para el crecimiento, en consecuencia, el entorno debe ser el responsable de un ambiente no propicio para la regeneración neuronal. (1ㅜ) Hay varias estrategias que en la actualidad están orientadas a proporcionar los ambientes permisivos para el crecimiento. Durante el desarrollo nervioso, una variedad de moléculas en la matriz extracelular promueven el crecimiento y orientación de los axones, estos posteriormente se inhiben en el SNC adulto. (40) Las proteínas de la matriz extracelular están surgiendo como factores clave para regenerar neuronas. (9)

- Transplante de células

Después de la lesión, con la pérdida de las células nerviosas y de células que proporcionan la mielina para una conducción adecuada, la solución obvia sería proporcionar células que puedan sustituir la pérdida de la función, servirían como fuente: células madre, células del bulbo olfativo (42), células de Schwann (43), ganglios de la raíz dorsal, nervio periférico. (44)

\section{- Implantes}

Una lesión medular resulta en una cavidad que se extiende con el tiempo, lo que deja anatómicamente incompleto el sitio de lesión. Las fibras nerviosas que puedan mostrar regeneración o crecimiento de brotes, se encontrarán con una brecha física que requiere un puente con un ambiente favorable. Por tanto, puentes como células de Rafé, tejido fetal, material artificial han sido implantados con cierto éxito (43). Las células de Rafé trasplantadas han demostrado capacidad de extender axones a través de la materia gris, formar sinapsis y disminuir la gliosis en el sitio. (ㄴ5) 
Implantes compuestos de las células de Schwann ( $\underline{43}$ ), e injertos de nervios intercostales (누) han demostrado regeneración axonal, siendo capaces de crecer a través de la brecha que produce la lesión. También, implantes de células del bulbo olfativo han demostrado que se alinean al tejido, emigran grandes distancias, y promueven la recuperación funcional y regeneración a través de sitio de la lesión (47). Células nerviosas progenitoras humanas y células madre embrionarias se han utilizado en los modelos de lesión espinal y han demostrado recuperación funcional. Los avances en el campo de los biomateriales han brindado la oportunidad de cerrar la brecha con materiales artificiales, como los hidrogeles biodegradables o combinaciones de hidrogeles y células (늑), que puede promover la regeneración. Las propiedades deseadas de estos puentes sintéticos son proporcionar al mismo tiempo un sustrato físico para el tejido y el crecimiento axonal sin desencadenar reacciones antigénicas. Aunque este enfoque es reciente, existen grandes avances con el uso de los polímeros. (푸)

- Recuperación de la función a través de estimulación eléctrica

La estimulación eléctrica funcional (FES) es una técnica que utiliza corrientes eléctricas para activar los nervios afectados por la lesión, hay una gran variedad de modalidades de FES, éstas se basan en estimulación transcutánea o directa de las terminaciones distales de los nervios. La FES contribuye a la disminución de las complicaciones médicas, tales como trombosis venosa, osteoporosis y fracturas de huesos se redujeron, así como también al fortalecimiento de las extremidades y para el acondicionamiento cardiovascular, ha tenido cierto éxito en términos de mejoras fisiológicas como el aumento de la masa muscular, mejora de la circulación de la sangre, función intestinal y de vejiga. (ㅆ9)

- Biomateriales para reparar la médula espinal

La falta de regeneración que se observa después de una lesión traumática de la médula espinal, ha llevado a desarrollar nuevas estrategias para tratar de reparar el tejido dañado. Los primeros reportes a nivel mundial señalan el uso de implantes de filamentos de carbón que sirvieran como puente para el crecimiento de los axones dañados en la médula espinal de rata (0ㅡ). Implantaron un filamento de carbón en ratas sometidas a un modelo de sección completa de la médula espinal y observaron 
crecimiento axonal sobre y entre los filamentos, concluyendo que los filamentos de carbón servían como superficie para adherir de manera favorable los axones en crecimiento así como probablemente funcionaban como guía mecánica.

El uso de microesferas con factor de crecimiento nervioso encapsulado en ovoalbúmina unida con polímeros biodegradables instaladas en el sitio de la lesión, (51) para favorecer los procesos de regeneración axonal. Esta tecnología se probó en células PC12 para determinar la bioactividad del NGF liberado. Los resultados demostraron que el NGF es bioactivo hasta por 91 días.

El Hidrogel biocompatible de poli[N-(2-hydripropil)metacrilamida], que además tiene una región de adhesión celular de fibronectina Arg-Gly y Asp (2). Este biomaterial se probó en un modelo de lesión de la médula espinal por hemisección, en ratas SpragueDawley. El hidrogel fue insertado en el interior de la médula espinal, posteriormente se cerró la duramadre. Los resultados demostraron que el polímero de hidrogel provee una estructura en tercera dimensión y una continuidad a través de la zona dañada, facilitando la migración y reorganización de las células. También se pudo observar angiogénesis y crecimiento axonal dentro de la microestructura y nuevo tejido en ella, así como crecimiento axonal dirigiéndose a la zona supraespinal dentro del segmento de la médula espinal reconstruido. En este trabajo también se observó que la presencia del hidrogel disminuye la necrosis y la formación de cavidades, por lo que los autores señalan que este polímero podría ayudar en la reparación de la médula espinal lesionada.

También se ha explorado el uso de polímeros en forma de tubos que guíen y sirvan de puente entre la zona de transición a los axones en crecimiento (53). Usando un polímero reabsorbible hecho de poli(D,L-ácido láctico) (PLA50) con un co-polímero de peso molecular alto de poli(L-ácido láctico) mezclado con oligómeros al $10 \%$ de poli(L-ácido láctico) (PLA100/10). Los polímeros se implantaron en el tejido nervioso de ratas adultas Fisher sometidas a una sección completa de la médula espinal y se hizo un seguimiento de 4 meses. Los resultados demostraron que desde las 2 semanas los tubos contenían tejido nervioso medular y vasos sanguíneos y se observó la mayor cantidad de axones mielinizados 1 mes después del implante. En este trabajo se concluye que existe crecimiento de fibras y mielinización dentro del implante hecho 
con el polímero PLA $\mathrm{A}_{100 / 10}, 2$ meses después del implante. Sin embargo, se observó un decremento de este fenómeno 4 meses después, por lo que los autores recomiendan más estudios para optimizar esta técnica.

Los filamentos hechos con poli- $\beta$-hidroxibutirato (PHB) y alginato de fibronectina + hidrogel es otro material biodegradable para facilitar el proceso de regeneración y dirigir a los axones en crecimiento después de una LTME (54), se observó que el implante de PHB reduce la muerte celular en un 50\% en una sección del tracto rubroespinal a nivel de la vértebra L1. El uso de los componentes por separado no tiene efecto en la sobrevida de las neuronas. Asimismo, se adicionaron células de Schwann neonatales en los transplantes de PHB, observando regeneración de los axones dentro del implante y a lo largo del tejido nervioso, sugiriendo que el uso de estos biomateriales, más las células de Schwann, puede servir como soporte neuronal con un incremento de la regeneración después de una LTME.

También se ha propuesto el uso de tubos de hidrogel hechos de poli(2-hydroxietil metacrilato-co-metil metacrilato) (p(HEMA-co-MMA)), como potenciales canales guías del crecimiento axonal en el sistema nervioso central. Las características de estos tubos son: suavidad y flexibilidad con semejanza a un gel con macro-poros interconectados entre las capas, que se controla por una formulación química (55). Sin embargo, se ha demostrado que la degradación de estos polímeros puede causar una reacción inflamatoria, aunque algunos de ellos son inmunológicamente inertes, especialmente resistentes dentro del sistema nervioso (드). En algunos polímeros la adhesión de los axones a estos compuestos es pobre (57), al utilizar redes recubiertas con una matriz de laminina, se logró que una gran cantidad de axones en crecimiento se unieran a la matriz. Se han desarrollado biomateriales con capacidad para unir péptidos (factores tróficos, fármacos, etc.) encapsulados, que se liberan lentamente (58). En los polisacáridos también se ha encontrado una aplicación de ingeniería para reparar el tejido dañado. El ácido hialurónico puede facilitar la regeneración axonal (59). Se han desarrollado polímeros que son solubles en agua y con capacidad para adherirse al tejido (60). Las fibras de colágena han servido como guía y soporte para el crecimiento axonal (61), asimismo, se han probado en combinación con otros materiales para inducir regeneración (62). El uso de materiales que sean 
biocompatibles para restaurar el tejido nervioso dañado ha avanzado rápidamente desarrollando materiales que funcionan como puentes para reparar la médula espinal. Aunque parece difícil utilizar esta tecnología, podría ser factible dados los recientes avances en la ciencia de biomateriales.

Estudios previos realizados por nuestro grupo en colaboración con diversas Instituciones (la Universidad Autónoma Metropolitana, el Instituto Nacional de Neurología y Neurocirugía, el Instituto Nacional de Investigaciones Nucleares y el Instituto Mexicano del Seguro Social) demostramos que los polímeros semiconductores derivados del pirrol y sintetizados por plasma (Polipirrol/Yodo) favorecen la preservación del tejido nervioso, al mostrar una mayor recuperación funcional motora y sensitiva después de una lesión por sección completa de la médula espinal en ratas $(63,64)$. Con base en estos hallazgos es importante explorar los mecanismos a través de los cuales estos biomateriales ejercen su efecto.

\subsection{Polímeros en aplicaciones biomédicas}

Los polímeros obtenidos mediante métodos convencionales de polimerización química o electroquímica se producen a gran escala en la industria y tienen un gran número de aplicaciones en el campo de los textiles, plásticos y materiales eléctricos. Debido a la uniformidad de la cadena polimérica que tienen, poseen una buena resistencia mecánica y excelentes propiedades elásticas y plásticas. Sin embargo, la mayoría de los polímeros obtenidos mediante los métodos convencionales se caracterizan por una baja resistencia a la corrosión y un alto grado de solubilidad. (65)

\section{Polimerización por plasma}

La polimerización por plasma es la formación de materiales poliméricos bajo la influencia de un gas parcialmente ionizado (plasma) compuesto de partículas altamente reactivas, moléculas, iones, y radicales. Se obtiene generalmente ionizando gases con ayuda de un campo eléctrico por radio frecuencia, de microondas, o 
mediante un filamento caliente. Por medio de esta técnica se puede sintetizar un polímero, el cual se deposita sobre todas las superficies que están expuestas al plasma. Este es un método efectivo para la preparación de películas delgadas con estructura densa y entrecruzada que se puede usar como capa aislante o semiconductora, como recubrimiento protector, como membrana permeable, etc. (66) La polimerización por plasma se lleva a cabo en el interior de la cámara tubular de vidrio bajo condiciones de vacío. En el proceso de polimerización por plasma, los reactivos (monómeros, polímeros, dopantes) ingresan en la cámara de reacción. Los componentes comienzan en estado líquido o sólido, en recipientes separados de la cámara. Se convierten en gas e ingresan en la cámara por acción del vacío generado. El polímero se forma a partir de las partículas reactivas resultantes de la ionización del gas (iones, electrones, fotones, moléculas en estados electrónicos excitados, átomos y especies neutras) bajo la influencia del plasma. Las partículas ionizadas interaccionan con la superficie del sustrato y entre ellas, recubriendo y depositándose como película delgada de material. No se requiere de intermediarios químicos para que ocurra la oxidación. La oxidación es promovida por el impacto de los electrones libres que se encuentran a lo largo del campo eléctrico que colisionan con las moléculas del monómero. (67)

Las ventajas y desventajas del uso de la polimerización por plasma:

\section{Ventajas:}

- El monómero reacciona para producir el polímero sin introducir ningún compuesto químico oxidante. (68)

- El polímero se deposita sobre cualquier superficie expuesta al plasma.

- En la síntesis ocurren ramificaciones y entrecruzamientos con otras cadenas modificando las propiedades químicas y físicas de los polímeros sintetizados, tienen una baja solubilidad y buena resistencia a la corrosión.

- Excelente resistencia a la mayoría de los productos químicos.

- Las películas tienen buena adhesión a superficies plásticas y metálicas.

- La polimerización por plasma puede mejorar selectivamente las propiedades de la superficie de otros materiales mientras la mayor parte de las características siguen siendo las mismas. (69) 
- Debido a las condiciones en la cámara de reacción durante la síntesis, el material y las superficies expuestas al plasma se esterilizan.

\section{Desventajas:}

- El costo de los equipos.

- Las superficies recubiertas tienen baja resistencia a la abrasión.

- Baja tasa de depósito de polímero.

- El proceso no se puede realizar en forma masiva

\section{Polímeros por plasma en aplicaciones biomédicas}

Los biomateriales se emplean con el objeto de reemplazar y/o restaurar el tejido dañado y reestablecer su función, esto implica que están expuestos de modo temporal o permanente a fluidos corporales, aunque también pueden estar localizados fuera del organismo. (70)

Algunas de las aplicaciones sugeridas para los biomateriales sintetizados por plasma son: prótesis vasculares, superficies compatibles con la sangre, lentes intraoculares, superficies para cultivo celular, electrodos implantables, oxigenadores de sangre, catéteres, modelos de superficies para la exploración con sistemas biológicos. Como podemos observar los polímeros sintetizados por plasma son de gran utilidad, en especial los derivados del pirrol ya que por sus características fisicoquímicas, podrían tener un gran potencial como promotores de la regeneración en lesiones de la médula espinal en pacientes, sin embrago se deben explorar sus posibles mecanismos de acción. (71)

\subsection{Evaluación de la lesión de la médula espinal en modelos experimentales}

En los estudios experimentales sobre lesiones de la médula espinal en modelos animales existen una gran variedad de estrategias para evaluar diferentes tipos de lesiones y/o tratamientos.

Con el fin de evaluar la recuperación funcional se han desarrollado diferentes escalas para medir la función motora, la escala más utilizada es la desarrollada por Basso, Beattie, Bresnahan (BBB), (72) es una escala cualitativa que está basada en la observación de los cambios conductuales de la locomoción (Anexo B). Por otra parte 
el análisis histológico es otra herramienta útil para obtener información sobre el estado estructural y patológico de la médula espinal después de una lesión, sin embargo no permite hacer comparaciones con el mismo individuo una vez tomada la muestra (73). Otra herramienta de evaluación de la función nerviosa es el monitoreo neurofisiológico de la médula espinal a través de registros electrofisiológicos (potenciales evocados), los cuales proveen medidas cuantitativas de la actividad eléctrica de la médula espinal. (74) Sin embargo, la mayoría de las técnicas para monitorear la función motora y sensitiva, tales como la evaluación de la locomoción (escala BBB) y la electrofisiología (potenciales evocados), dependen de una actividad integrada más allá de la integridad de la médula espinal. (75)

La resonancia magnética (MR) es el método más prometedor para determinar el estado de la médula espinal. Los resultados de la MR pueden correlacionarse con el estado neurológico y ayudan a establecer un pronóstico de la lesión. $(\underline{49}, \underline{76})$

\subsection{Resonancia magnética}

La Resonancia Magnética (MR) es un fenómeno físico por el cual ciertos elementos como el hidrógeno pueden absorber selectivamente energía electromagnética al ser colocados en un campo magnético potente y liberar ese exceso de energía en un proceso llamado relajación.

La MR utiliza un fuerte campo magnético estacionario $\left(\mathbf{B}_{\mathbf{0}}\right)$ para iniciar la alineación paralela al campo de los dipolos magnéticos de los protones de hidrógeno de un tejido de estudio. Dentro del campo magnético los núcleos atómicos precesan o giran con un eje rotacional paralelo al campo con una frecuencia proporcional a la intensidad de éste. La frecuencia es representada por la ecuación de Larmor:

$$
\omega=\gamma B
$$

Donde $\gamma$ es la relación giromagnética y es una constante específica para cada núcleo. Se genera entonces una magnetización longuitudinal $\mathrm{M}_{0}$. La aplicación de una señal particular (a la frecuencia de Larmor) de Radiofrecuencia (RF) da como resultado la absorción de energía de los núcleos atómicos en los tejidos, cambiando la dirección del dipolo magnético y su precesión (a un plano transversal al eje del campo 
magnético $\mathrm{B}_{0}$ ), esto depende de la amplitud y duración del pulso de RF aplicado. (Figura 1.5)
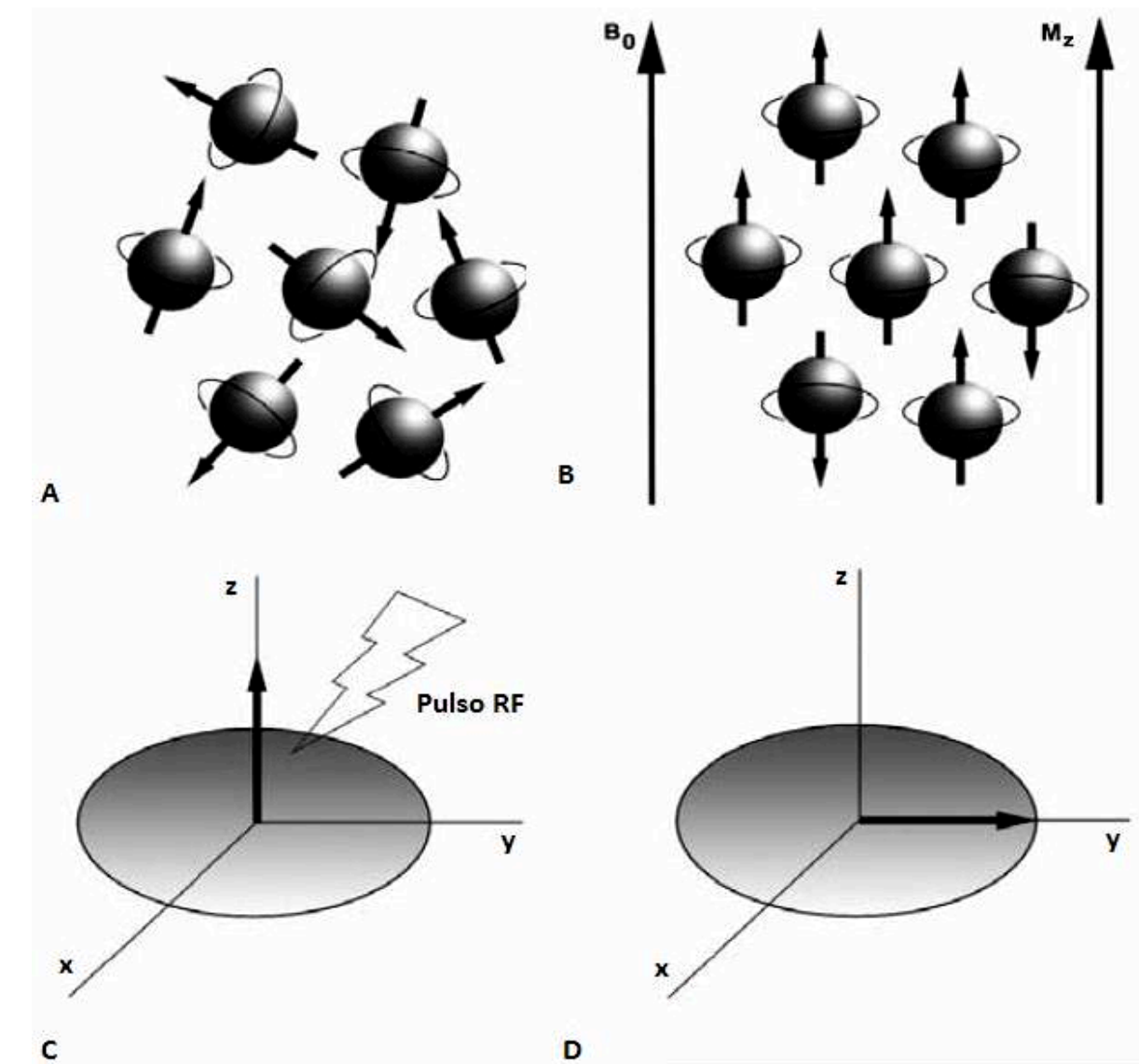

Figura 1.5: Esquema del proceso de resonancia magnética. Conjunto de núcleos en ausencia de un campo magnético, giran alrededor de su eje en direcciones aleatorias (A). En presencia de un campo magnético los núcleos se alinean de forma paralela al campo (B). Pulso de RF (C). Cambia la dirección de la magnetización a un plano transversal al campo magnético $B_{0}(D)$

Después de aplicar el pulso de RF, la magnetización gira en el plano transversal (MXY). Es ésta magnetización la que da lugar a la señal de MR. Sin embargo, la señal de MR desaparece reduciendo la magnetización transversal y volviéndose a realinear con el campo $\mathrm{B}_{0}$ causando la Relajación Longitudinal (T1) y la Relajación Transversal (T2). (Figura 1.6). 


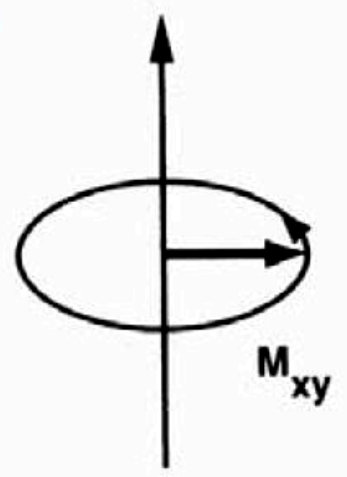

B

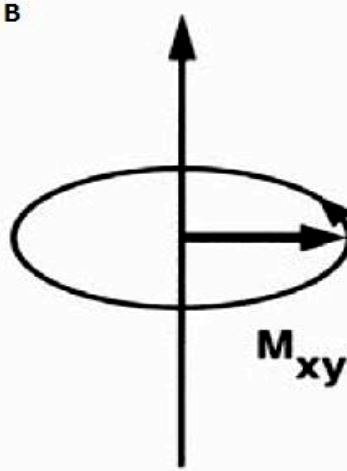

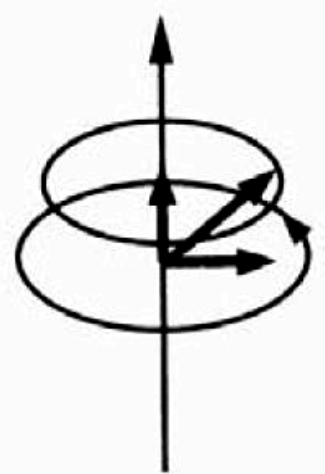
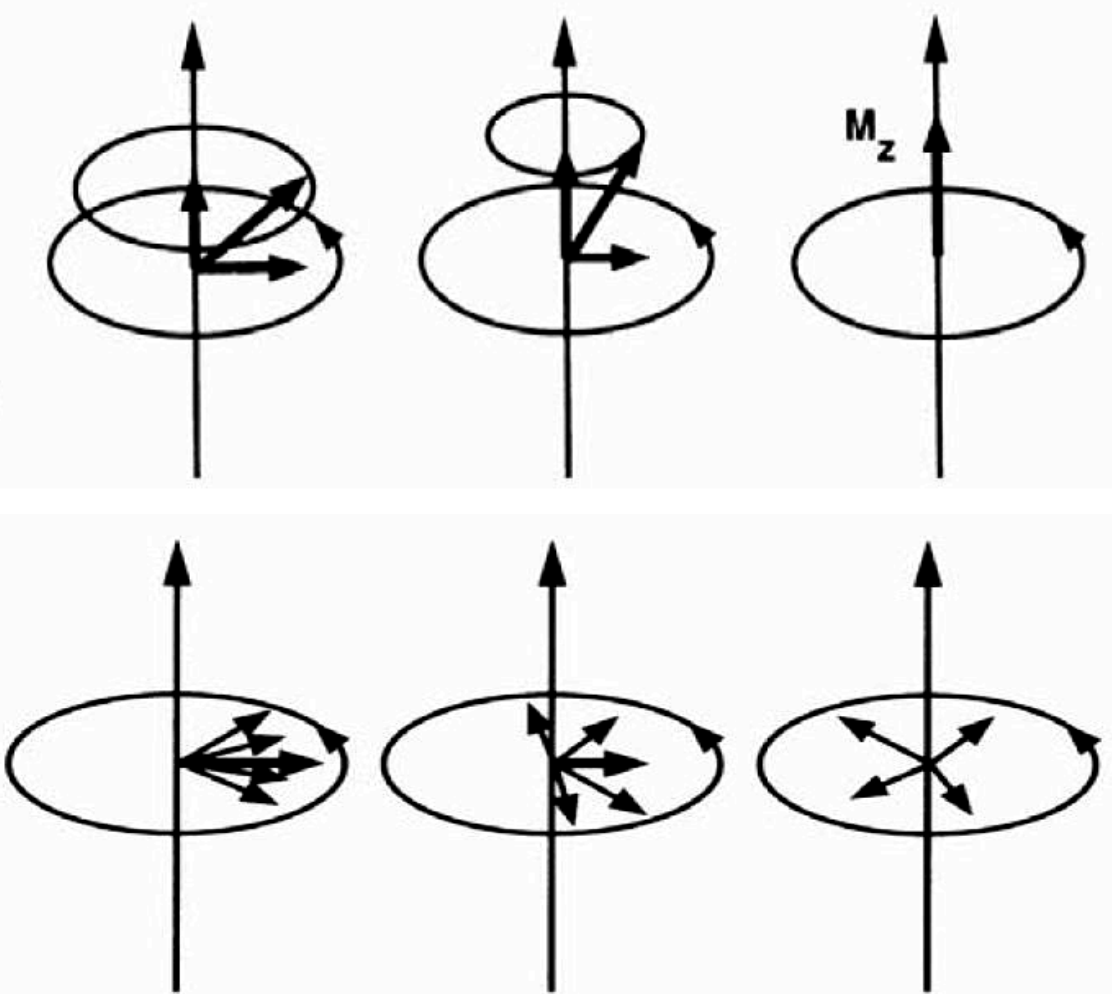

Figura 1.6: Relajación longitudinal: Decaimiento de la magnetización transversal y aumento de la magnetización en el eje z debido a la interacción de los núcleos con el entorno (A). La pérdida de fase de precesión de los núcleos provoca la pérdida de la magnetización transversal (B)

Los núcleos atómicos emiten energía a la frecuencia de Larmor. Si se coloca una bobina receptora se inducirá un voltaje durante la precesión de los núcleos atómicos. Esta tensión inducida, es conocida como Decaimiento de Inducción Libre (FID). La magnitud inicial de la señal FID depende del valor de $\mathrm{M}_{\mathrm{Z}}$ inmediatamente antes del pulso de RF. (Figura 1.7) 

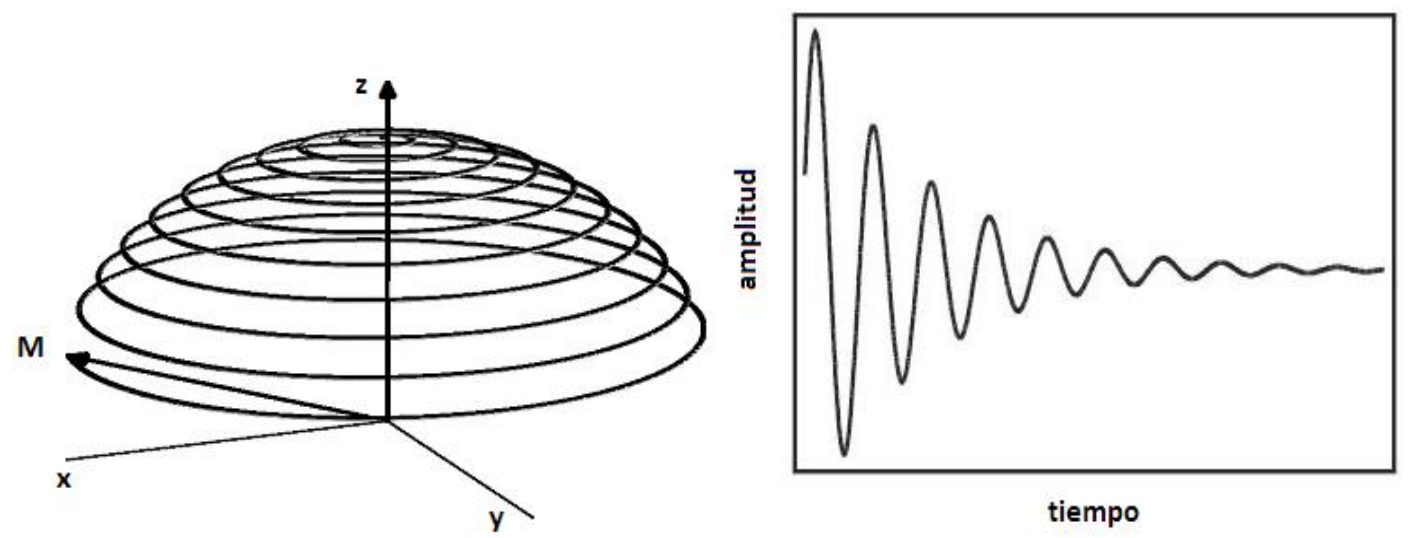

Figura 1.7: Decaimiento de inducción libre (FID). Es proporcional a la cantidad de magnetización transversal generado por el pulso de RF

En general, tres aspectos de una señal de MR son de interés: su magnitud o amplitud, su frecuencia y su fase. La magnitud de la señal está relacionada con el valor de la magnetización inmediatamente antes del pulso de RF. La frecuencia de la señal está relacionada con el campo magnético $\mathrm{B}_{0}$. Si todos los núcleos atómicos experimentan el mismo campo $\mathrm{B}_{0}$, entonces una sola frecuencia se presenta dentro de la FID. En realidad, hay muchos campos magnéticos en todo el imán, y por lo tanto muchas señales de MR. Estas señales se superponen de manera que el FID contiene muchas frecuencias. Es más fácil de examinar una señal de componentes múltiples en términos de frecuencia y no del tiempo. La conversión de la señal en el dominio del tiempo a una en el dominio de la frecuencia se realiza mediante la transformada de Fourier.

La frecuencia específica a la que un núcleo atómico absorbe depende de los campos magnéticos que experimenta y proviene de dos fuentes. Uno es el campo $\mathrm{B}_{0} \mathrm{y}$ el otro es el originado por su entorno molecular. Por ejemplo en pacientes, la mayor parte de la señal de MR proviene del hidrógeno y éste surge de dos fuentes: el agua y la grasa. El agua tiene dos átomos de hidrógeno unidos a un átomo de oxígeno, mientras que la grasa tiene los átomos de hidrógeno unidos a un marco a lo largo de una cadena de carbono. Debido a su entorno molecular diferente, un protón de agua tiene un diferente campo magnético local que un protón de grasa. Esta diferencia de entorno local es proporcional al campo $\mathrm{B}_{0}$. Diferencias de cambio químico entre los protones en diferentes ambientes moleculares proporcionan la base para la espectroscopia por 
MR. Mientras que la obtención de Imágenes por Resonancia Magnética (IMR) utiliza la dependencia de la relación entre la frecuencia de la energía que absorbe un núcleo atómico y el campo magnético que experimenta para localizar las frecuencias de los núcleos atómicos en diferentes regiones del espacio. El campo magnético se hace dependiente espacialmente a través de la aplicación de gradientes de campo magnético. Estos gradientes son pequeñas perturbaciones superpuestas al campo $\mathrm{B}_{0}$, junto con los tiempos de relajación T1 y T2 que son la base para el contraste de los tejidos en la formación de imágenes. $(77,78)$

En MR existen técnicas que proporcionan información complementaria a la anatómica, que es la usualmente empleada. Entre estas destacan la difusión, la perfusión y la espectroscopia.

\section{Difusión por Resonancia Magnética}

La base física de las imágenes potenciadas en difusión radica en la sensibilidad de la secuencia de contraste para captar y cuantificar el movimiento de las moléculas de agua. El desplazamiento de estas moléculas es aleatorio y se conoce como movimiento browniano (79). Las moléculas que experimentan este tipo de desplazamiento describen una ruta caótica por los choques continuos con las partículas de su entorno y su velocidad es proporcional a la temperatura del sistema.

Pese a que el desplazamiento inducido por una sola molécula no resulta apreciable, el choque de un gran cantidad de ellas produce un desplazamiento significativo y cuantificable (80). Aunque en promedio no exista un flujo neto, es posible calcular la

distancia recorrida de la molécula en un tiempo determinado, (81) mediante la relación:

$$
R=\sqrt{6 D \tau}
$$

donde $\mathrm{D}$ es el coeficiente de difusión de la molécula y $\tau$ el intervalo de tiempo durante el cual se desplaza. En los tejidos biológicos, el coeficiente de difusión no es la única causa del movimiento molecular, la microcirculación sanguínea contribuye aumentando la difusión. Por ello se usa el término coeficiente de difusión aparente (ADC). 
La ecuación que permite relacionar la señal de la imagen potenciada en difusión (S) y una imagen potenciada en T2 (no sensible a la difusión) $\left(\mathrm{S}_{0}\right)$ fue descrita por Stejskal y Tanner (82) como:

$$
S=S_{0} e^{-b(A D C)}
$$

Puede considerarse que las imágenes de difusión se corresponden con imágenes T2 atenuadas por una exponencial que tiene como variables el factor de potenciación en difusión b y el ADC del tejido.

La selección del valor b adecuado tiene una influencia decisiva en las imágenes resultantes, ya que constituye un descriptor de la potenciación. El factor b se relaciona según la ecuación:

$$
b=\gamma^{2} G^{2} \delta^{2}\left(\Delta-\frac{\delta}{3}\right)
$$

Donde $\gamma$ es la constante giromagnética del protón, $\mathrm{G}$ la intensidad del gradiente, $\delta$ su duración y $\Delta$ el tiempo entre los pulsos de gradiente. El valor $\mathrm{b}$ determina inversamente cuánta contribución T2 tiene la imagen obtenida. Es necesario disponer de una imagen basal $\left(\mathrm{S}_{0}, \mathrm{~b}=0 \mathrm{~s} / \mathrm{mm}^{2}\right)$ ya que la intensidad del vóxel depende del movimiento molecular del agua y del contraste T2 del propio tejido.

Para cada corte de una secuencia potenciada en difusión se dispone de una imagen potenciada en $\mathrm{T} 2(\mathrm{~b}=0 \mathrm{~s} / \mathrm{mm} 2)$ y de una serie de imágenes potenciadas en cada una de las direcciones de difusión empleadas. El número mínimo de direcciones para calcular las imágenes isotrópicas es tres.

Cuando se cuantifica la difusión en un sistema biológico estructurado, como el sistema nervioso, el desplazamiento de las moléculas queda limitado por barreras físicas (como una red trabecular o fibras axonales) que provocan que su difusión sea dependiente de la dirección, esto provoca anisotropía. En un sistema homogéneo, sin barreras una partícula experimenta un movimiento browniano moviéndose libremente en cualquier dirección con difusión isotrópica (Figura 1.8).(83) 

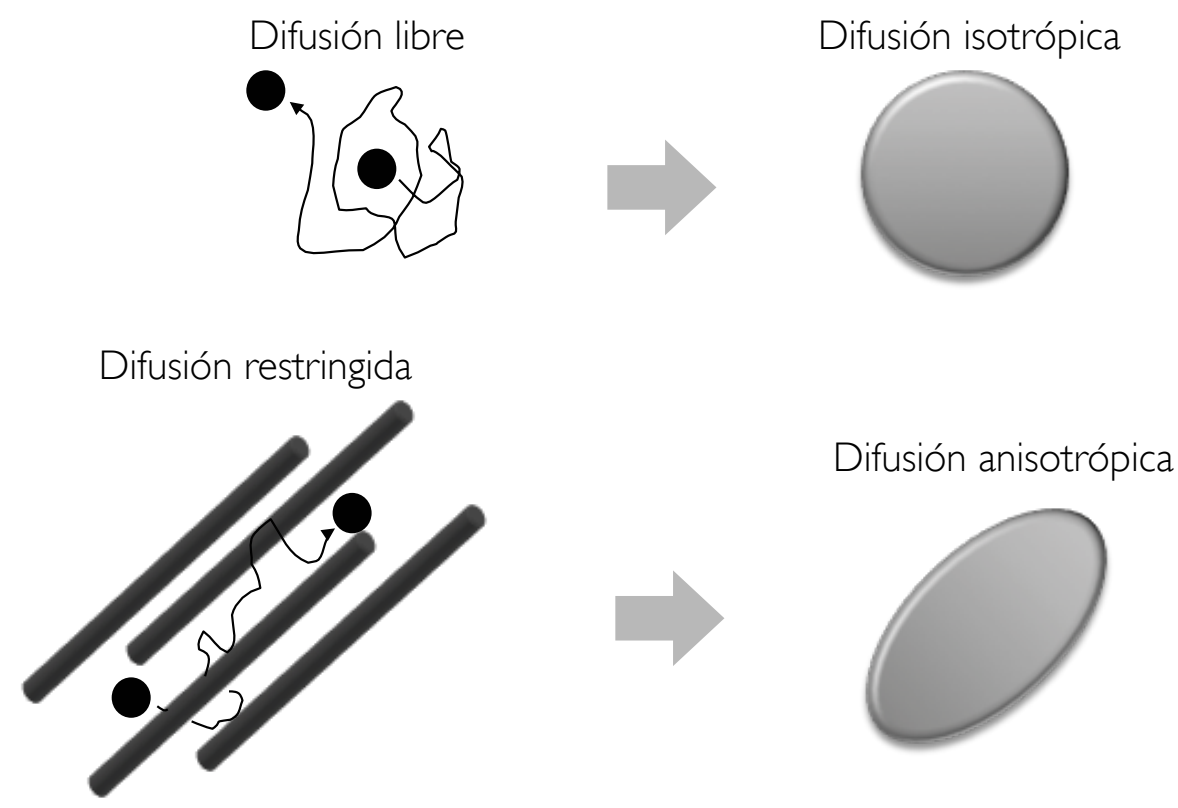

Figura 1.8: Esquema de difusión libre y restringida.

Podemos obtener imágenes potenciadas en difusión (DWI) activando un gradiente en una dirección determinada con un cierto valor b. La imagen obtenida lleva información relativa al ADC pero relacionada con la dirección. Para obtener una imagen independiente de la orientación y que únicamente esté relacionada con el ADC, se realiza en cada pixel el cálculo de la media geométrica o la media aritmética de los valores obtenidos en imágenes generadas con gradientes ortogonales. (84) La anisotropía de la difusión, implica que para caracterizarla no nos sirva un único valor escalar como ocurría en la difusión isotrópica, por el contrario se precisan un conjunto de valores que describan la dependencia de las direcciones de medida. El procesamiento de los valores de difusión se realiza creando una estructura llamada tensor, definido como un conjunto de magnitudes coexistentes (por ejemplo, los valores de difusión para un mismo vóxel) y que además son dependientes de su dirección y de las coordenadas. La matriz del tensor está formada por los valores del ADC obtenidos para cada una de las direcciones de codificación.

Es necesario obtener las direcciones principales de difusión en cada vóxel mediante su diagonalización. Para descomponer una matriz de datos cuadrada y simétrica en un sistema de matrices equivalente se suele emplear el formado por tres vectores unitarios (de longitud igual a 1) y ortogonales (perpendiculares entre sí) que definen las 
direcciones principales de difusión y una matriz diagonal con las longitudes correspondientes a cada vector. El resultado de la diagonalización se corresponde con los valores propios y vectores propios de la matriz. Con la diagonalización, el máximo de los valores y su vector correspondiente indican la dirección principal de difusión dentro de un vóxel. Las direcciones secundarias de difusión indican si un vóxel tiene una dirección predominante (anisotropía) o si su difusión es equivalente en todas las direcciones (isotropía).

De la diagonalización del tensor es posible calcular un conjunto de variables codificables como mapas paramétricos de difusión. Pese a que el propio ADC es una imagen paramétrica, el resto se calcula de la combinación de los valores propios del tensor.

Otros mapas paramétricos son estadísticos, donde se toman los valores propios como una población de muestras, interpretando su dispersión como un indicador de anisotropía. Se representa por medio de la anisotropía fraccional (FA), que evalúa directamente la desviación de los valores propios del tensor respecto a su media, proporcionando un índice normalizado entre 0 y 1 , donde 0 indica una difusión puramente isotrópica (esfera) y 1 la anisotropía ideal (elipse). Figura 1.8

El método más comúnmente empleado para producir DWI es una combinación de secuencias de Gradiente Pulsado de Spin Eco (Pulsed Gradient Spin Echo, PGSE), e Imagen Ecoplanar (Echo Planar Imaging, EPI). Las aplicaciones de EPI se derivan de la mayor velocidad de adquisición; las indicaciones principales son la perfusión, la difusión, la activación cortical y en teoría siempre que sea necesario reducir el tiempo de exploración y, como consecuencia, la reducción de artefactos por movimiento. (83) La porción PGSE se añade a la parte delantera de la secuencia como una fase de preparación. A menudo, las secuencias se disponen para proporcionar múltiples imágenes con una gama de direcciones de difusión y valores b , y a veces el software del escáner calcula un mapa de ADC. (ㅁ5) 


\section{Uso de la Resonancia magnética en lesiones de la médula espinal}

La MR es un método no invasivo que permite estudiar los cambios fisiopatológicos en lesiones de la médula espinal. Es capaz de identificar los cambios patológicos después del daño, tales como hemorragia, edema y cambios estructurales degenerativos secundarios como la formación de quistes y de cicatrices gliales, también permite observar cambios metabólicos que acontecen durante la evolución de la lesión y se puede emplear para observar la activación cortical después del daño (ㅎ6). No sólo en los seres humanos, sino también en animales pequeños como las ratas la MR es de gran interés para el seguimiento de los cambios en modelos de lesión de la médula espinal por varias razones: se puede evaluar la evolución de la lesión a través del tiempo en el mismo animal, permiten establecer una correlación de los resultados con análisis histológicos, y de la función motora. $(\underline{86}, \underline{87})$

Numerosos estudios realizados en roedores in vivo, utilizan sistemas dedicados experimentales de alto campo (hasta $17.6 \mathrm{~T}$ ) combinando bobinas de superficie e implantables, logrando obtener imágenes de alta resolución de los cambios morfológicos en la médula espinal lesionada $(\underline{88}, \underline{89})$, como hemorragia, edema e inflamación.

A diferencia de los sistemas experimentales, los sistemas clínicos dan acceso a un mayor número de secuencias de pulso y permiten comparar directamente los resultados entre los seres humanos y animales de experimentación. Generalmente, los sistemas clínicos están equipados con una interfaz más amigable, la cual ayuda a reducir el tiempo de preparación de los estudios, sin embargo resulta de gran interés conocer los cambios fisiopatológicos que se pueden observar en un sistema clínico de MR y extrapolar los criterios de adquisición del estudio en un equipo con mayor intensidad de campo. (이)

La MR es útil principalmente para visualizar estructuras de tejidos blandos, incluyendo la médula espinal. Por ejemplo los protones de hidrógeno dentro de grandes complejos moleculares, como las proteínas y los lípidos, tienden a disipar la energía por inducción con núcleos no excitados de manera más eficiente que las moléculas más pequeñas, como las del agua. Durante un determinado período de relajación T2, lípidos y proteínas presentan una mayor pérdida de intensidad de la 
señal (es decir, aparecerá más oscura) que los tejidos con alto contenido de agua. Esto permite que mediante el empleo de la secuencia de relaxometria T2 (T2MAP) se puedan observar los cambios representativos que proporcionen información para clasificar el estado de la lesión en aguda o crónica. (91) (92)

Las imágenes ponderadas en T2, desempeñan un papel clave en la formación de imágenes clínicas de MR de la médula espinal. Las imágenes ponderadas en T2 son muy sensibles al evidenciar condiciones patológicas, sin embargo es de manera inespecífica. Pueden mostrar aumento en el contenido de agua de un tejido, que se relaciona con un incremento en el contraste T2. Por lo tanto, las imágenes potenciadas en T2 se consideran una herramienta clínica cualitativa, sin embargo, si se obtiene la curva de decaimiento de T2, hay una oportunidad para extraer información cuantitativa del tejido. El tiempo de relajación T2 (o tiempo de relajación transversal), describe la descomposición irreversible de la señal de MR en el plano transversal. Inmediatamente después de un pulso de excitación, la señal de MR es máxima, ya que todos los protones están alineados. Sin embargo, la intensidad de la señal decae a cero a una velocidad determinada por la distribución del campo magnético o la distribución del desplazamiento químico. Seguido del pulso de excitación, un pulso de $180^{\circ}$ reenfoca la señal desfasada por las inhomogeneidades del campo magnético para ser reorientada y producir un eco. La altura de este eco disminuye exponencialmente con el tiempo desde el pulso de excitación con una constante de tiempo T2. Entonces, la relaxometría T2 representa un método de análisis cuantitativo de MR, derivando de los valores numéricos de los voxeles para los tiempos de relajación.(93)

Pese a que las imágenes convencionales de resonancia magnética son un método efectivo para detectar lesiones en el sistema nervioso, se han desarrollado nuevas técnicas de imágenes que pueden mostrar la fisiología y función normal y anormal. En este sentido, las moléculas de agua (contenidas en el cuerpo humano) tienen un movimiento aleatorio normal. Este movimiento es la base de una técnica conocida como imágenes ponderadas en difusión, las cuales son útiles en la evaluación de infartos y tumores cerebrales. ( $\underline{76})$ 
En un medio homogéneo el movimiento de las moléculas de agua tiende a formar una esfera. En las imágenes de difusión, la escala de tonos de grises representan el desplazamiento, así, en las zonas en que las moléculas se desplazan fácilmente, se observa una señal baja (hipontensas). En el caso del parénquima las moléculas no se desplazan tan fácilmente, pues existen membranas que impiden el desplazamiento, por lo que se representa en tonos grises. (94)

Por otro lado, el problema de las imágenes ponderadas en difusión es que su interpretación no es intuitiva por ello el mapa ADC (coeficiente de difusión aparente), es el resultado del postproceso de las imágenes que permite hacer una evaluación cuantitativa del movimiento de las moléculas de agua.

Estas imágenes se adquieren muy rápidamente por lo que no tienen mucho detalle estructural pues no se pretende reproducir la anatomía sino representar una función. En este estado se produce restricción del desplazamiento de las moléculas de agua, las cuales colisionan con las membranas celulares, impidiendo un desplazamiento normal. (75)

La restricción de la difusión puede ser producida por otras causas. En los casos de producción de edema, destrucción de la citoarquitectura en el caso de una lesión, se producen variaciones de la difusión del aguan en comparación con un tejido normal.

La presencia de múltiples tractos nerviosos produce que las moléculas de agua tiendan a moverse en forma anisotrópica. Las moléculas se mueven más fácilmente en el sentido de las vías nerviosas. Por lo que la morfología de es de una esfera, sino más bien en forma elipsoide, cuyo eje principal sigue la dirección de las vías nerviosas. Esta asimetría se representa en las imágenes de anisotropía fraccional (FA), en las cuales las áreas con mayor anisotropía se ven hipertensas (blancas), como los haces mielinizados y las áreas de baja anisotropía se ven hipointensas (oscuras), como la sustancia gris de la médula espinal. $(75,95)$ 


\section{Justificación}

La lesión de la médula espinal es un padecimiento que provoca daños progresivos e irreversibles en las funciones motoras, sensitivas y autonómicas. Actualmente no existe un tratamiento efectivo. Por consiguiente, existe una gran necesidad de desarrollar nuevas terapias a través de la investigación clínica y científica con el fin de mejorar la función neurológica.

Los posibles tratamientos se prueban en modelos animales de experimentación, y los resultados se evalúan mediante escalas cualitativas de la calidad de la marcha y con análisis histológicos (post mortem). Aunque estos métodos son ampliamente utilizados en la investigación, no ofrecen un monitoreo cuantitativo para estudiar la dinámica del daño o son terminales en su evaluación.

Por lo anterior, en este trabajo se propone evaluar el efecto del Polipirrol/Yodo como estrategia terapéutica en la lesión por contusión de médula espinal y el empleo de la resonancia magnética como método de evaluación longitudinal no invasivo. 


\section{Hipótesis}

Si el efecto del Polipirrol/Yodo incide sobre la recuperación funcional y neuroprotección después de un modelo de lesión por contusión de la médula espinal en ratas, entonces se presentarán cambios significativos en los en los parámetros de difusión por resonancia magnética (ADC, FA) al ser comparado con el grupo control. 


\section{Objetivos}

\subsection{Objetivo general}

Evaluar el efecto sobre la recuperación funcional y la neuroprotector del tratamiento con Polipirrol/Yodo sintetizado por plasma en un modelo de lesión por contusión moderada de la médula espinal de ratas in vivo, mediante el monitoreo de parámetros de difusión por resonancia magnética, empleando un equipo clínico de 3 Tesla.

\subsection{Objetivos particulares}

1. Conocer la viabilidad para obtener evaluaciones cuantitativas de relaxometría T2, coeficiente de difusión aparente y fracción de anisotropia en ratas in vivo con un equipo clinico de $3.0 \mathrm{~T}$

2. Determinar los cambios presentados en los valores de los parámetros de relaxometría T2, ADC y FA después de la lesión por contusión de la médula espinal de ratas.

3. Desarrollar un diseño experimental que permita evaluar el efecto del tratamiento (Polipirrol/Yodo) en un modelo experimental con ratas.

4. Monitorizar los parámetros de resonancia magnética (T2MAP, ADC y FA) en las ratas después de la lesión de la médula espinal.

5. Evaluar la recuperación funcional motora en las ratas después de la lesión de la médula espinal a través de la escala BBB.

6. Cuantificar el tejido preservado mediante estudios histológicos en ratas después de la lesión de médula espinal. 


\section{Materiales y Métodos}

\subsection{Síntesis del polímero}

La síntesis del polímero se realizó en el departamento de física del Instituto Nacional de Investigaciones Nucleares. Empleando la técnica de polimerización por plasma, se sintetizó una película de Polipirrol/Yodo (PPy/I) en un reactor tubular de vidrio de $9 \mathrm{~cm}$ de diámetro interno y $20 \mathrm{~cm}$ de longitud con volumen aproximado de $1400 \mathrm{~cm}^{3}$, una distancia entre electrodos de $7 \mathrm{~cm}$ (Figura 5.1). Con los siguientes parámetros de reacción (Tabla 5.1) (68).

Tabla 5.1: Parámetros del reactor de plasma para la síntesis del polímero

\begin{tabular}{ll}
\hline Radiofrecuencia & $13.5 \mathrm{Mhz}$ \\
\hline Potencia promedio & $80 \mathrm{~W}$ \\
Temperatura & $365 \mathrm{~K}$ \\
\hline Presión promedio & $10^{-2} \mathrm{mbar}$ \\
Diferencia de potencial & $700 \mathrm{~V}$ \\
Tiempo de reacción & $240 \mathrm{~min}$ \\
\hline
\end{tabular}

El reactor cuenta con bridas de acero inoxidable en los extremos que tienen tres puertos de acceso cada una. En el puerto central de cada lado se insertan electrodos de acero inoxidable con longitud de $2 \mathrm{~cm}$ y diámetro de $7 \mathrm{~cm}$. La separación entre los electrodos es de $7 \mathrm{~cm}$ aproximadamente. Los electrodos se conectan a un generador de radiofrecuencia RFX-600 Advanced Energy. El sistema de vacío que se conecta en un extremo consta de una bomba para vacío Alcatel Pascal 2010C1 y un condensador Alcatel LNT 25 S para gases residuales, este es enfriado mediante Nitrógeno líquido, además cuenta con un medidor Pirani modelo 945 MKS Instruments HPSTM.(Figura 5.1)

En el otro extremo se conectan dos recipientes que contienen los reactivos para realizar la síntesis, por puertos separados para que todos los componentes se mezclen en el interior del reactor. El plasma fue formado por descargas de resplandor con acoplamiento resistivo producidas con el generador de radio frecuencia. 
En la síntesis del PPy/I se empleó el monómero de Pirrol en estado líquido (Aldrich, 98\%), permitiendo que reaccionara entre sí en la cámara de reacción y se utilizó Yodo como dopante (Aldrich, 99.5\%). Los materiales son líquidos a condiciones atmosféricas, sin embargo, entran al reactor en fase gaseosa debido a la diferencia de presión entre los recipientes de los reactivos y la cámara de reacción. La polimerización se realizó reduciendo primero la presión en el interior del reactor hasta aproximadamente $10^{-2} \mathrm{mbar}$, después se aplicaron descargas eléctricas con la atmósfera residual. Una vez que la presión y las descargas están estables se abren las válvulas del monómero y dopante para introducirlos al reactor en fase vapor. En el interior del reactor, la energía de las partículas aceleradas por los campos eléctricos hace que reaccionen los monómeros y dopantes ya sea ionizándolos, excitándolos o formando radicales libres sintetizando así polímeros con estructura basada en la de los monómeros.

Una vez sintetizado el polímero, se desprendió de las paredes de la cámara de reacción con acetona, conservando $1 \mathrm{~cm}^{2}$ de la película para los análisis de caracterización, el resto se destino para la preparación del tratamiento.

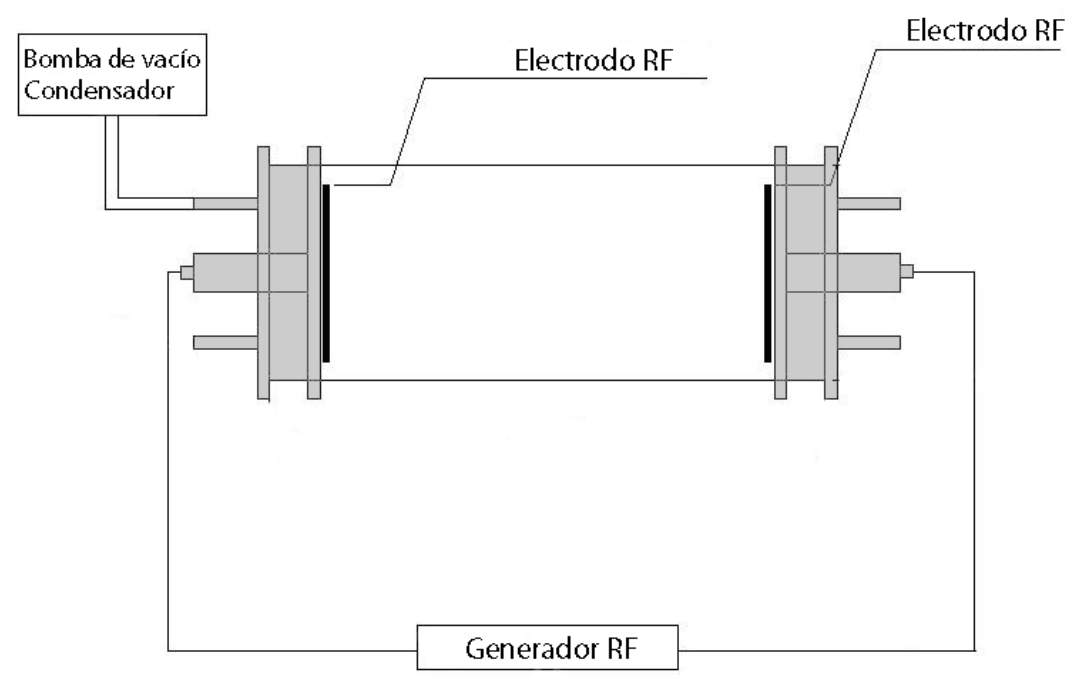

Figura 5.1: Esquema del reactor de plasma 


\subsection{Caracterización del polímero}

Para caracterizar el material se realizaron análisis de infrarrojo (IR), descripción morfologica con análisis elemental y determinación del tamaño de partícula, estas ténicas se llevaron a cabo en las instalaciones del Instituto Nacional de Investigaciones Nucleares.

\section{Análisis infrarrojo}

El análisis de composición del polímero por IR se realizó con una muestra en forma de película del material en un espectrofotómetro Perkin Elmer 2000, usando 32 exploraciones con un intervalo de longitud de onda de $400-4000 \mathrm{~cm}^{-1}$ con una resolución de $4 \mathrm{~cm}^{-1}$.

\section{Descripción morfológica y análisis elemental}

Las características morfológicas de los materiales fueron observadas con un Microscopio Electrónico de Barrido (SEM) JEOL JSM-5900LV usando un voltaje de aceleración de $20 \mathrm{kV}$, para aumentar la magnificación de las imágenes las muestras fueron cubiertas con una fina capa de oro. El microscopio fue acoplado con una sonda de espectroscopia de dispersión de energía (Sapphire EDAX NXL-30), para el análisis elemental.

\section{Tamaño de partícula}

Para realizar el análisis de distribución de tamaño de partícula se tomaron imágenes del material molido en un mortero de ágata por diez minutos. La muestra fue de aproximadamente 400 partículas usando el tamaño de partícula con más representación de las micrografías analizadas.

\subsection{Elaboración del tratamiento con Polipirrol/Yodo}

La preparación de tratamiento se realizó en el Instituto Nacional de Investigaciones Nucleares y en el Instituto Nacional de Neurología y Neurocirugía. Una vez caracterizado el polímero, se preparó una suspensión a partir de fragmentos de la película de PPy/I, moliéndolos en un mortero de ágata durante $5 \mathrm{~min}$. Se pesaron $5 \mathrm{mg}$ de PPy/I y se le adicionó $1 \mathrm{ml}$ de solución fisiológica ( $0.9 \%$ Cloruro de Sodio) en viales 
de $5 \mathrm{ml}$ para después colocarlos en un agitador ultrasónico durante 30min para disgregar los aglomerados formados. Finalmente los viales fueren esterilizados en autoclave.

\subsection{Diseño experimental}

Conforme a los lineamientos establecidos en el reglamento de la ley general de salud en materia de investigación para la salud (título Séptimo: De la investigación que incluye la utilización de animales de experimentación), publicada en 1987. Se desarrolló el siguiente modelo experimental. (Anexo A)

Se diseñó un estudio experimental, aleatorizado, controlado con placebo y segado al tratamiento, para el cual se emplearon ratas sanas hembras adultas (8-9 semanas de edad) de la cepa Long Evans con peso corporal de entre 220-240g.

Las ratas fueron sometidas a un modelo de lesión por contusión moderada de la médula espinal a nivel torácico 9 (T9) y posteriormente se dividieron en 3 grupos experimentales.

Grupo 1: Control. Ratas con el modelo de contusión de la médula espinal $(\mathrm{n}=4)$

Grupo 2: Vehículo. Ratas con el modelo de contusión de la médula espinal $+30 \mu l$ de solución fisiológica $(\mathrm{n}=4)$

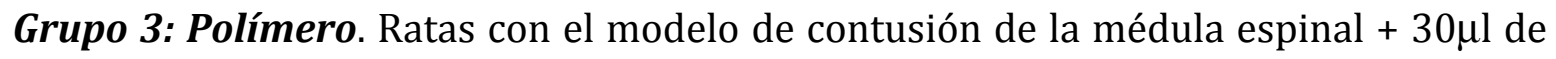
PPy/I en suspensión a una concentración de $5 \mathrm{mg} / \mathrm{ml}(\mathrm{n}=4)$

\subsection{Procedimientos quirúrgicos}

Todos los procedimientos quirúrgicos fueron realizados bajo anestesia general con una mezcla de Ketamina $(77.5 \mathrm{mg} / \mathrm{Kg})$ y Xilacina $(12.5 \mathrm{mg} / \mathrm{Kg})$ en las instalaciones del proyecto CAMINA A.C.

\section{Lesión por contusión de la médula espinal y administración de tratamiento}

Previa asepsia, los animales se anestesiaron vía intramuscular, posteriormente se les practicó a una cirugía con abordaje posterior donde se realizó una incisión sagital en la piel seguida de una disección de los músculos paravertebrales de las apófisis espinosas del nivel torácico 8 a 10 (T8, T9 y T10). Se extirparon las apófisis espinosas 
T9 y T10 y se realizó una laminectomía extendiéndola bilateralmente hasta los procesos facetarios conservando las meninges. A continuación, los animales fueron colocados en un aparato de cirugía estereotáxica NYU (New York University) impactor con el que se les provocó una lesión por contusión moderada de la médula espinal utilizando un cilindro de acero inoxidable de $10 \mathrm{~g}$, el cual se dejó caer de una altura de $25 \mathrm{~mm}$ sobre la médula espinal expuesta a nivel de la vértebra T9. Mediante una computadora y un software provisto en el equipo NYU impactor se midieron parámetros como la deformación de la médula espinal al momento del impacto, y sólo se incluyeron en el estudio los animales que presentaran un error $\leq 5 \%$ para obtener lesiones altamente reproducibles (72).

Para finalizar el procedimiento, el músculo, la fascia y la piel de la incisión se suturaron por planos, los animales fueron colocados en una unidad de cuidados intensivos para especies pequeñas, se les administró antibiótico y analgésico; además se le facilito agua y alimento a libre demanda.

Transcurridas 48 horas después de la lesión, los animales fueron nuevamente anestesiados para retirar los puntos de sutura de la cirugía previa y localizar el sitio de la lesión en seguida fueron asignados aleatoriamente a uno de los tres grupos experimentales.

Los animales correspondientes al grupo control se suturaron nuevamente, a los del grupo vehículo se les administró $30 \mu \mathrm{l}$ de solución fisiológica directamente en el epicentro de la lesión utilizando una jeringa Hamilton. Finalmente a los animales del grupo tratamiento se les administraron $30 \mu \mathrm{l}$ del polímero en suspensión a una concentración de $5 \mathrm{mg} / \mathrm{ml}$ (previa agitación mecánica con un mezclador de vórtice durante 20s) (96) a nivel de la lesión orientando el bisel de la aguja lateralmente. (97, 98) Posteriormente, fueron suturados y recibieron los cuidados post-operatorios pertinentes.

\subsection{Resonancia magnética}

Todos los experimentos se realizaron en el hospital Médica Sur (Imagen por resonancia magnética) en un resonador clínico de 3.0T utilizando una bobina de muñeca. Cada rata se colocó bajo anestesia (Ketamina-Xilacina 77.5-12.5mg/Kg i.p.) 
en posición decúbito ventral en un sistema de fijación para minimizar los movimientos respiratorios y obtener una posición reproducible durante la adquisición de la imagen. Se evaluaron tres parámetros: relaxometría T2 (T2MAP), Coeficiente de Difusión Aparente (ADC) y Anisotropía Fraccional (FA) a niveles cervical y de la lesión (torácico T9). El seguimiento se realizó con el siguiente esquema: una semana antes de la lesión, 1, 4 y 8 semanas después de la lesión.

\section{Diseño y construcción de dispositivo de fijación}

Se diseñó y construyó un dispositivo de fijación para ratas elaborado con materiales compatibles con entornos magnéticos (Acrílico y Nylamid®), el cual permite inmovilizar a las ratas para obtener imágenes de alta resolución con equipos clínicos de resonancia magnética, figura 5.2.

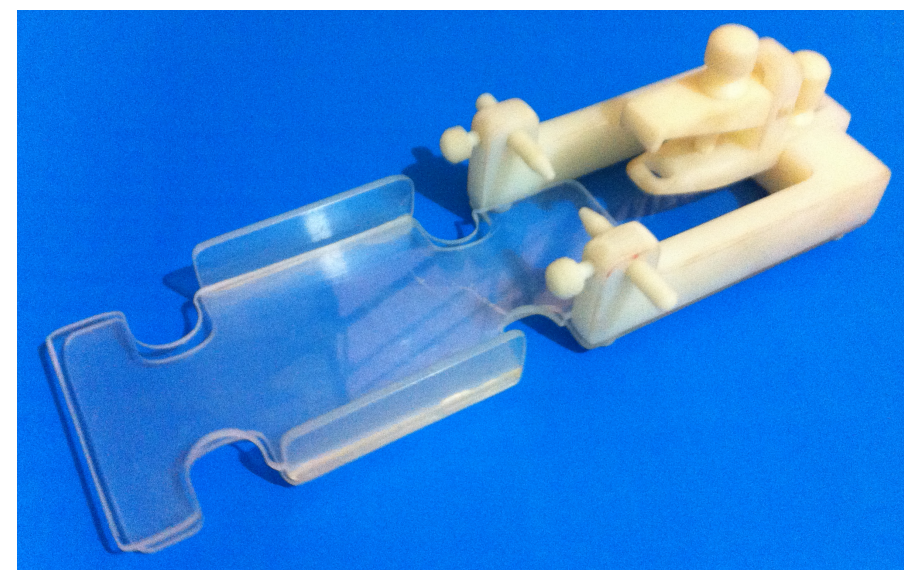

Figura 5.2: Dispositivo de fijación

Así mismo, en la figura 5.3 se observa el esquema detallado del sistema de fijación, el cual está constituido por una base de acrílico (1) que cuenta con 4 muescas para el posicionamiento de las extremidades del roedor así como barreras a los costados para impedir el movimiento lateral, esta base se une por medio de tornillos (4) a una marco en forma de herradura (2) que sirve de soporte para el sistema de inmovilización de la cabeza (3) que se desplaza con una corredera y puede ser ajustado con un tornillo (6) con el fin de adaptarlo al largo de la cabeza del roedor. Para el sistema de inmovilización de la cabeza el sistema de fijación también cuenta con unas barras deslizables que se colocan en el canal auditivo del roedor (9) y sus respectivos tornillos para asegurarlas (5), mientras que para asegurar el hocico se dispone de una 
mordaza incorporada el sistema de inmovilización de la cabeza mediante un perno (8) que puede ser ajustada por medio de un tornillo (7) en posición adecuada.

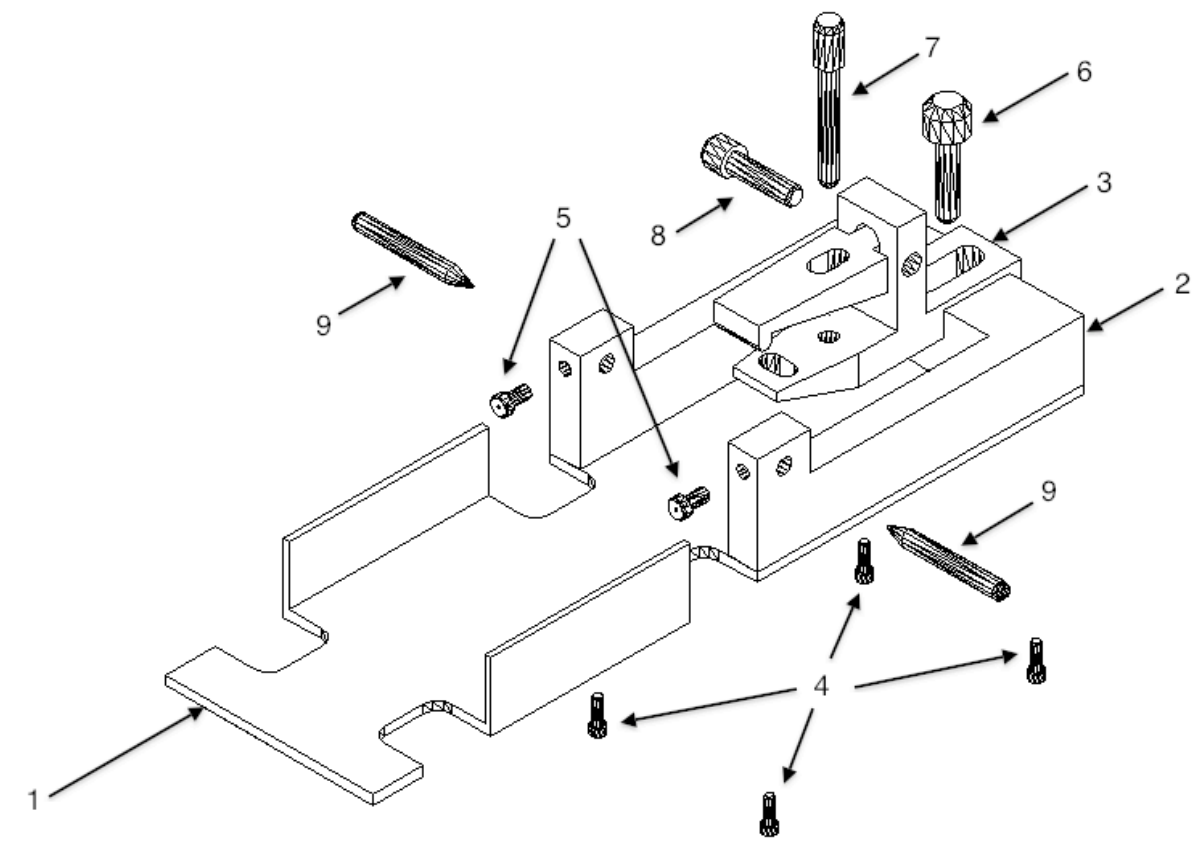

Figura 5.3: Esquema de dispositivo de fijación

\section{Estudio piloto}

Se realizó un estudio piloto para determinar la viabilidad de las mediciones in vivo de los parámetros de difusión en un equipo clínico de MR 3.0T,(99) y establecer las estimaciones de las variaciones de esos parámetros y especificar los tiempos e intervalos de medición. Se emplearon 3 ratas de la cepa Long Evans a las cuales se les realizó un escaneo por resonancia magnética que incluyó secuencias anatómicas de exploración, T1, T2 y T2MAP (relaxometría T2) y de difusión DWI (ADC), DTI (FA), 48 horas después se les practicó un modelo de lesión por contusión moderada de la médula espinal a nivel torácico 9 (T9), finalmente 48 horas después de la lesión se repitieron las secuencias. Fueron medidos los parámetros de relaxometría T2, ADC y FA antes y después de la lesión (100)

Según las mediciones obtenidas se determinó que era posible observar los cambios antes y después de la lesión por contusión $(\underline{100}, \underline{101})$ sin embargo, se incrementaron los periodos de evaluación al detectar que los tiempos de anestesia tan frecuentes ponían en riesgo la vida de los animales de experimentación. Subsecuentemente, se 
estandarizó el protocolo de adquisición de las imágenes y los parámetros finales a medir durante el estudio definitivo (99).

\section{Secuencias de Resonancia Magnética}

Todos las secuencias se realizaron en un equipo clínico de MR de 3T (Signa HDxt, GE®) Healthcare, Waukesha, WI, EE.UU.) (Figura 5.4C), utilizando una bobina transmisora/receptora de cuadratura para muñeca (modelo BC-10, Clinic Mayo Medical Devices $®$, Rochester, MN)(Figuras 5.4A y B). Cada rata se colocó en el sistema de fijación en decúbito para minimizar los movimientos respiratorios y obtener una posición reproducible durante la adquisición de la imagen y para el seguimiento.(Figura 5.4A y B)

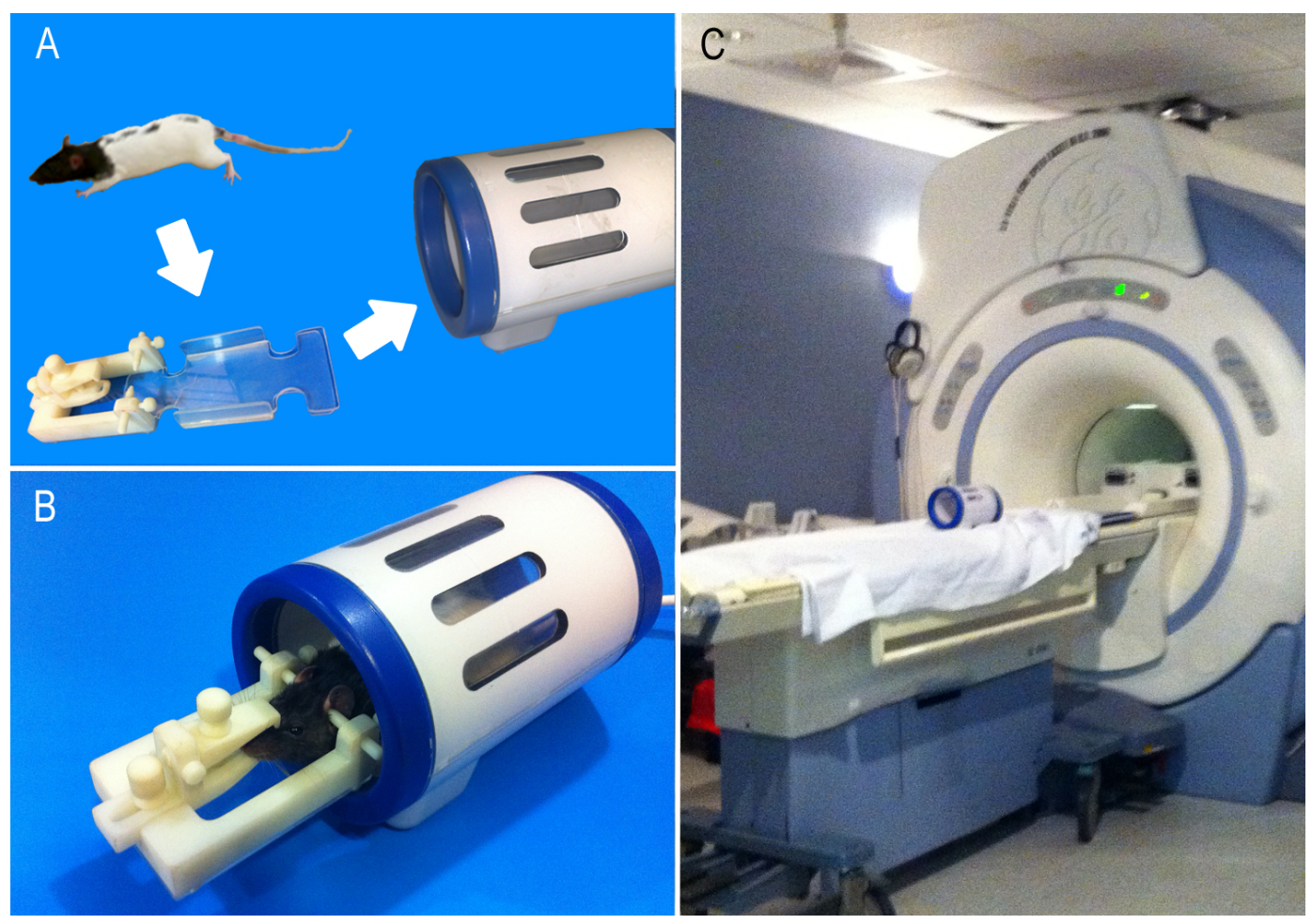

Figura 5.4: (A) Esquema de colocación de la rata en el sistema de fijación y bobina, (B) Ubicación dentro de la bobina de la muñeca en cuadratura (Mayo Clinic, modelo BC-10, Rochester, MN) con el dispositivo de fijación, (C) Escáner clínico de MR 3T (Signa HDxt, GE Healthcare, Waukesha, WI, EE.UU.)

Se programaron 4 evaluaciones como seguimiento: Previo (una semana antes de la lesión), Sem1 (7 días después), Sem4 (4 semanas después de lesión) y Sem8 (8 semanas después de la lesión). El protocolo de secuencia que se realizó en cada ocasión incluyó: 3D-Spoiled Gradient Echo (SPGR) secuencias de TR/TE 9.9ms / 
4.3ms, cortes sagitales con ponderación $\mathrm{T}_{1}$ y $\mathrm{T}_{2}$, matriz de $512 \times 512$, grosor de corte de 3mm, TE 11/110 ms, TR 350/3000 ms, respectivamente. Relaxometría T2 (T2MAP) fue adquirido con TE 6.2-49.7 ms, TR 800ms, 256x265 matriz, grosor de corte $3 \mathrm{~mm}$. Las Imágenes Ponderadas en Difusión (DWI) fueron adquiridas en el plano sagital con b-value $=1000 \mathrm{~mm} \mathrm{~s}^{-2}$, TE 75ms, TR $6000 \mathrm{~ms}$, matriz 256x256, grosor de corte $3 \mathrm{~mm}$. Las Imágenes de Tensor de Difusión (DTI) se obtuvieron en cortes axiales, con un bvalue $=1000 \mathrm{~mm} \mathrm{~s}^{-2}$, TE $78 \mathrm{~ms}$ y TR $6000 \mathrm{~ms}$, matriz $256 \times 256,3 \mathrm{~mm}$ de grosor de corte, en 25 direcciones de gradiente de difusión. El tiempo total de adquisición de las secuencias fue de $40 \mathrm{~min}$. (Tabla 5.2)

Tabla 5.2: Parámetros de las secuencias de resonancia magnética

\begin{tabular}{lllll}
\hline Secuencia & TE/TR (ms) & Matriz & $\begin{array}{l}\text { FOV } \\
(\mathbf{m m})\end{array}$ & $\begin{array}{l}\text { Grosor de corte } \\
(\mathbf{m m})\end{array}$ \\
\hline 3D-SPGR & $3.4 / 9.9$ & $512 \times 512$ & 120 & 2 \\
Sagital T $_{1}$ & $11 / 350$ & $512 \times 512$ & 100 & 3 \\
Sagital T & $110 / 3000$ & $512 \times 512$ & 100 & 3 \\
T2MAP & $6.2-49.7 / 800$ & $256 \times 256$ & 120 & 3 \\
DWI & $75 / 6000$ & $256 \times 256$ & 100 & 3 \\
DTI & $78 / 6000$ & $256 \times 256$ & 100 & 3 \\
\hline
\end{tabular}

\section{Post-procesamiento de imágenes y medición de parámetros}

Las secuencias de T2MAP, DWI y DTI para la medición de los parámetros relaxometría T2, ADC y FA fueron trasladados a una estación de trabajo independiente, y empleando el software Functool ${ }^{\circledR}$ v9.4.04b (GE® Healthcare, Waukesha, WI, EE.UU.), se generaron los respectivos mapas y se superpusieron a las imágenes anatómicas (SPGR, T1 y T2). Se obtuvieron dos mediciones individuales con la región de interés (ROI de $10-12 \mathrm{~mm}^{2}$ ) que abarcara el área de la zona de lesión (nivel T9) y otra la médula espinal a nivel cervical para cada secuencia: T2MAP (ms), ADC $\left(\mathrm{mm}^{-2} \mathrm{~s}\right)$ y FA (adimensional) (Figura 5.5) en cada período de evaluación (Previo, Sem1, Sem4 y Sem8). 


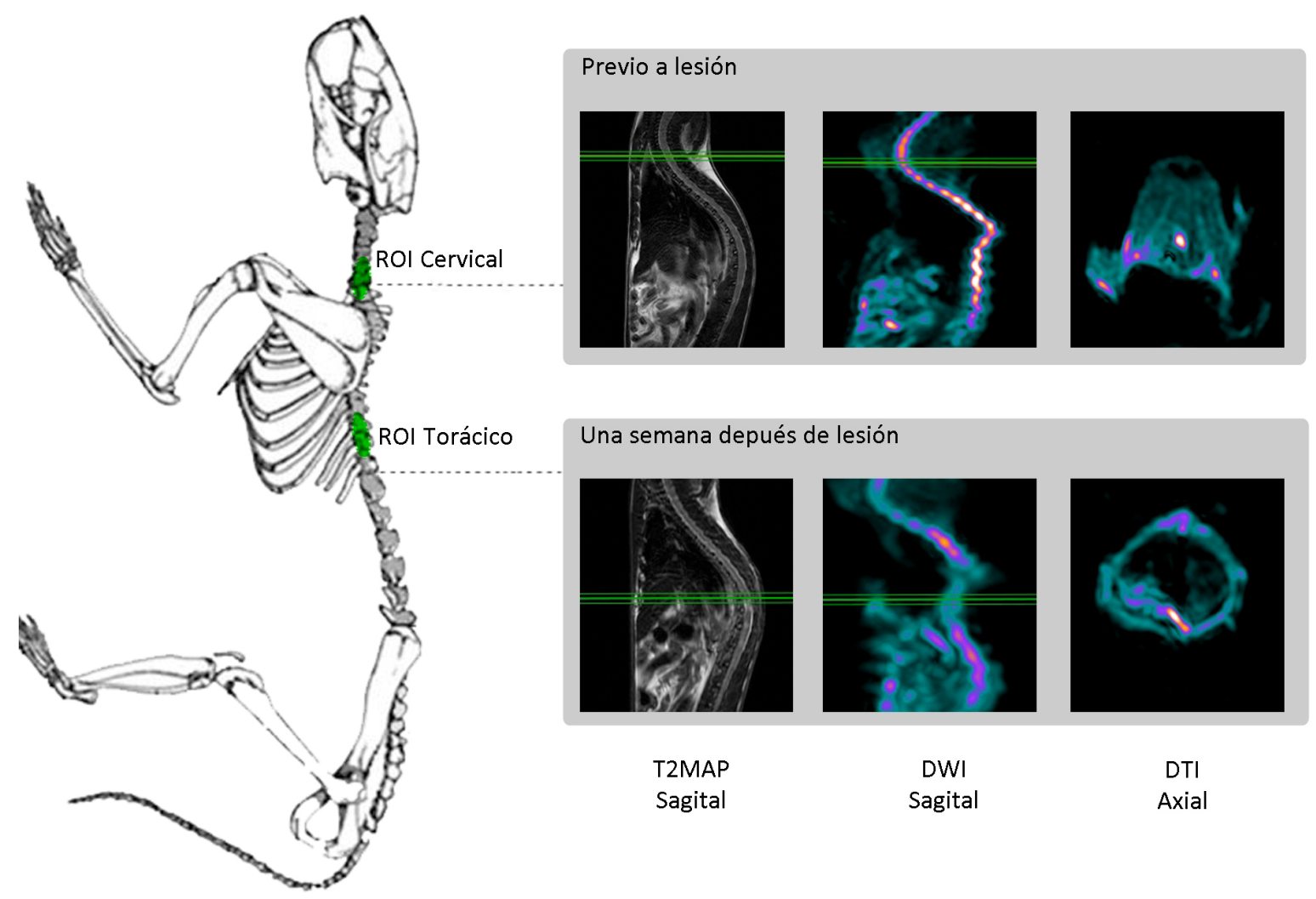

Figura 5.5: Representación esquemática de la localización de los ROIs (izquierda) y ejemplos de la secuencias empleadas para la medición de parámetros (derecha). Líneas verdes, referencia del nivel de los cortes. Modificado de (102)

\subsection{Evaluación funcional}

La evaluación funcional de la calidad de la marcha se llevó a cabo en las instalaciones del proyecto CAMINA A.C., utilizando la escala BBB (Basso, Beattie y Bresnahan)(103), la cual evalúa la respuesta funcional motora con base en el movimiento de las articulaciones de la cadera, rodilla y tobillo de cada pata a través de 22 grados de recuperación motora; donde el grado 0 representa la ausencia de movimiento y el grado 21 una marcha normal. Puntuaciones entre 0 y 7 indican movimientos aislados en las articulaciones de la cadera, rodilla y tobillo. Las puntuaciones de 8 a 13 indican la colocación plantar de la pata y movimientos coordinados con las extremidades anteriores. Resultados entre 14 y 21 muestran separación de los dedos de las patas anteriores, la estabilidad del tronco y la posición de la cola.(104) (Anexo B). 
Los animales fueron evaluados el día siguiente de la lesión y posteriormente se realizaron evaluaciones una vez por semana durante ocho semanas. Las evaluaciones fueron realizadas por un investigador experto ciego a los grupos experimentales.

\subsection{Estudio histológico}

Ocho semanas después de la lesión, se analizó histológicamente el tejido nervioso a nivel de la lesión, para ello, previa anestesia los animales fueron sometidos a una toracotomía, a continuación, mediante una punción en el vértice cardiaco se procedió a la perfusión vía intracardiaca con una bomba peristáltica de $200 \mathrm{ml}$ de solución salina más 500u.i. de heparina, seguido sin interrupción de $400 \mathrm{ml}$ de paraformaldehído a una velocidad de $30 \mathrm{ml} / \mathrm{min}$. Al finalizar este procedimiento se extrajo un segmento de $1.5 \mathrm{~cm}$ de la médula espinal a partir del epicentro de la lesión y se colocó la muestra en un frasco con el mismo fijador. El tejido de la médula espinal fue deshidratado en alcoholes graduales y se aclaró con xileno y se incluyó en moldes de parafina. Se realizaron cortes longitudinales secuenciales a partir del canal ependimario $(10 \mu \mathrm{m}$ de espesor) con un microtomo, en un intervalo de 10 cortes obteniéndose 4 muestras. Los cortes se pasaron a un baño de flotación y se colocaron en laminillas para ser tratados con el procedimiento de hematoxilina y eosina de Harris. (Anexo C).

Las imágenes fueron obtenidas utilizando un sistema equipado con el software IM500, una cámara digital 300 FX, dos microscopios Leica MZ6 y DME. Se cuantifico la cantidad de tejido preservado en los cortes histológicos que incluyeran el canal ependimario para asegurar que todas las muestras estuvieran al mismo nivel y fueran comparables. El sacrificio de los animales se llevó a cabo en el proyecto CAMINA A.C., mientras que el procesamiento de las muestras histológicas se realizó en el centro médico nacional siglo XXI del IMSS y el análisis de tejido se efectuó el Instituto Nacional de Neurología y Neurocirugía.

\subsection{Estadística}

A todos los datos se les realizó una prueba de estadística descriptiva, así como, la prueba de homogeneidad de varianzas de Levene para determinar si se utilizaba una 
estadística paramétrica o no paramétrica. Posteriormente, para analizar los datos de las evaluaciones funcionales con la escala BBB y las mediciones de los parámetros de resonancia magnética (T2MAP, ADC y FA) a nivel cervical y torácico se utilizó la prueba de ANOVA de medidas repetidas seguida de la prueba de Dunnett mientras que para analizar la cantidad de tejido preservado se utilizó una ANOVA de una vía seguida de la prueba de Dunnett. Para estudiar la supervivencia al procedimiento de lesión y al tratamiento se emplearon las curvas de Kaplan-Meier, finalmente para medir el grado de relación entre las variables (BBB, T2MAP, ADC, FA y tejido preservado), se empleo el coeficiente de correlación de Spearman. Para analizar todos los datos se utilizó el software SPSS 20.0. 


\section{Resultados}

\subsection{Síntesis y caracterización del polímero}

\section{Análisis infrarrojo}

La estructura del PPy/I se analizó por espectroscopia IR y se presenta en la Figura 6.1 el espectro de transmitancia. El primer espectro corresponde al monómero Pirrol y el segundo al PPy/I (Polipirrol/Yodo) sintetizado por plasma.

La más significativa absorción se encuentra centrada en $3430 \mathrm{~cm}^{-1}$, que corresponde a la vibración N-H de los enlaces del pirrol (105). Hay una absorción en 2932 cm-1 que indica la presencia de enlaces $\mathrm{C}-\mathrm{H}$ alifáticos que son provenientes de los fragmentos de pirrol originados por las colisiones de alta energía de las partículas en el plasma durante la síntesis.

Los enlaces triples $\mathrm{C} \equiv \mathrm{N}$ y $\mathrm{C} \equiv \mathrm{C}$, se deben a oxidación y deshidrogenación intensa de las moléculas y están centrados en el pico $2220 \mathrm{~cm}^{-1}$. Los dobles enlaces consecutivos en diferentes combinaciones entre $\mathrm{N}, \mathrm{C}$ y $\mathrm{O}$ tales como $\mathrm{N}=\mathrm{C}=\mathrm{C}, \mathrm{O}=\mathrm{C}=\mathrm{C}, \mathrm{C}=\mathrm{C}=\mathrm{C}$ se pueden asociar a la absorción en $2364 \mathrm{~cm}^{-1}$. Estos enlaces pueden ser interpretados como extensiones de conjugación de enlaces dobles y sencillos, alternados que produce una distribución electrónica a la mitad de ambas densidades en esos segmentos. Los dobles enlaces individuales como $\mathrm{C}=\mathrm{O}, \mathrm{C}=\mathrm{C}$ y $\mathrm{C}=\mathrm{N}$ se pueden relacionar con la absorción en $1630 \mathrm{~cm}^{-1}$. Los enlaces múltiples $\mathrm{C}=0$ y C=N son una indicación de la deshidrogenación y/o oxidación del polímero ya que no pertenecen a la estructura química del pirrol, por lo que se formaron durante la síntesis. Los enlaces $\mathrm{C}=\mathrm{C}$ si son parte de la estructura del pirrol y por consiguiente de sus polímeros. La substitución de anillos heteroaromáticos se puede asociar a la absorción en $1435 \mathrm{~cm}^{-1}$. 


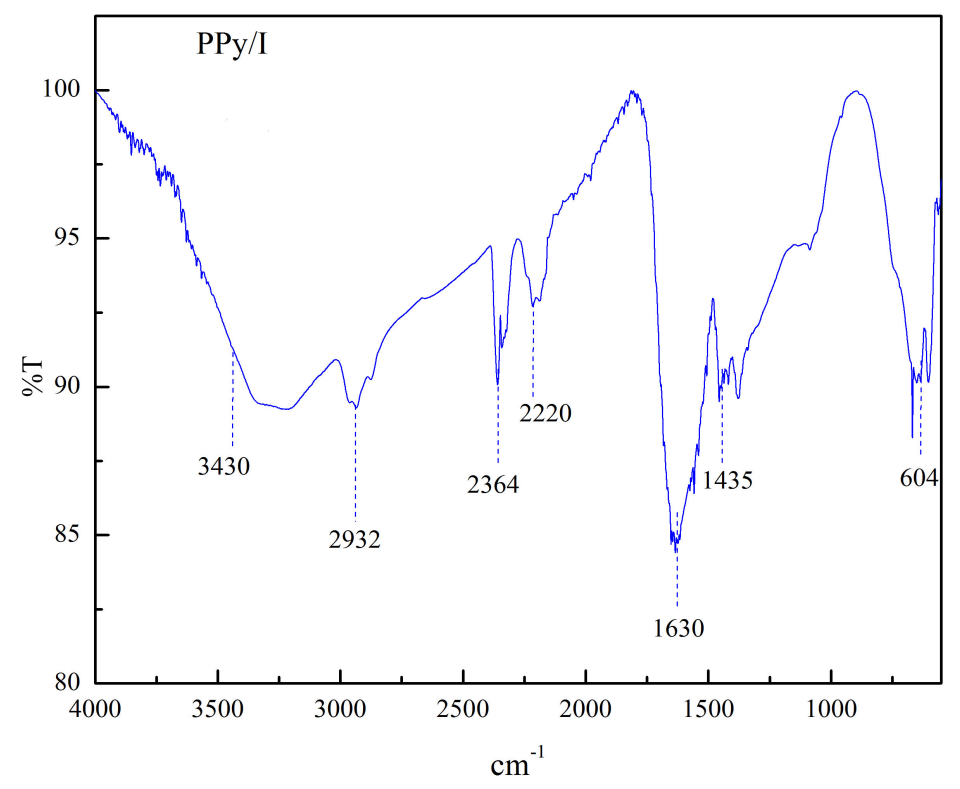

Figura 6.1: Espectros infrarrojos de PPyl sintetizado por plasma a $80 \mathrm{~W}$ durante $240 \mathrm{~min}$

\section{Descripción morfológica y análisis elemental}

EL polímero se formó por capas delgadas. La superficie de PPy/I se muestra en la figura 6.2A, la cual es esencialmente lisa con algunos pliegues formando líneas que apenas sobresalen del fondo. Esta morfología puede originarse en la cara del polímero que se formó pegado al vidrio de las paredes del reactor. La figura 6.2B muestra un perfil del polipirrol formado por una capa sólida de aproximadamente $5.5 \mu \mathrm{m}$. La superficie no es tan lisa como en el caso anterior, sino que tiende a formarse con burbujas en diferentes estados de crecimiento, parece ser la cara de la capa hacia la fase gaseosa. Ambas morfologías se encuentran comúnmente en polipirroles por plasma.

La micrografía de la figura 6.2C presenta al PPy/I después de moler varias capas durante 5 min manualmente. Se pueden ver fragmentos irregulares sólidos de muchos tamaños y aristas, lo que indica que las capas eran sólidas sin poros debajo de la superficie. El diámetro aparente promedio de las partículas varía entre 1 y $19 \mu \mathrm{m}$. 

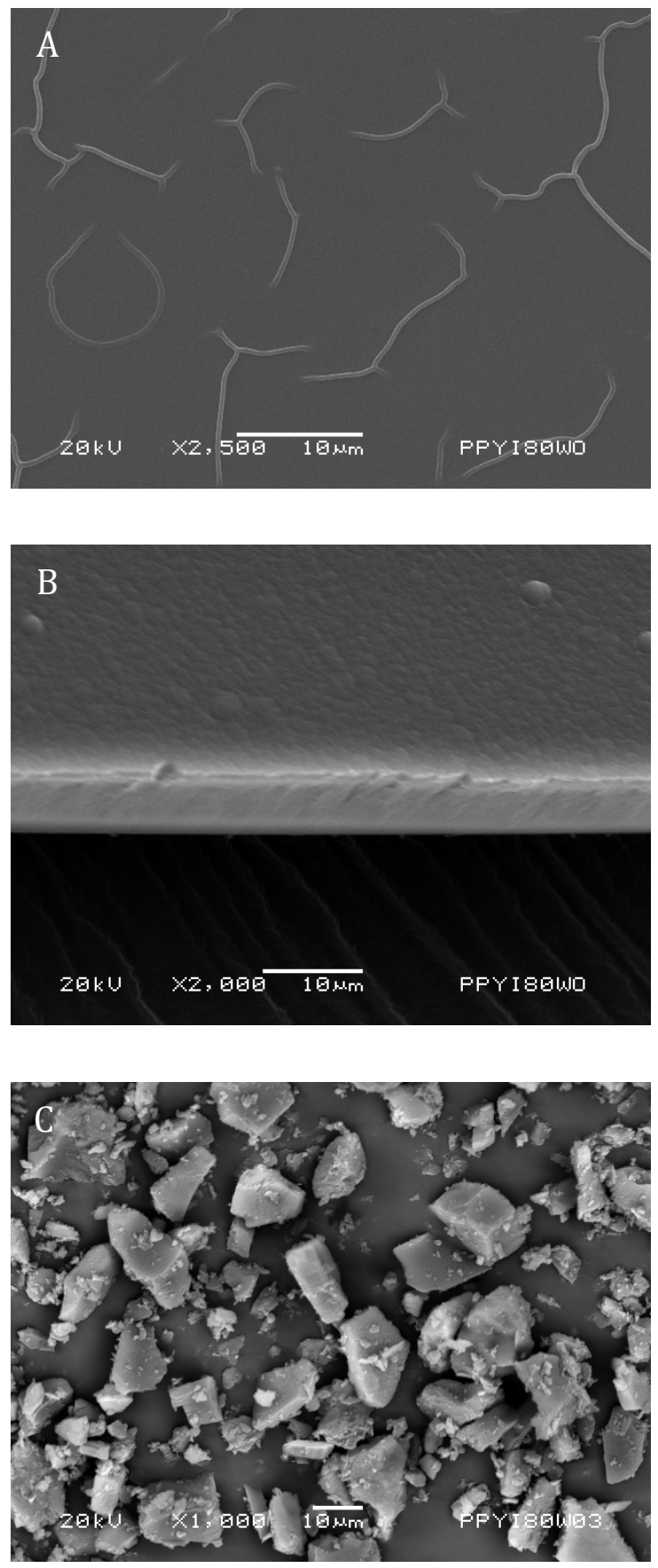

Figura 6.2: Micrografías SEM de PPy/I. (A) Superficie de la película 2500X, (B) Perfil de la película 2000X, (C) Partículas resultantes después de moler la película $1000 \mathrm{X}$

El análisis elemental del PPy/I se presenta en la tabla 6.1. Se muestra el porcentaje atómico correspondiente a los elementos que constituyen el polímero y la relación $\mathrm{C} / \mathrm{N}, \mathrm{C} / \mathrm{O}$ y C/I. La relación estequiométrica $\mathrm{C} / \mathrm{N}$ es 4,4 átomos de carbono por 1 de nitrógeno en las moléculas de pirrol. En el PPy/I esta relación es de 5.8 que indica que el contenido de nitrógeno se redujo probablemente debido a la fragmentación 
molecular durante la síntesis, ya que si se forman compuestos de bajo peso molecular pueden ser evacuados del reactor por el sistema de vacío. Así, esta relación indica que los compuestos nitrogenados formaron compuestos intermedios con tendencia a menor masa molecular que los compuestos formados solo de carbono, tal vez por la menor capacidad de enlace del nitrógeno de 3 que la del carbono que es de 4.

Por su parte, el contenido de yodo indica la magnitud de dopaje que tienen los polipirroles. Este contenido es pequeño y puede ser medido por molécula de pirrol dividiendo el contenido de $\mathrm{C}$ entre 4 , que es el número de átomos de $\mathrm{C}$ por pirrol. La relación Pirrol/I de 27.7 indica que en promedio hay un yodo por cada 27 anillos de pirrol. Los átomos con menor capacidad de enlace son más susceptibles de reaccionar bajo las condiciones energéticas en plasmas, tanto para enlazarse como para romper esos enlaces.

La presencia de oxígeno en el material indica que de alguna manera los polímeros se oxidaron, tal vez por la atmósfera de aire residual al inicio de la síntesis o por interacción superficial con la atmósfera al final de ella, o con el agua y/o acetona usados durante la humectación y separación del polímero de la superficie del reactor. El hecho es que muchos polímeros por plasma presentan oxidación de diferente magnitud en su estructura y los polipirroles de este trabajo no escapan a este hecho. En estas condiciones el contenido de oxígeno puede ser tratado de manera similar al del yodo. La relación C/O de 9.2 es equivalente a la relación Pirrol/0 de 2.3, lo que indica aproximadamente un oxígeno por cada 2 anillos de pirrol en la estructura de PPy/I. Por mucho, el contenido de oxígeno supera al de yodo y su influencia debería de ser valorada en estudios posteriores.

\begin{tabular}{cc} 
Tabla 6.1: Composición elemental y relación atómica del PPy/I \\
\hline Elemento & \% At. \\
\hline C & 77.7 \\
N & 13.2 \\
O & 8.4 \\
I & 0.7 \\
C/N & 5.8 \\
C/O & 9.2 \\
$(\mathbf{C} / 4) / \mathbf{I}$ & 27.7 \\
\hline
\end{tabular}




\section{Tamaño de partícula}

El tamaño de las mesopartículas del PPy/I está en el intervalo de 0.06 y $39.5 \mu$ m y su centro está en aproximadamente $4.2 \mu \mathrm{m}$.

\subsection{Resonancia magnética}

Se obtuvieron las imágenes de todas las secuencias con una buena resolución espacial (Tabla 5.2), que permitió además de observar los cambios después de la lesión de médula espinal, cuantificar los parámetros de difusión.

Se midieron por cada rata ( $\mathrm{n}=12$ en total) dos ROIs (uno a nivel cervical y otro en nivel torácico) por cada una de las tres secuencias propuestas (T2MAP, DWI y DTI) en cada uno de los tiempos establecidos en el diseño experimental (Previo, Sem1, Sem4, Sem8), obteniendo un total de 288 muestras para las pruebas estadísticas.

Las secuencias convencionales T1 y T2 no mostraron cambios a nivel cervical donde se realizó la evaluación cualitativa, sin embargo, las secuencias T1 mostraron cambios apenas perceptibles en la intensidad de la señal a nivel torácico que pueden ser asociados con la LTME, esto permitió revelar la ubicación de la zona de la lesión (figura 6.3), por otro lado, los cambios en la intensidad de las imágenes potenciadas en T2 destacaron la presencia de edema en sitio de la lesión siete días después del daño con ligeras variaciones a lo largo del estudio (figura 6.4). Así mismo se observaron cambios anatómicos correspondientes al acinturamiento de la médula espinal debido a la perdida de tejido nervioso a nivel de la lesión y la presencia de quistes en la zona adyacente, que se confirmaron en el estudio histológico. 

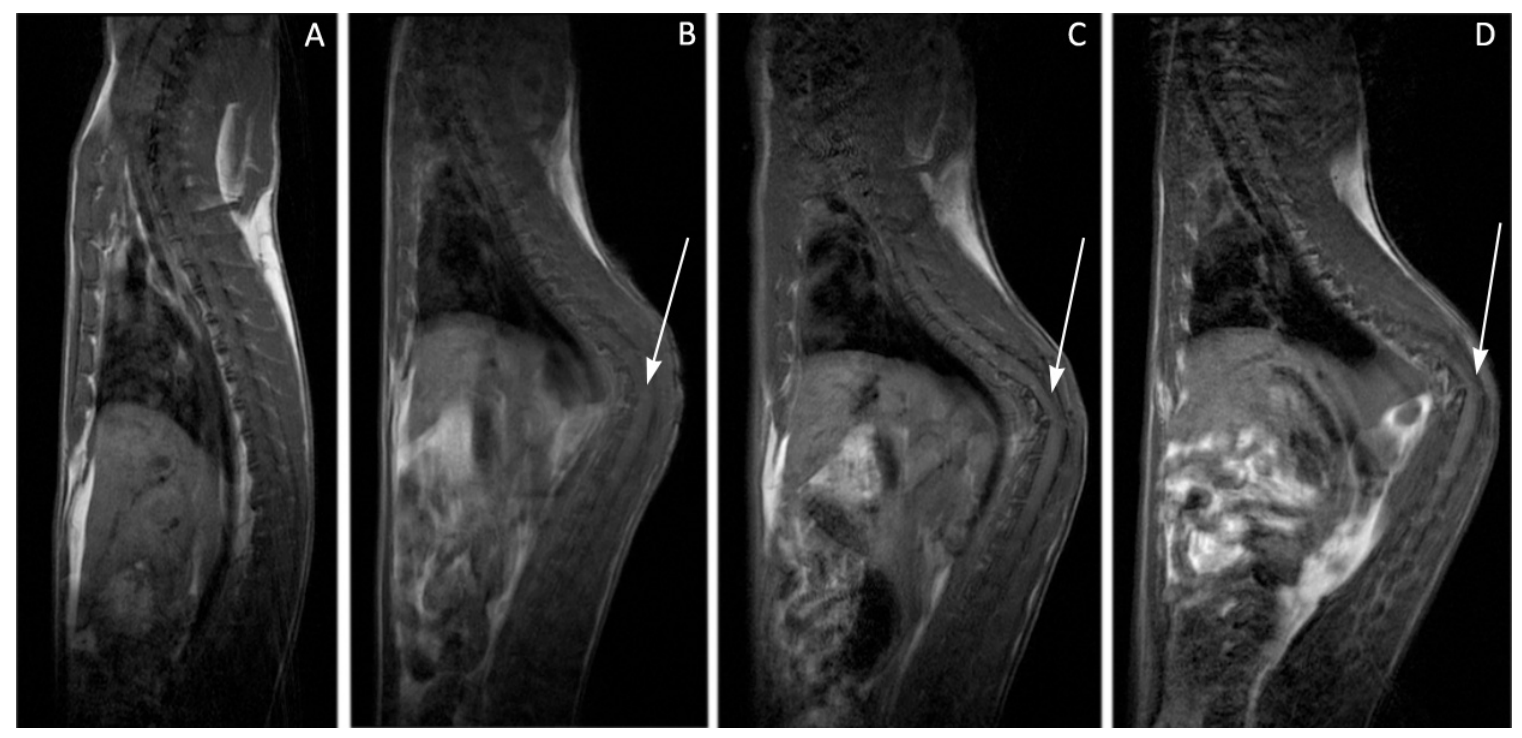

Figura 6.3: Imágenes representativas sagitales $T 1$ de resonancia magnética in vivo de la médula espinal de rata (Grupo Control). (A) Rata Sana. (B) Rata una semana después la lesión. (C) Rata cuatro semanas después de la lesión. (D) Rata ocho semanas después de lesión. Las flechas indican nivel de lesión.

Un análisis visual de las secuencias (T2MAP, DWI y DTI) antes y después de la lesión nos permite tener una comparación cualitativa de los cambios en la intensidad de la imagen asociada con la lesión. En general, se evidencia un incremento en la intensidad de las imágenes en las secuencias T2MAP y un decremento en las secuencias DWI y DTI presentes en la zona de lesión, debido a la perdida de la organización del tejido nervioso (figura 6.5). Sin embargo, no se observan cambios relevantes en las evaluaciones posteriores en comparación con lo observado en la primera semana después de la lesión. 

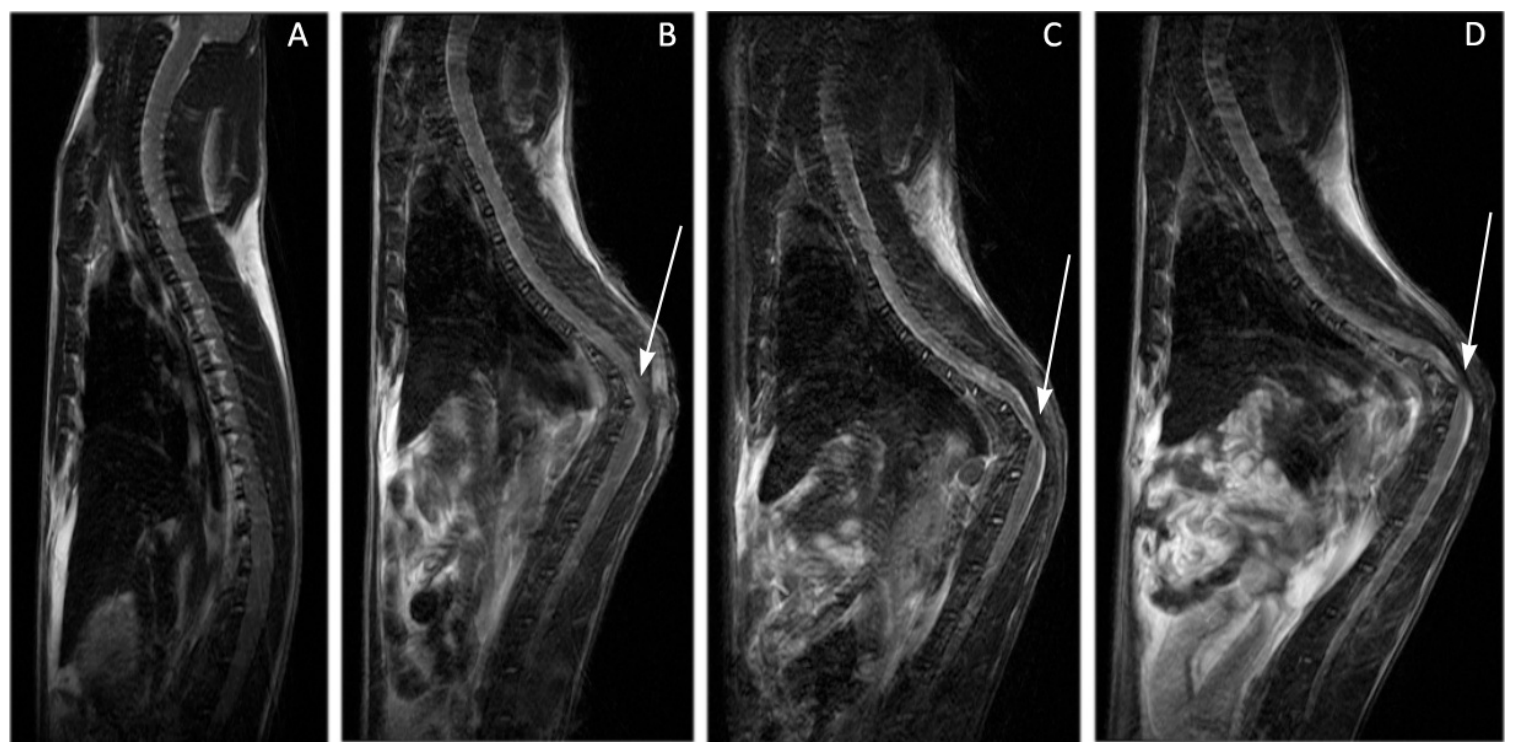

Figura 6.4: Imágenes representativas sagitales T2 de resonancia magnética in vivo de la médula espinal de rata (Grupo Control). (A) Rata Sana. (B) Rata una semana después de la lesión. (C) Rata cuatro semanas después de la lesión. (D) Rata ocho semanas después de lesión. Flechas indican nivel de lesión. 

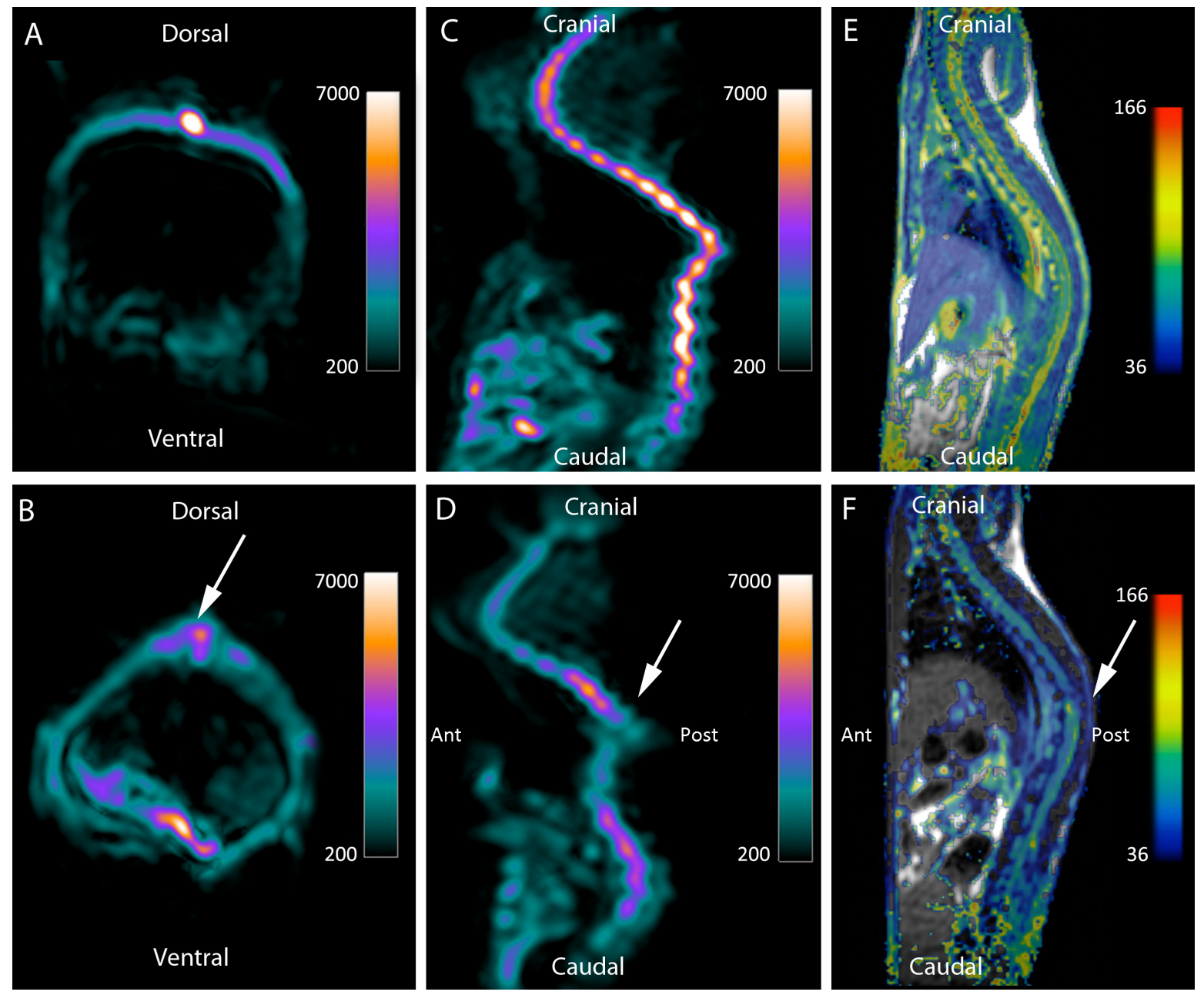

Figura 6.5: Secuencias in vivo de resonancia magnética de tensor difusión DTI, DWI, y T2MAP antes y después de la lesión por contusión moderada de la médula espinal de ratas (Grupo Control). (A y B): Corte axial DTI, en nivel vertebral T10 se observan diferencias en la intensidad de la señal entre la médula espinal previo a la lesión (A) y la zona de lesión 1 semana después de la contusión (B). (C y D): Corte sagital DWI de la médula espinal de rata sana $(C)$, la flecha indica el lugar de la contusión una semana después de la lesión (D). (E y F)

Imágenes sagitales T2MAP de una rata sana $(E)$ y se muestran los cambios sutiles en los tiempos de relajación en el sitio de la lesión medular. Las flechas $(B, D$ y F) muestran el sitio de lesión 1 semana después.

Las mediciones de T2MAP a nivel cervical no presentaron grandes variaciones a lo largo del estudio ni entre los grupos experimentales. (Figura 6.6A) Mientras que las mediciones a nivel torácico mostraron evidencia de un aumento de T2MAP a partir de la semana $1 \mathrm{y}$ hasta la semana 4 en todos los grupos experimentales y se mantuvo constante en la semana 8, pero no se observó una diferencia significativa entre los grupos. (Figura 6.6B) 

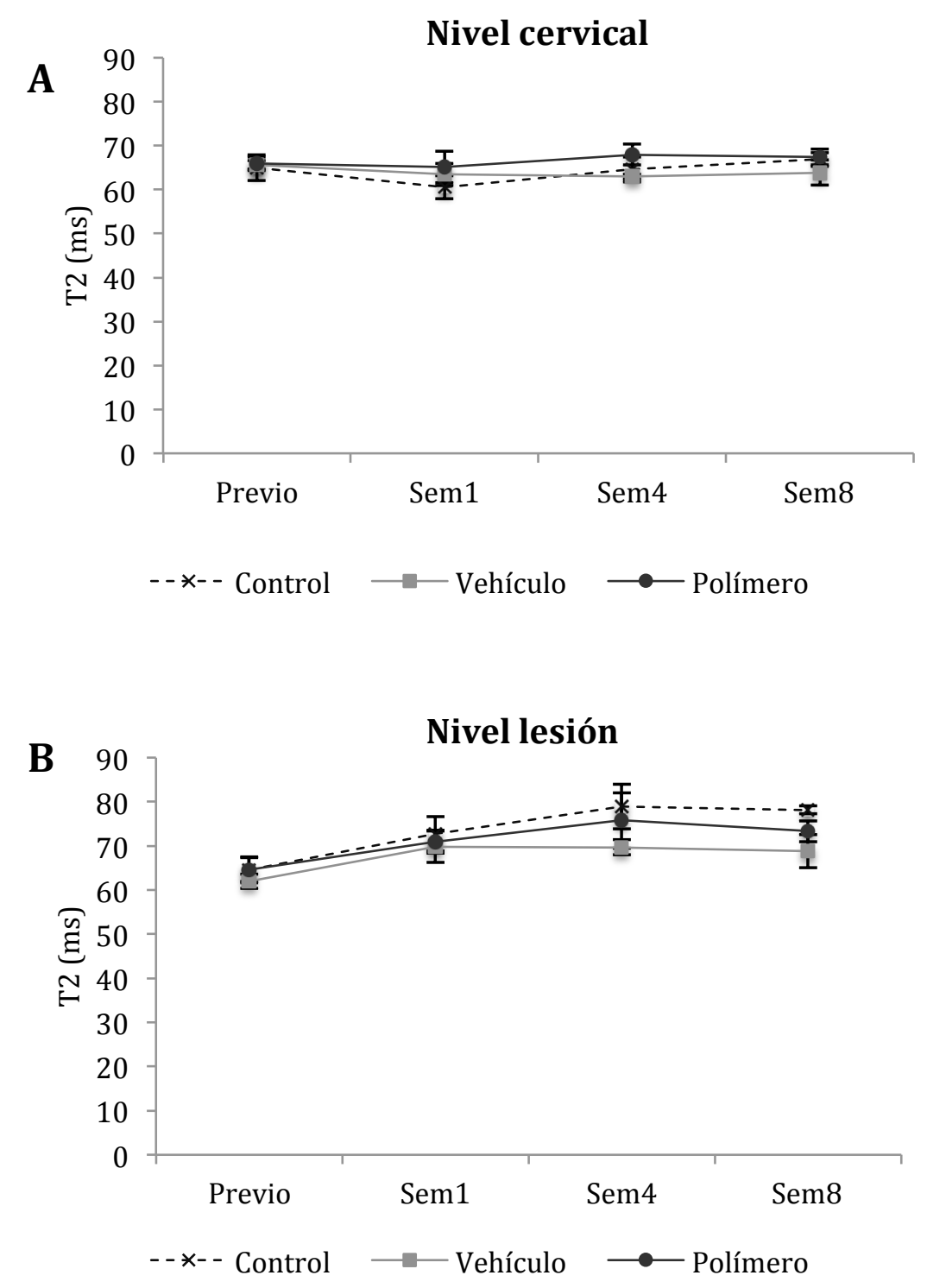

Figura 6.6: Gráfica de T2MAP. (A)Nivel cervical, (B)Nivel lesión. Los valores están expresados como medias $\pm E . E$. ( $n=4$ por grupo). Análisis de ANOVA de medidas repetidas seguido de prueba de Dunnett. ${ }^{*} p<0.05$

Los valores de los tiempos de relajación T2 están relacionados con la organización celular de los tejidos, a mayor organización, menor es el tiempo de relajación y en la imagen aparecerá hipointenso, como el tejido medular sano (altamente organizado) y con una estructura anisotrópica. Además el tiempo de relajación T2 también está en función del contenido de agua del tejido. Un aumento en los tiempos de relajación T2 se asocia con el daño de la matriz extracelular y/o con el grado de hidratación del tejido. Entonces, el incremento en T2MAP en las primeras 4 semanas está relacionado 
con el edema, la inflamación y perdida de tejido nervioso. Después de finalizar estos procesos y con el establecimiento de los quistes y la formación de la cicatriz glial estos valores se estabilizan, pero se mantienen elevados. (Figura 6.6)

En las mediciones de ADC torácico se observa un incremento continuo de los valores de difusión en todos los grupos, sin embargo existe una diferencia estadísticamente significativa entre el grupo polímero al ser comparado con el grupo control ( $\mathrm{p}=0.016)$. Por otro lado, no se encontró diferencia entre los grupos vehículo y control, p=0.104. (100) Figura 6.7. El incremento en los valores de la difusión se encuentra relacionado con la destrucción de las membranas celulares después de la lesión, que implica un aumento de la libertad del agua con un incremento en los valores de ADC. 

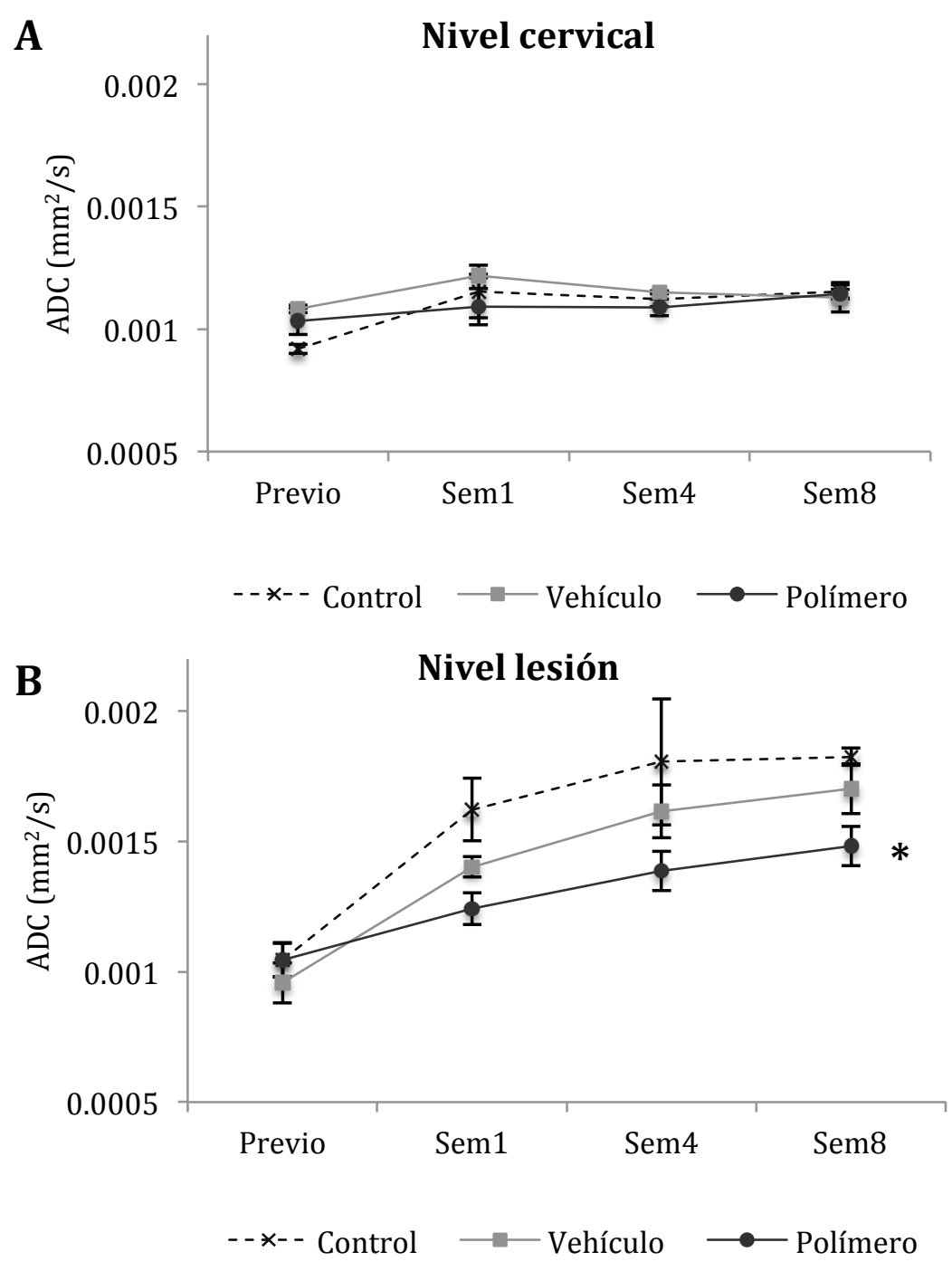

Figura 6.7: Gráfica de ADC. (A)Nivel cervical, (B)Nivel lesión. Los valores están expresados como medias $\pm E$.E. ( $n=4$ por grupo). Análisis de ANOVA de medidas repetidas seguido de prueba de Dunnett. * $p<0.05$

Los valores de FA a nivel cervical no mostraron cambios significativos durante en estudio ni entre grupos experimentales, sin embargo se observó una ligera disminución de los valores en todos los grupos. 

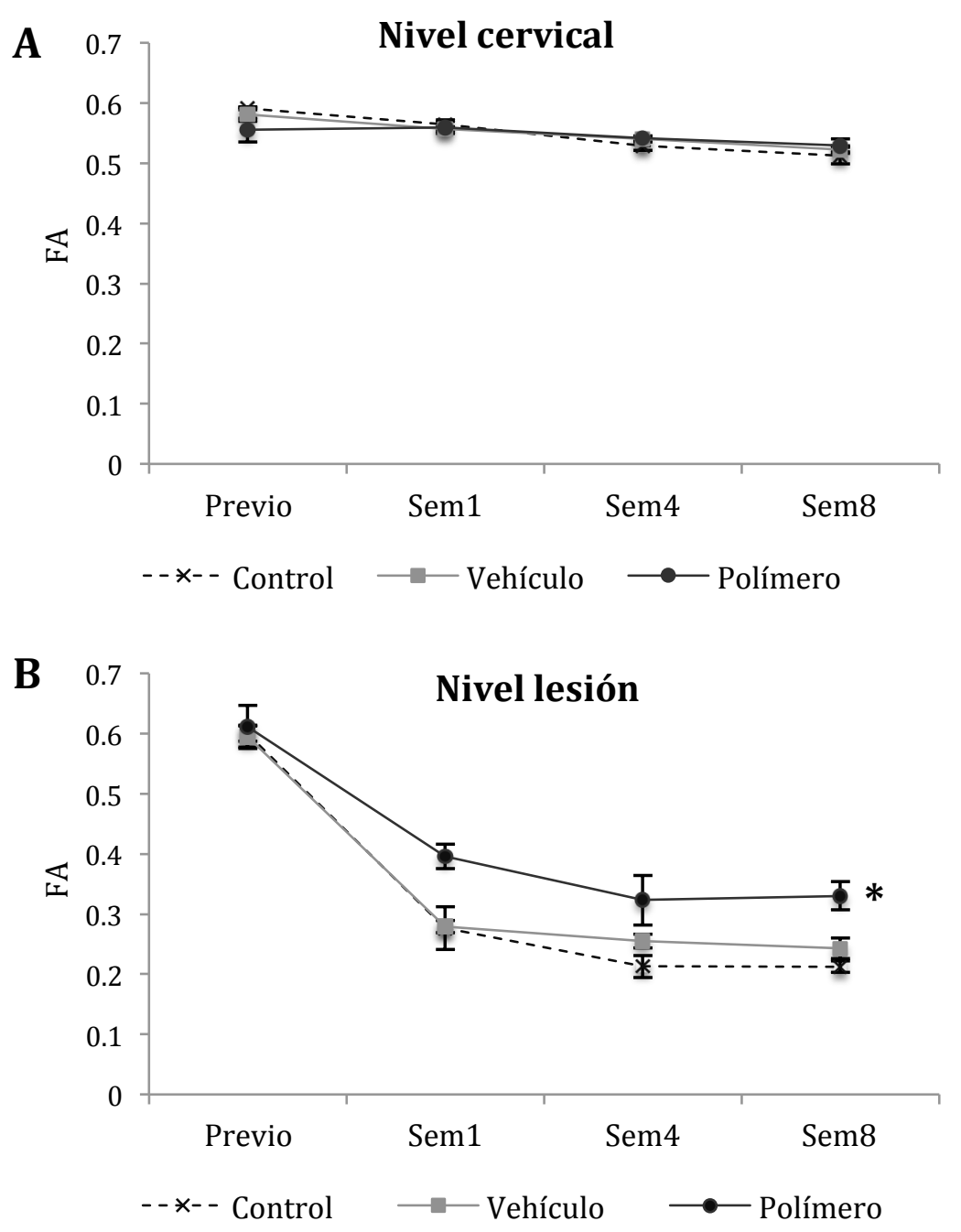

Figura 6.8: Gráfica de FA. (A)Nivel cervical, (B)Nivel lesión. Los valores están expresados como medias \pm E.E. ( $n=4$ por grupo). Análisis de ANOVA de medidas repetidas seguido de prueba de Dunnett. ${ }^{*} p<0.05$

A nivel torácico se encontró una disminución súbita de los valores de FA en la semana 1 y un cambio paulatino hacia la semana 4, en la última evaluación se observó una estabilización de los valores. Se presentó una diferencia estadística significativa del grupo polímero contra el control ( $\mathrm{p}=0.001)$, mientras que al comparar el control y vehículo no se encontraron diferencias. Los valores de FA varían entre 0 (difusión isotrópica) y 1 (difusión anisotrópica). La difusión es anisotrópica en los tractos de sustancia blanca de fibra, como membranas axonales y vainas de mielina presentan barreras para el movimiento de moléculas de agua, en direcciones no paralelas a su propia orientación. La reducción de FA es indicativa de pérdida del arreglo celular. La 
disminución de los valores FA evidencia el daño en el tejido nervioso después de la lesión, en un inicio por la pérdida de la citoarquitectura por la muerte celular, y después debido a la degeneración axonal y desmielinización, posteriormente con la formación de la cicatriz glial se contiene la extensión del daño, pero los valores continúan bajos debido a la perdida irreversible de tejido. (figura 6.8)

\subsection{Evaluación funcional}

Todos los animales incluidos en el estudio presentaron evaluaciones BBB de 0 al día siguiente de la lesión.

Al término del estudio se realizó un análisis estadístico de las evaluaciones BBB. Se promediaron los valores obtenidos de las patas traseras en cada evaluación a fin de valorar la recuperación de la función motora. El grado de recuperación motora entre los grupos experimentales fue comparado por medio de la prueba ANOVA de medidas repetidas seguido de la prueba de Dunnett, considerando una diferencia significativa de $\mathrm{p}<0.05$. De acuerdo a la escala de BBB, la puntuación promedio ( \pm error estándar) de los animales del grupo control fue de $0.38 \pm 0.48$ a la semana, $4.63 \pm 1.31$ a las cuatro semanas y $6 \pm 2.08$ a las ocho semanas, presentando movimiento amplio de dos articulaciones y limitado de la tercera. Los animales del grupo vehículo $0.38 \pm 0.48$ a la primera semana, $1.88 \pm 1.25$ en la cuarta semana y $4.25 \pm 2.60$ en la semana ocho, mostrando movimiento limitado de las tres articulaciones de las PT (cadera, rodilla y tobillo). Mientras para el grupo polímero se observaron valores promedio de $2.38 \pm 1.55$ en la primera semana, $8.38 \pm 2.87$ en la cuarta semana y $12.5 \pm 3.7$ en la octava semana, observándose pasos plantares y coordinados entre PD y PT constantes. No separa los dedos o solo ocasionalmente cuando avanza la pata hacia delante. $\mathrm{Al}$ hacer contacto con el piso predominio de la alineación paralela de la pata al cuerpo. El análisis comparativo de estos resultados mostró diferencias significativas entre los grupos control y el grupo que recibió el polímero $\mathrm{p}=0.029$. Sin embargo no se observaron diferencias significativas entre los grupos experimentales control y vehículo $\mathrm{p}=0.345$. (Figura 6.9)

$\mathrm{Al}$ observar los valores BBB se aprecia una tendencia creciente en las evaluaciones en todos los grupos experimentales, sin embargo esta tendencia termina en la semana 
seis para el grupo control, mientras que persiste hasta la semana ocho para el grupo polímero. Por otro lado, se observa un ligero decremento en la evaluación del grupo vehículo en la última semana, también se puede observar que el grupo tratamiento comienza sus evaluaciones por encima de los otros dos grupos experimentales.

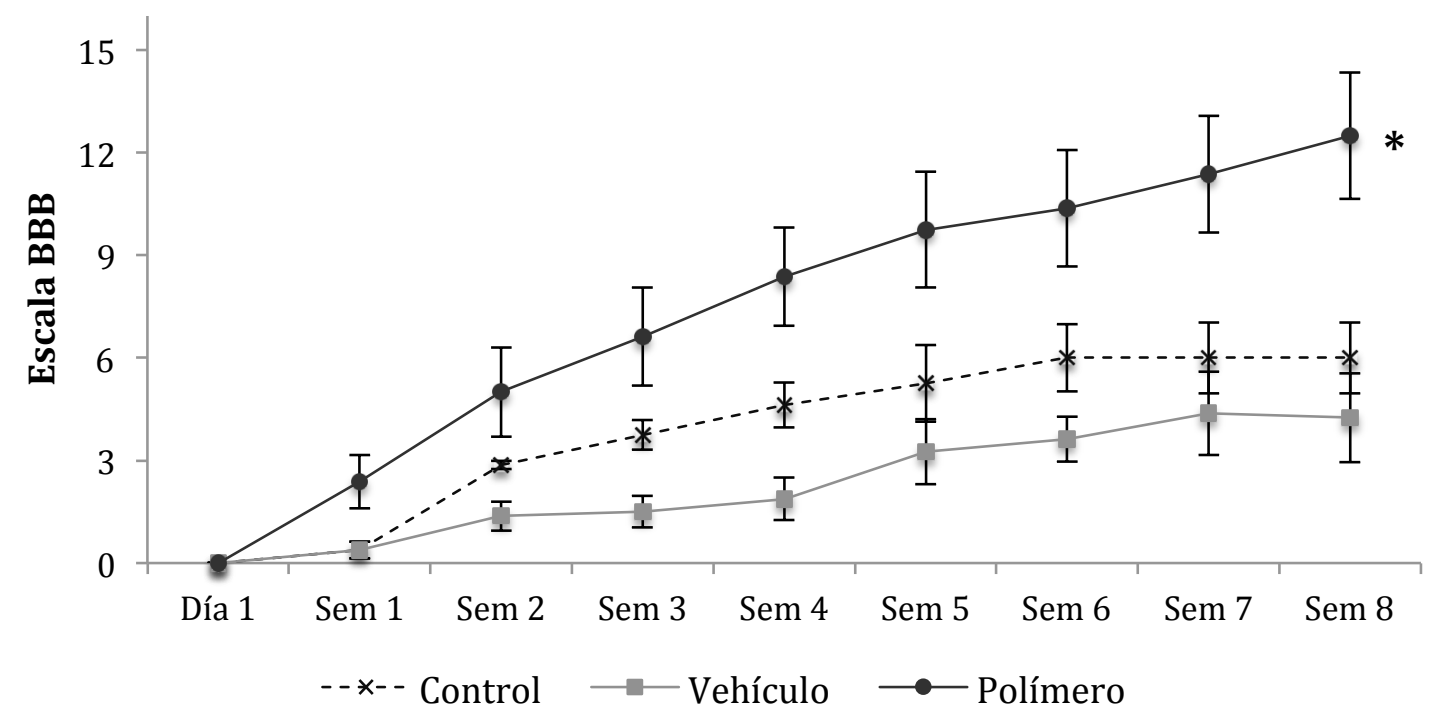

Figura 6.9: Gráfica de la recuperación motora evaluada con la escala BBB. Los resultados están expresados como medias \pm E.E. ( $n=4$ por grupo). ANOVA de medidas repetidas seguida de la prueba de Dunnett. *Diferencia significativa al comparar con el grupo control $p<0.05$.

\subsection{Estudio histológico}

Ocho semanas después de la lesión, los animales fueron sacrificados para analizar el tejido preservado de la médula espinal que fue procesado por la técnica de Hematoxilina Eosina (Apéndice C) (Figura 6.10).

En el tejido del grupo polímero, se encontró el polímero diseminado e integrado con el tejido nervioso en la zona de lesión, también se observó proliferación celular, se presentaron pocas cavidades en la interfaz del tejido y el polímero. En el grupo vehículo se encontraron quistes en la zona de lesión, pero no en la periferia, mostrando preservación del resto de tejido. Las muestras del grupo control presentaron quistes de tamaños variables predominado los de gran tamaño en el epicentro de la lesión y más pequeños en direcciones cefálica y caudal, la zona de lesión se presentó extendida hacia la sustancia blanca y gris adyacente, en las 
muestras en donde los quistes fueron de menor tamaño se observó un acinturamiento del tejido en la zona de lesión (Figura 6.10).
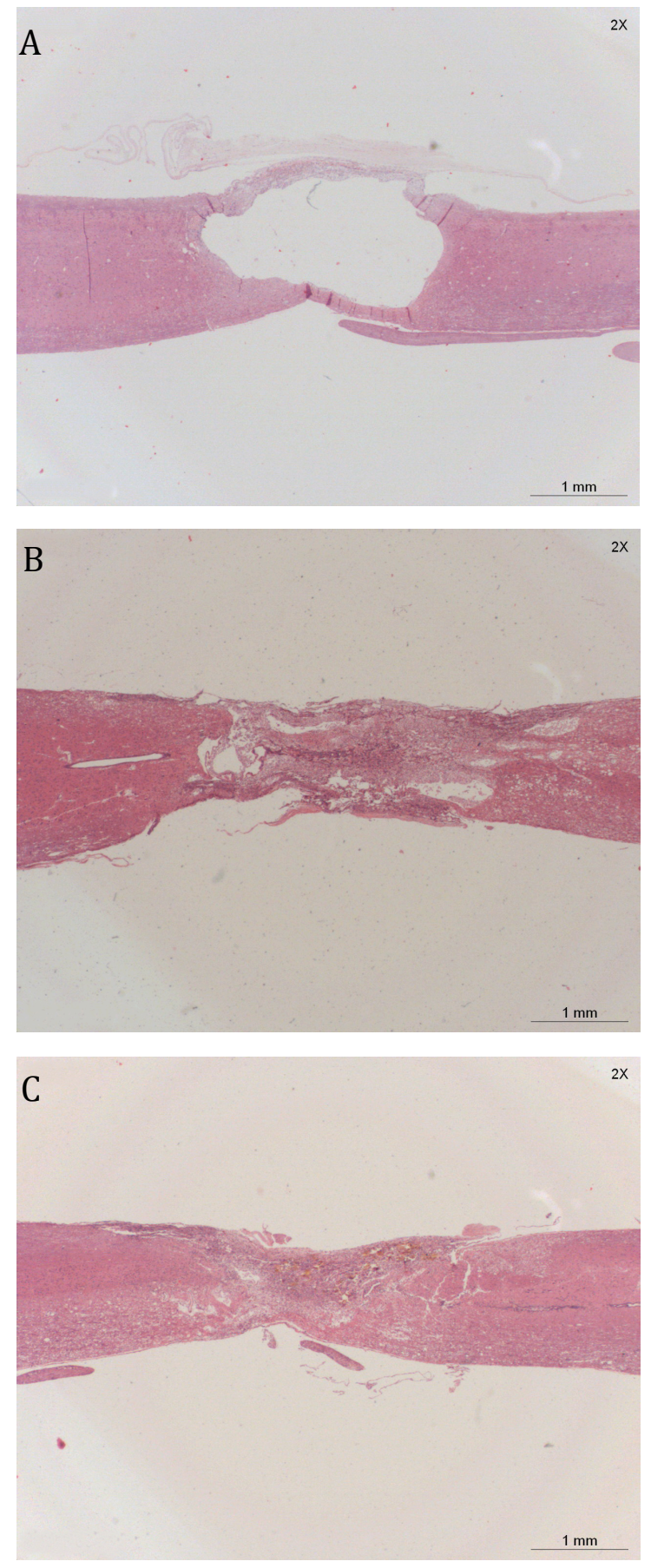

Figura 6.10: Imágenes representativas de cortes histológicos longitudinales de la médula espinal 8 semanas después de la lesión. Técnica histológica Hematoxilina Eosina. (A) Control, (B) Vehículo, (C) Polímero 
En todas las muestras se observó presencia de células inflamatorias en la sustancia gris y blanca, y en la zona de lesión y se observa que estas células se encuentran en mayor proporción en el grupo control.

Se observaron cambios morfológicos en el tejido nervioso muy evidentes mediante técnicas convencionales de resonancia magnética (contraste T1 y T2) en los animales que presentaron acinturamiento o desarrollo de quistes grandes en el epicentro de la lesión en la semana ocho del estudio, esto fue confirmado con las muestras histológicas. Figura 6.11.

El análisis de tejido preservado se cuantificó para cada grupo y se muestra en la figura 6.12. La media del porcentaje del tejido preservado se analizó en un área total de $33 \mathrm{~mm}^{2}$. En el grupo control fue del $27.75 \%$, mientras que en el grupo polímero fue de $45.69 \%$, y en el vehículo de 35\% y las medias fueron $9.16 \mathrm{~mm}^{2}, 15.08 \mathrm{~mm}^{2}$ y $11.55 \mathrm{~mm}^{2}$ respectivamente, con una $\mathrm{p}<0.05$ para el grupo polímero, análisis ANOVA de una vía, seguido por la prueba de Dunnett. Figura 6.12. 

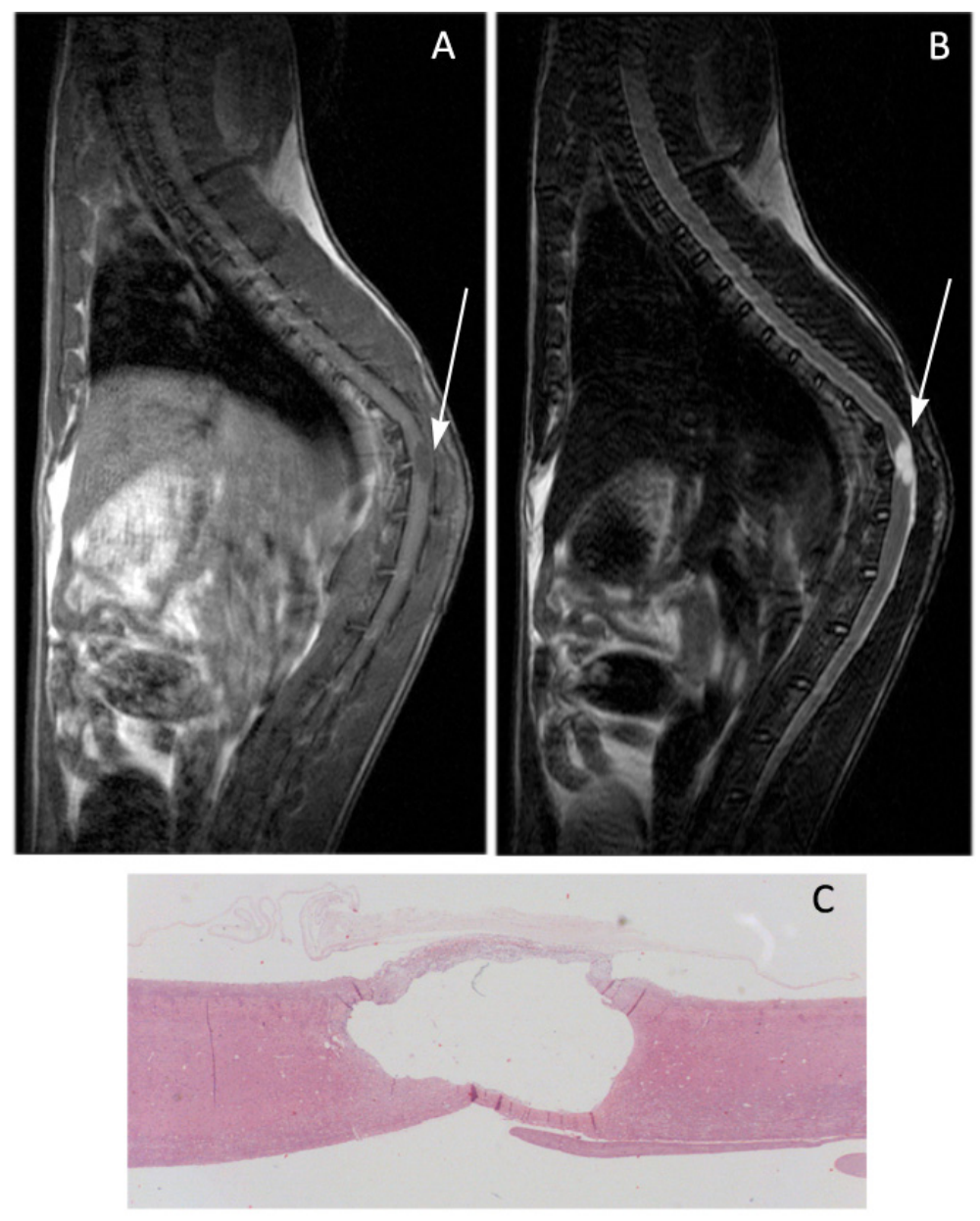

Figura 6.11: Imágenes comparativas de Resonancia Magnética e Histología de rata ocho semanas después de la lesión por contusión moderada de la médula espinal (grupo control). (A) Corte sagital contraste T1. (B) Corte sagital contraste T2. (C) Muestra Histológica de médula espinal en la zona de lesión, técnica histológica Hematoxilina Eosina. Flechas indican zona de lesión.

Se observó inflamación en el tejido adyacente, y en la zona de lesión, aunque esta respuesta fue mayor en el grupo de control, después de un análisis cualitativo con criterios morfológicos(106). Se observó la presencia de la proliferación de fibroblastos y colágeno en todos los grupos. El grupo control mostró menos colágeno en el epicentro de la lesión en comparación con los otros dos grupos. El tejido de la médula espinal vecina apareció menos dañado en las ratas del grupo polímero. 


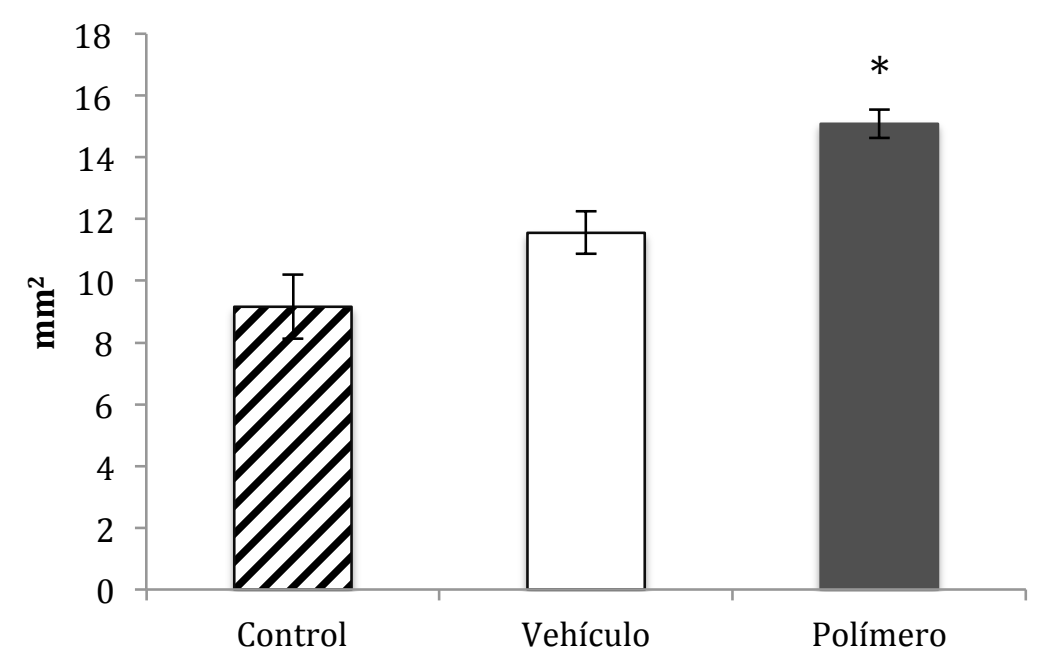

Figura 6.12: Gráfica del análisis de tejido preservado. Los resultados están expresados como medias $\pm E$.E. (8 semanas después de la lesión, $n=4$ por grupo). ANOVA de una vía seguida de prueba de Dunnett. ${ }^{*} p<0.05$.

\subsection{Sobrevida}

Se evaluó la tasa de supervivencia de los animales con el método de Kaplan Meier, utilizando los datos de mortalidad entre los grupos y empleando la prueba de log-rank. Los animales fueron monitorizados durante 8 semanas después de la lesión y se registró el momento de la muerte de cada una, seis ratas del grupo control $(\mathrm{n}=10,40 \%$ finalizaron el estudio) murieron durante el seguimiento, en el grupo vehículo también murieron cuatro ( $\mathrm{n}=8$, la mitad finalizó el estudio), mientras que en el grupo polímero no se presentaron decesos ( $\mathrm{n}=4$, todos terminaron el estudio), sin embargo no se presentaron diferencias estadísticas significativas en la prueba. 


\subsection{Correlación}

Empleando el coeficiente de correlación de Spearman Rho en las últimas evaluaciones (8 Sem) en el sitio de lesión; se presentaron asociaciones significativas positivas entre las variables $\mathrm{BBB}$ vs FA (Figura $6.13 \mathrm{E}$, rho $=0.608$ ) y de tejido preservado vs FA (Figura 6.13F, rho=0.636) indicando que a mayor anisotropía en la médula espinal mayor evaluación funcional y/o mayor cantidad de tejido preservado. Mientras que se observó una asociación significativa negativa entre BBB vs ADC (Figura 6.13C, rho=0.606) y de tejido preservado vs ADC (Figura 6.13D, rho=-0.623) señalando que a mayor difusión se presenta menor recuperación funcional y/o cantidad de tejido preservado. Finalmente, no se encontraron correlaciones significativas entre las otras variables. (Figura 6.13) 

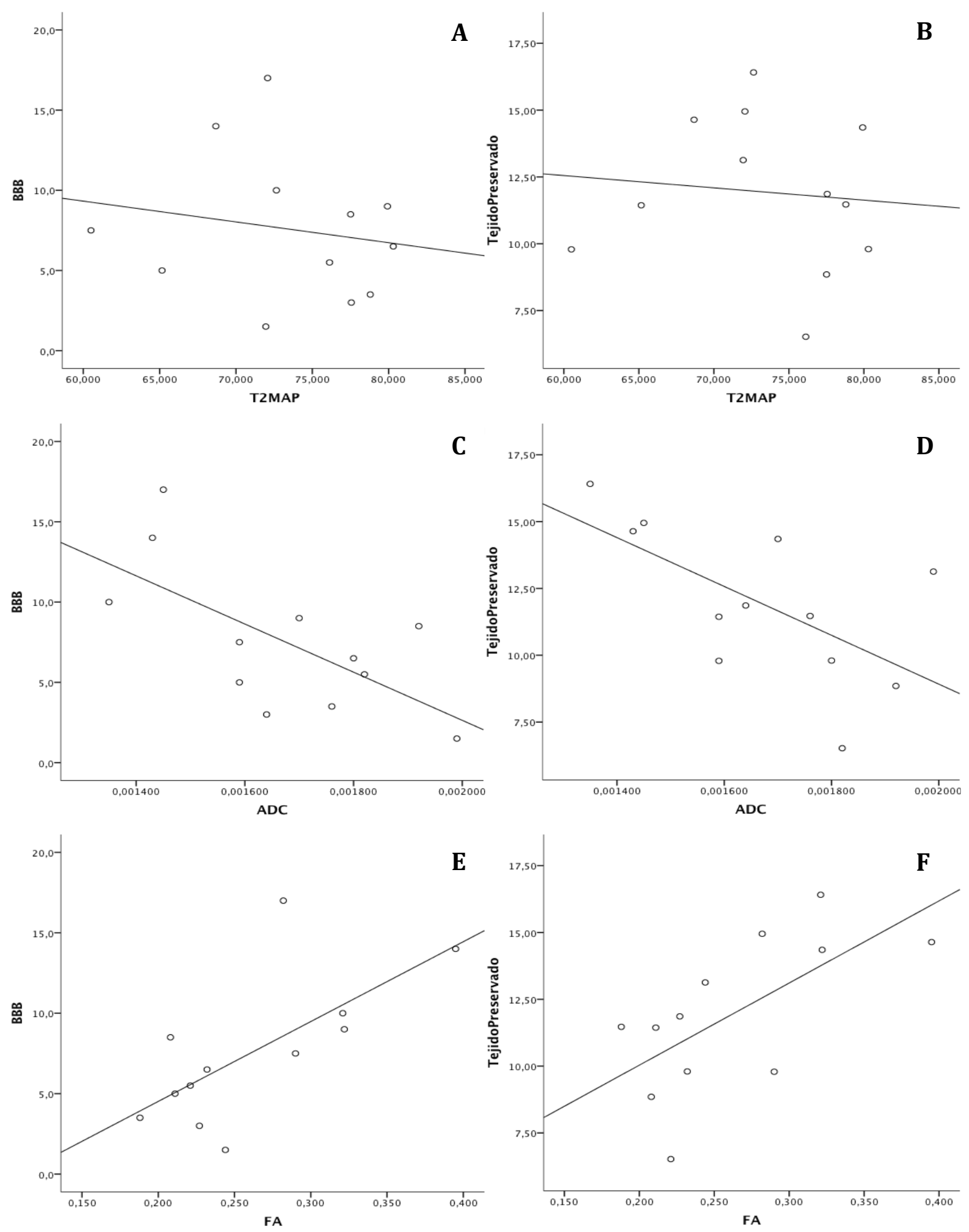

Figura 6.13: Diagramas de dispersión de parámetros de MR relaxometría T2 (T2MAP), Coeficiente de Difusión Aparente (ADC) y Anisotropía Fraccional (FA) vs escala funcional (BBB) y tejido preservado.

Correlación Spearman, 8 semanas después de la lesión. 


\section{Discusión}

En el presente trabajo se evaluó el efecto del Polipirrol/Yodo sintetizado por plasma como tratamiento en un modelo de lesión por contusión moderada de la médula espinal de ratas. Las características del polímero fueron determinadas por medio de un análisis infrarrojo, descripción morfológica con análisis elemental y medición del tamaño de partícula. Se desarrollo un ensayo clínico aleatorizado controlado y se administro el polímero in situ para probar su efecto en la lesión de la médula espinal de ratas. El efecto del tratamiento en los animales de experimentación se observó a través de la evaluación de la recuperación motora empleando la escala funcional BBB durante ocho semanas después de la lesión más la administración del tratamiento, y después con la medición de la cantidad de tejido preservado, simultáneamente a la evaluación de la recuperación motora se probó la utilidad de la difusión por resonancia magnética como método para la determinación del estado de la medula espinal y la evaluación del efecto del Polipirrol/Yodo como tratamiento.

\section{Síntesis y caracterización del polímero}

Se sintetizó el Polipirrol/Yodo mediante polimerización por plasma con la metodología propuesta por $(64, \underline{68}, \underline{73})$, y se pudo mostrar que las características de este polímero fueron similares a las reportadas en los trabajos previos, con lo que se pudo evidenciar que es un método de síntesis reproducible, sin embargo se debe tomar en cuenta que las diferencias observadas entre los polímeros son producto de las variaciones en los parámetros de síntesis.

La síntesis del polímero mediante la polimerización por plasma permitió obtener un material con alto entrecruzamiento compuesto por anillos de pirrol completos y fragmentados capaces de formar redes tridimensionales, este entrecruzamiento en el polímero puede servir desde el punto de vista biológico como una estructura de apoyo en donde las células nerviosas pueden anclarse en combinación con la formación de una gran variedad de especies químicas formadas a partir de la fragmentación del anillo de pirrol (73). Por otro lado, se observó la formación de enlaces triples que se deben a oxidación (por la interacción atmosférica del polímero) y deshidrogenación 
(figura 6.1), esta cantidad de oxígeno puede tener repercusiones en la efectividad las características neuroprotectoras del polímero, ya que el estado oxidado del material forma atrapadores de radicales libres actuando como antioxidantes, interviniendo de este modo en el proceso de lipoperoxidación.

La morfología superficial del polímero se presenta parcialmente lisa con pliegues que sobresalen del fondo, burbujas y poros (으) (figura 6.2), pero después de la molienda, se forman fragmentos irregulares de diversos tamaños y aristas, estos aglomerados rugosos aumentan la superficie donde las células pueden interactuar con el material, esta característica morfológica puede relacionarse con la tolerancia del tejido nervioso y la supervivencia que se observó en los animales del grupo polímero al ser comparada con los grupos de control y el vehículo.

\section{Resonancia magnética}

Los modelos experimentales de lesión de médula espinal en animales son esenciales para el estudio de nuevos tratamientos en humanos, sin embargo existe la dificultad de realizar un seguimiento in vivo de forma cuantitativa del estado de la médula espinal, mediante el empleo de un escáner clínico MR de 3T en combinación con una bobina de muñeca y un dispositivo de fijación, se logró la cuantificación de parámetros de difusión en un modelo de lesión de médula espinal en ratas, además los valores de los parámetros de referencia obtenidos con este protocolo podrían servir de referencia para la planificación de futuros experimentos. (99-101) La evaluación de los modelos animales con equipos clínicos, que actualmente están disponibles en muchos lugares para el diagnostico humano, permite ampliar el número de investigaciones donde es posible combinar estudios prospectivos cuyos resultados merecen la comparación entre animales y humanos, y que eventualmente favorecerán la generalización del conocimiento. (99)

En los estudios preliminares para determinar el protocolo usado en este trabajo para la adquisición de los datos, permitió mostrar que los parámetros de MR obtenidos cuantitativamente (T2MAP, ADC y FA) son sensibles a los cambios presentados después de un modelo animal de lesión de médula espinal, (99) se mostraron cambios en todos los parámetros propuestos y se ha observado que estos se encuentran 
comprometidos en diversas patologías del sistema nervioso, en un marco temporal obtenido con los estudios preliminares para determinar los tiempos de monitoreo después de una lesión de médula espinal $(100,101)$ se observo que los parámetros de difusión propuestos presentan cambios según lo observado en eventos cerebro vasculares (107), sin embargo aun esta a discusión su valor pronostico debido a la estandarización de los protocolos en la clínica, por otro lado, cada día es más aceptado el valor pronostico de difusión MR en el pronostico de la lesión de la médula espinal. (76)

En el caso del tiempo de relajación T2 (T2MAP) se observó un decremento de los parámetros a nivel torácico 48 horas después de la lesión (100) y un aumento progresivo de a partir de la semana 1 y hasta terminar el estudio, se sabe que el tiempo de relajación T2 de un tejido esta en función del contenido de agua del mismo, así como de la organización estructural del tejido que la contiene, (92) por lo que los incrementos observados son esperados después de una lesión de la médula espinal como lo muestran otros estudios que miden este parámetro en tejido nervioso y se relaciona con anormalidades neocorticales (92) y esclerosis en el hipocampo, (108, 109) sin embargo hasta el momento no se encuentra reportado el uso de este parámetro para documentar su empleo en la lesión de médula espinal.

Por otro lado, el aumento en los valores de ADC está relacionado con la perdida en la cito arquitectura del tejido nervioso, la perdida de integridad de las membranas celulares y la formación de quistes que permiten una mayor difusión en el sitio de lesión.(110) La diferencia significativa al comparar el grupo polímero con el control implica que se presenta menor destrucción del tejido nervioso y formación de quistes. (Figura 6.7 y 6.11). Los resultados de las mediciones de ADC suguieren que se presenta menor destrucción del tejido nervioso en el grupo polímero al ser contrastado con el grupo control.

El parámetro FA mostro diferencias significativas a nivel de la lesión al comparar el grupo polímero con el grupo control (figura 6.8), se observo una disminución en todos los grupos, que se encuentra relacionada con una difusión mas isotrópica que en evaluaciones previas a la lesión, al no existir barreras que direccionaran el movimiento de las moléculas de agua en al sitio de lesión el valor tiende a disminuir 
en todos los grupos, pero en menor medida en el grupo polímero. La tendencia de los valores sugieren que se encuentran relacionados con los mecanismos de daño secundario de lesión y que corresponden a procesos de desmielinización y aparición de quistes en el tejido nervioso.

Los parámetros de difusión propuestos (ADC y FA) podrían ser marcadores pronósticos del estado anatómico y funcional de la médula espinal al presentar correlaciones significativas con las evaluaciones estándar en modelos de lesión experimentales de la médula espinal (escala BBB y cuantificación de tejido preservado). Figura 6.13.

El tipo de asociación que se observó entre los parámetros de MR con las técnicas BBB y de cuantificación de tejido preservado corresponde con el comportamiento esperado. Esto implica que a mayor valor de ADC, mas facilidad de difusión, se puede esperar menor cantidad de tejido nervioso preservado y también presentar menor recuperación funcional después de la lesión; por otro lado, a mayor valor de FA, mas anisotropía, se puede predecir una mayor evaluación funcional al igual que mas cantidad de tejido preservado.

\section{Evaluación funcional}

La evaluación funcional de la calidad de la marcha mostró una mayor recuperación motora en los animales del grupo polímero, el grupo vehículo no mostro diferencia significativa al ser comparados con el grupo control, sin embargo el grupo vehículo obtuvo una puntuación menor a nivel global (figura 6.9), este comportamiento es importante en el sentido de que la administración in situ del volumen tanto del vehículo como del polímero supondría una lesión extra a la producida por el modelo de lesión por contusión propuesto para este trabajo, de tal manera que los beneficios del tratamiento con PPy/I superan al traumatismo ocasionado por la administración del volumen de liquido.

\section{Estudio histológico}

La polimerización por plasma permite la síntesis sin la intervención de agentes externos que favorezcan la reacción, y sólo intervienen los monómeros iniciales y especies químicas derivadas de estos, así la respuesta inflamatoria está limitada a la 
provocada por sustancias derivadas de la combinación de monómeros (68), por otro lado, el polímero (PPy/I) tienen la ventaja de ser no-biodegradable y por tanto no hay degradación de material que pueda provocar una mayor respuesta inflamatoria dando lugar a una mayor pérdida de tejido (Figura 6.12) y cavitación quística (Figura 6.10), (73) estas ventajas se vieron reflejadas en la biocompatibilidad del material, ya que, no se observó mortalidad durante el estudio debido al tratamiento.

Los resultados del presente trabajo pueden ser tomados en cuenta para proponer al Polipirrol/Yodo como estrategia terapéutica encaminada ha reparar la médula espinal, sin embargo, se requieren más estudios para determinar los mecanismos específicos sobre los que intervienen. Por otro lado, los hallazgos de este estudio mostraron que es posible utilizar un equipo clínico de MR para evaluar modelos animales y los parámetros de difusión propuestos actúan como biomarcadores del estado anatómico y funcional de la médula espinal. 


\section{Conclusiones}

Un sistema clínico de MR en combinación con una bobina para muñeca y el sistema de fijación puede ser empleado para el análisis no invasivo de la medula espinal de ratas y representa una herramienta que se encuentra más accesible que sistemas experimentales de MR con mayor intensidad de campo, convirtiéndose en una alternativa para observar efectos terapéuticos experimentales in vivo permitiendo comparar directamente los resultados entre humanos y animales de experimentación. Los parámetros propuestos para la evaluación de la médula espinal (T2MAP, ADC y FA) resultaron indicadores sensibles a los cambios anatómicos y funcionales que se presentan en la médula espinal de ratas después de la lesión de la médula espinal.

El parámetro T2MAP no mostro diferencias significativas entre los grupos experimentales a ningún nivel de evaluación (cervical y torácico) durante el estudio, sin embargo, se observó una tendencia a incrementar sus valores a nivel torácico en los tres grupos de experimentación.

El parámetro ADC mostro diferencias significativas del grupo polímero al ser comparado con el grupo control a nivel torácico, mientras a nivel cervical no se presentaron diferencias ni tendencias de las evaluaciones entre los grupos ni a lo largo del estudio.

Los valores de FA mostraron diferencias significativas del grupo polímero al ser comparado con el grupo control a nivel torácico, mientras no se presentaron diferencias a nivel cervical.

Los parámetros de MR (T2MAP, ADC y FA) representan marcadores diagnósticos en la lesión traumática de médula espinal, sin embargo sólo los parámetros de ADC y FA presentaron correlación significativa con las técnicas de evaluación del estado de la médula espinal (escala BBB y cuantificación de tejido preservado) al evaluar el efecto del PPy/I en este diseño experimental, y en este sentido representan marcadores pronósticos. 
El PPy/I favoreció una mayor recuperación motora al ser administrado in situ, después de una lesión por contusión moderada de la medula espinal de ratas al ser evaluada por medio de la escala BBB en comparación con el grupo control.

El PPy/I tiene un efecto neuroprotector a dosis de $30 \mu \mathrm{l}(5 \mathrm{mg} / \mathrm{ml})$ administrado in situ en una lesión por contusión moderada de la médula espinal en ratas que se observa al conservar mayor cantidad de tejido nervioso al ser comparado con el grupo control. 


\section{Perspectivas}

1. Emplear técnicas histológicas que permitan identificar los tipos celulares presentes en el sitio de lesión y la cantidad de mielina.

2. Evaluar el efecto del PPy/I sobre diversos marcadores de regeneración para determinar si la recuperación funcional se debe a su capacidad de regular dicho evento.

3. Evaluar el efecto del PPy/I después de una LTME en otras especies de animales.

4. Estandarizar las secuencias de difusión por MR en pacientes con diagnóstico de lesión de médula espinal, para poder correlacionar las alteraciones iniciales con la evaluación del daño y poder establecer si los parámetros medidos por MR son una herramienta útil para establecerlos como factor pronóstico de mejoría o deterioro de la función nerviosa. 


\section{Anexo}

\section{A. Reglamento de la ley general de salud en materia de investigación para la salud}

TITULO SÉPTIMO

De la Investigación que incluya a la utilización de animales de experimentación.

CAPITULO ÚNICO

ARTíCULO 121.- En las investigaciones experimentales con animales, referidas a la salud humana, se deberán llenar los requisitos que establezcan las normas de las propias instituciones de salud, autorizadas por la Secretaría y satisfacer lo señalado en este Capítulo.

ARTíCULO 122.- Las investigaciones se diseñarán a modo de evitar al máximo el sufrimiento de los animales.

ARTíCULO 123.- Cuando sea necesario sacrificar a un animal de experimentación, se empleará un procedimiento que asegure en lo posible su muerte sin sufrimiento.

ARTíCULO 124.- Los bioterios deberán estar de acuerdo con la especie, conformación corporal, hábitos, preferencias posturales y características locomotoras de los animales, para proporcionarles comodidad, excepto cuando las variables experimentales justifiquen otras situaciones.

ARTíCULO 125.- Los bioterios de producción o mantenimiento crónico serán supervisados por profesionales calificado y competente en la materia y deberán permitir el crecimiento, maduración, reproducción y comportamiento normal de los animales, de conformidad con las normas que la propia institución emita.

ARTíCULO 126.- El titular de la institución de salud en donde se realice investigación a la que se refiere este Capítulo, deberá establecer y vigilar el cumplimiento de las medidas de seguridad para el cuidado y manejo de los animales, así como las medidas de profilaxis y vacunación necesarias para la protección del personal ocupacionalmente expuesto. 


\section{B. Escala BBB para evaluar la función locomotora}

Grado 0: No se observan movimientos de las patas traseras (PT).

Grado 1: Movimiento limitado (arco $<50 \%$ ) de una o dos articulaciones, usualmente de la cadera y/o rodilla.

Grado 2: Movimiento amplio (arco<50\%) de una articulación con o sin movimiento limitado de otra.

Grado 3: Movimiento amplio de dos articulaciones.

Grado 4: Movimiento limitado de las tres articulaciones de la PT (cadera, rodilla y tobillo).

Grado 5: Movimiento limitado de dos articulaciones y amplio de la tercera.

Grado 6: Movimiento amplio de dos articulaciones y limitado de la tercera.

Grado 7: Movimiento amplio de las tres articulaciones de la PT (Cadera rodilla y tobillo).

Grado 8: Movimientos rítmicos (coordinados) de ambas patas PT sin soporte del peso o colocación de la planta pero sin soportar peso.

Grado 9: Colocación plantar con soporte de peso cuando no esta caminando o pasos ocasionales ( $<=50 \%)$, frecuentes $(51 \%$ al $94 \%)$ o constantes $(95 \%$ al $100 \%)$ con soporte de peso dorsal, sin apoyo plantar.

Grado 10: Pasos ocasionales con soporte plantar, sin coordinación entre patas delanteras (PD) y PT.

Grado 11: Pasos frecuentes o constantes con soporte de peso plantar, sin coordinación entre PD y PT.

Grado 12: Pasos frecuentes o constantes con soporte de peso plantar, y coordinación ocasional entre PD y PT.

Grado 13: Pasos frecuentes o constantes con soporte de peso plantar, y coordinación frecuente entre PD y PT.

Grado 14: Constantemente da pasos con soporte de peso plantar, coordinación constante entre PD y PT, y hay rotación interna o externa de patas, principalmente al hacer contacto con el piso o al despegar. También pasos plantares frecuentes, coordinación constante entre PD y PT, y pasos dorsales ocasionales. 
Grado 15: Pasos plantares y coordinados entre PD y PT constantes. No separa los dedos o solo ocasionalmente cuando avanza la pata hacia delante. Al hacer contacto con el piso predominio de la alineación paralela de la pata al cuerpo.

Grado 16: Pasos plantares y coordinados entre PD y PT constantes durante la marcha. La separación de los dedos ocurre frecuentemente cuando avanza la pata hacia delante. Al hacer contacto con el piso predominio de la alineación paralela de la pata al cuerpo, pero, la rota al levantarla.

Grado 17: Pasos plantares y coordinados entre PD y PT constantes durante la marcha. La separación delos dedos ocurre frecuentemente cuando avanza la pata hacia delante. Al hacer contacto con el piso predominio de la alineación paralela de la pata al cuerpo, pero, al levantar la pata la mantiene alineada (sin rotar).

Grado 18: La separación de los dedos es constante durante la marcha. Al hacer contacto con el piso predominio de la alineación paralela de la pata al cuerpo, pero, la rota al levantarla.

Grado 19: Pasos plantares y coordinados entre PD y PT constantes durante la marcha. La separación de los dedos ocurre constantemente durante la marcha. Al hacer contacto con el piso y levantar, predominio de la alineación paralela de la pata al cuerpo. Arrastra la cola parte o todo el tiempo.

Grado 20: Pasos plantares, marcha coordinada y separación de dedos constante. Al hacer contacto con el piso y levantar, predominio de la alineación paralela de la pata al cuerpo, la cola levantada constantemente e inestabilidad del tronco.

Grado 21: Igual al anterior, pero, tronco constantemente estable. 


\section{Procedimiento de tinción. Método de Hematoxilina y Eosina de Harris}

FIJACIÓN:

Formalina neutra al 10\%, estabilizada, fijadores de Bouin.

SECCIONES:

En parafina, celoidina o por congelación, de 3 a 20 micrones.

SOLUCIONES:

- Alcohol ácido al 1\%.

- Agua amoniacal.

- Solución saturada de carbonato de litio.

- Solución de eosina-floxina.

HEMATOXILINA DE HARRIS:

Hematoxilina

Etanol al $100 \%$ $50.0 \mathrm{ml}$

Alumbre de potasio o de amonio $100.0 \mathrm{~g}$

Agua destilada $1000.0 \mathrm{ml}$

Oxido rojo de mercurio $2.5 \mathrm{~g}$

Use un frasco de $2000 \mathrm{ml}$ para el alumbre y el agua, y uno más pequeño para el etanol y la hematoxilina. Disuelva completamente el alumbre en el agua con la ayuda de calor y de un agitador magnético. Agita vigorosamente para mezclar la hematoxilina en el alcohol, a temperatura ambiente. Remueva el alumbre en el agua destilada de la fuente de calor. Lentamente combine las dos soluciones. Disuelva las soluciones ya combinadas a la fuente de calor. Haga hervirla tan rápido como sea posible, aproximadamente $1 \mathrm{~min}$ o menos. Remueva con calor y lentamente añada el óxido de mercurio. Si el oxido de mercurio se añade rápidamente, la reacción hará que la solución hierva y se derrame. Devuelva la solución a la fuente de calor hasta que se torne de un color púrpura, luego remuévela del calor, y póngala en un recipiente con agua fría. La solución entonces está lista. Añada $20 \mathrm{ml}$ de ácido acético para intensificar la tinción nuclear. Filtre la solución cada vez antes de usarla.

PROCEDIMIENTO: 
1. Desparafinice las láminas e hidrate hasta llegar al agua destilada. Utilice “dezenkerice", si es necesario antes de teñir.

2. Tiña en hematoxilina de Harris filtrada recientemente de 6-15min.

3. Lave en agua corriente de $2-5 \mathrm{~min}$.

4. Diferencie en alcohol ácido al 1\%, de 1-2 remojones.

5. Lave levemente en agua corriente.

6. Coloque las láminas en una solución débil de agua amoniacal o en una solución saturada de carbonato de litio hasta que las secciones se vean de un color azul brillante.

7. Lave concienzudamente en agua corriente por $10 \mathrm{~min}$.

8. Coloque en etanol al $80 \%$ por $1-2 \mathrm{~min}$.

9. Contraste en la solución de toxina-floxina por $2 \mathrm{~min}$.

10. Deshidrate y aclare a través de 2 cambios de etanol al 95\% cada uno, luego etanol absoluto, y luego xileno, $2 \mathrm{~min}$ en cada cambio.

11. Montar con medio resinoso.

RESULTADOS:

Núcleos

Citoplasma

La mayoría de otros tejidos azul

rosado a rojo

rosado a rojo 


\section{Referencias}

1. Guyton AC. Anatomía y fisiología del sistema nervioso. 2 ed: Editorial médica panamericana; 1997.

2. Guyton AC, Hall JE. Tratado de fisiología médica. 10 ed: Editorial McGraw-Hill; 2001.

3. Paulsen DF. Histología básica: Editorial el manual moderno; 1991.

4. Alcaraz RV. Estructura y función del sistema nervioso: recepción sensorial y estados del organismo: Editorial el manual moderno; 2001.

5. Kandel ER, Schwartz JH, Jessell TM. Principios de neurociencia. 4 ed: McGraw-Hill; 2001.

6. Díaz AR. Efecto de la ciclosporina-A sobre la expresión y actividad de la cintaza del óxido nítrico en tejido medular de rata. México D.F.: UNAM 2003.

7. Birmingham UoAa. Spinal Cord Injury Facts and Figures at a Glance. Birmingham, Alabama: National Spinal Cord Injury Statistical Center; 2012 [cited 2012]; Available from: http://www.nscisc.uab.edu.

8. Profyris C, Cheema SS, Zang DW, Azari MF, Boyle K, Petratos S. Degenerative and regenerative mechanisms governing spinal cord injury. Neurobiol Dis. 2004;15(3):415-36.

9. Hulsebosch CE. Recent advances in pathophysiology and treatment of spinal cord injury. Advances in physiology education. 2002;26(4):238-55.

10. Lee JM, Zipfel GJ, Choi DW. The changing landscape of ischaemic brain injury mechanisms. Nature. 1999 Jun 24;399(6738 Suppl):A7-14.

11. Bareyre FM, Schwab ME. Inflammation, degeneration and regeneration in the injured spinal cord: insights from DNA microarrays. Trends Neurosci. 2003 Oct;26(10):55563.

12. Faden Al, Simon RP. A potential role for excitotoxins in the pathophysiology of spinal cord injury. Ann Neurol. 1988 Jun;23(6):623-6.

13. Diaz-Ruiz A, Ibarra A, Perez-Severiano F, Guizar-Sahagun G, Grijalva I, Rios C. Constitutive and inducible nitric oxide synthase activities after spinal cord contusion in rats. Neurosci Lett. 2002 Feb 22;319(3):129-32.

14. Batchelor PE, Tan S, Wills TE, Porritt MJ, Howells DW. Comparison of inflammation in the brain and spinal cord following mechanical injury. J Neurotrauma. 2008 Oct;25(10):1217-25.

15. Zurita M, Vaquero J, Zurita I. Presence and significance of CD-95 (Fas/APO1) expression after spinal cord injury. J Neurosurg. 2001 Apr;94(2 Suppl):257-64.

16. Christensen MD, Everhart AW, Pickelman JT, Hulsebosch CE. Mechanical and thermal allodynia in chronic central pain following spinal cord injury. Pain. 1996 Nov;68(1):97-107.

17. Christensen MD, Hulsebosch CE. Chronic central pain after spinal cord injury. J Neurotrauma. 1997 Aug;14(8):517-37. 
18. Bracken MB, Holford TR. Effects of timing of methylprednisolone or naloxone administration on recovery of segmental and long-tract neurological function in NASCIS 2. J Neurosurg. 1993 Oct;79(4):500-7.

19. Hall ED, Braughler JM. Non-surgical management of spinal cord injuries: a review of studies with the glucocorticoid steroid methylprednisolone. Acta Anaesthesiol Belg. 1987;38(4):405-9.

20. Bracken MB, Shepard MJ, Collins WF, Jr., Holford TR, Baskin DS, Eisenberg HM, et al. Methylprednisolone or naloxone treatment after acute spinal cord injury: 1-year follow-up data. Results of the second National Acute Spinal Cord Injury Study. J Neurosurg. 1992 Jan;76(1):23-31.

21. Hall ED. Pharmacological treatment of acute spinal cord injury: how do we build on past success? J Spinal Cord Med. 2001 Fall;24(3):142-6.

22. Blight AR, Zimber MP. Acute spinal cord injury: pharmacotherapy and drug development perspectives. Curr Opin Investig Drugs. 2001 Jun;2(6):801-8.

23. Liu S, Ruenes GL, Yezierski RP. NMDA and non-NMDA receptor antagonists protect against excitotoxic injury in the rat spinal cord. Brain Res. 1997 May 9;756(1-2):160-7.

24. Haghighi SS, Johnson GC, de Vergel CF, Vergel Rivas BJ. Pretreatment with NMDA receptor antagonist MK801 improves neurophysiological outcome after an acute spinal cord injury. Neurol Res. 1996 Dec;18(6):509-15.

25. Yuceer N, Attar A, Sargon MF, Egemen N, Turker RK, Demirel E. The early protective effects of L-arginine and Ng-nitro-L-arginine methyl ester after experimental acute spinal cord injury. A light and electron microscopic study. J Clin Neurosci. 2000 May;7(3):238-43.

26. Phillis JW, Goshgarian HG. Adenosine and neurotrauma: therapeutic perspectives. Neurol Res. 2001 Mar-Apr;23(2-3):183-9.

27. Diaz-Ruiz A, Salgado-Ceballos H, Montes S, Guizar-Sahagún G, Gelista-Herrera N, Mendez-Armenta $\mathrm{M}$, et al. Delayed administration of dapsone protects from tissue damage and improves recovery after spinal cord injury. J Neurosci Res. 2011 Mar 1;89(3):373-80.

28. Brewer KL, Bethea JR, Yezierski RP. Neuroprotective effects of interleukin-10 following excitotoxic spinal cord injury. Exp Neurol. 1999 Oct;159(2):484-93.

29. Takami T, Oudega M, Bethea JR, Wood PM, Kleitman N, Bunge MB. Methylprednisolone and interleukin-10 reduce gray matter damage in the contused Fischer rat thoracic spinal cord but do not improve functional outcome. J Neurotrauma. 2002 May;19(5):653-66.

30. Hains BC, Yucra JA, Hulsebosch CE. Reduction of pathological and behavioral deficits following spinal cord contusion injury with the selective cyclooxygenase-2 inhibitor NS-398. J Neurotrauma. 2001 Apr;18(4):409-23.

31. Hansebout RR, Tanner JA, Romero-Sierra C. Current status of spinal cord cooling in the treatment of acute spinal cord injury. Spine (Phila Pa 1976). 1984 Jul-Aug;9(5):508-11.

32. Eldadah BA, Faden Al. Caspase pathways, neuronal apoptosis, and CNS injury. J Neurotrauma. 2000 Oct;17(10):811-29.

33. Bredesen DE. Apoptosis: overview and signal transduction pathways. J Neurotrauma. 2000 Oct;17(10):801-10. 
34. Schwab ME. Repairing the injured spinal cord. Science. 2002 Feb 8;295(5557):1029-31.

35. Lacroix S, Tuszynski MH. Neurotrophic factors and gene therapy in spinal cord injury. Neurorehabil Neural Repair. 2000;14(4):265-75.

36. Kwon BK, Tetzlaff W. Spinal cord regeneration: from gene to transplants. Spine (Phila Pa 1976). 2001 Dec 15;26(24 Suppl):S13-22.

37. Jones LL, Oudega M, Bunge MB, Tuszynski MH. Neurotropic factors, cellular bridges and gene therapy for spinal cord injury. J Physiol. 2001; 533: 83-89.

38. Díaz RA, Guízar SG, Ríos CC. Estrategias neuroprotectoras después de una lesión traumática de la médula espinal. Rev Med IMSS. 2002;40 (5): 437-455.

39. Rosenberg LJ, Teng YD, Wrathall JR. 2,3-Dihydroxy-6-nitro-7-sulfamoylbenzo(f)quinoxaline reduces glial loss and acute white matter pathology after experimental spinal cord contusion. J Neurosci. 1999 Jan 1;19(1):464-75.

40. Hayes KC, Potter PJ, Wolfe DL, Hsieh JT, Delaney GA, Blight AR. 4-Aminopyridinesensitive neurologic deficits in patients with spinal cord injury. J Neurotrauma. 1994 Aug;11(4):433-46.

41.Salgado-Ceballos H, Guizar-Sahagun G, Feria-Velasco A, Grijalva I, Espitia L, Ibarra A, et al. Spontaneous long-term remyelination after traumatic spinal cord injury in rats. Brain Res. 1998 Jan 26;782(1-2):126-35.

42. Lu J, Ashwell K. Olfactory ensheathing cells: their potential use for repairing the injured spinal cord. Spine 2002;27:887-892.

43. Bunge MB. Bridging areas of injury in the spinal cord. Neuroscientist. 2001 Aug;7(4):325-39.

44. Ozdemir M, Attar A, Kuzu I. Regenerative treatment in spinal cord injury. Curr Stem Cell Res Ther. 2012 Sep;7(5):364-9.

45. Houle J. The structural integrity of glial scar tissue associated with a chronic spinal cord lesion can be altered by transplanted fetal spinal cord tissue. J Neurosci Res. 1992 Jan;31(1):120-30.

46. Cheng H, Cao Y, Olson L. Spinal cord repair in adult paraplegic rats: partial restoration of hind limb function. Science. 1996 Jul 26;273(5274):510-3.

47. Ramon-Cueto A, Plant GW, Avila J, Bunge MB. Longdistance axonal regeneration in the transected adult rat spinal cord is promoted by olfactory ensheathing glia transplants. J Neurosci. 1998; 18:3803-3815.

48. Geller HM, Fawcett JW. Building a bridge: engineering spinal cord repair. Exp Neurol. 2002 Apr;174(2):125-36.

49. McDonald JW, Sadowsky C. Spinal-cord injury. Lancet. 2002 Feb 2;359(9304):41725.

50. Khan T, Dauzvardis M, Sayers S. Carbon filament implants promote axonal growth across the transected rat spinal cord. Brain Res. 1991 Feb 8;541(1):139-45.

51. Cao X, Schoichet MS. Delivering neuroactive molecules from biodegradable microspheres for application in central nervous system disorders. Biomaterials. 1999 Feb;20(4):329-39. 
52. Woerly S, Pinet E, de Robertis L, Van Diep D, Bousmina M. Spinal cord repair with PHPMA hydrogel containing RGD peptides (NeuroGel). Biomaterials. 2001 May;22(10):1095-111.

53. Oudega M, Gautier SE, Chapon P, Fragoso M, Bates ML, Parel JM, et al. Axonal regeneration into Schwann cell grafts within resorbable poly(alpha-hydroxyacid) guidance channels in the adult rat spinal cord. Biomaterials. 2001;22: 1125-1136.

54. Novikov LN, Novikova LN, Mosahebi A, Wiberg M, Terenghi G, Kellerth JO. A novel biodegradable implant for neuronal rescue and regeneration after spinal cord injury. Biomaterials. 2002 Aug;23(16):3369-76.

55. Dalton PD, Flynn L, Shoichet MS. Manufacture of poly(2-hydroxyethyl methacrylate-co-methyl methacrylate) hydrogel tubes for use as nerve guidance channels. Biomaterials. 2002;23: 3843-3851.

56. Gautier SE, Oudega M, Fragoso M, Chapon P, Plant GW, Bunge MB, et al. Poly(alpha-hydroxyacids) for application in the spinal cord: resorbability and biocompatibility with adult rat Schwann cells and spinal cord. J Biomed Mater Res. 1998 Dec 15;42(4):642-54.

57. Rangappa N, Romero A, Nelson KD, Eberhart RC, Smith GM. Laminin-coated poly(Llactide) filaments induce robust neurite growth while providing directional orientation. J Biomed Mater Res. 2000;51: 625-634.

58. Pechar M, Ulbrich K, Subr V, Seymour LW, Schacht EH. Poly(ethylene glycol) multiblock copolymer as a carrier of anti-cancer drug doxorubicin. Bioconjug Chem. 2000;11: 131-139.

59. Seckel BR, Jones D, Hekimian KJ, Wang KK, Chakalis DP, Costas PD. Hyaluronic acid through a new injectable nerve guide delivery system enhances peripheral nerve regeneration in the rat. J Neurosci Res. 1995;40: 318-324.

60. Campoccia D, Doherty P, Radice M, Brun P, Abatangelo G, Williams DF. Semisynthetic resorbable materials from hyaluronan esterification. Biomaterials. 1998 Dec;19(23):2101-27.

61. Heffner CD, Lumsden AG, O'Leary DD. Target control of collateral extension and directional axon growth in the mammalian brain. Science. 1990;247: 217-220.

62. Tong XJ, Hirai K, Shimada H, Mizutani $Y$, Izumi T, Toda N, et al. Sciatic nerve regeneration navigated by laminin-fibronectin double coated biodegradable collagen grafts in rats. Brain Res. 1994 Nov 7;663(1):155-62.

63. Olayo R, Rios C, Salgado-Ceballos H, Cruz GJ, Morales J, Olayo MG, et al. Tissue spinal cord response in rats after implants of polypyrrole and polyethylene glycol obtained by plasma. J Mater Sci Mater Med. 2008 Feb;19(2):817-26.

64. Cruz GJ, Mondragon-Lozano R, Diaz-Ruiz A, Manjarrez J, Olayo R, Salgado-Ceballos $\mathrm{H}$, et al. Plasma polypyrrole implants recover motor function in rats after spinal cord transection. J Mater Sci Mater Med. 2012 Jul 14.

65. Aldea E. Plasma polimerization processes characteristics and aplications. Bucarest1999.

66. Morales J. Polimerización por plasma: tratamiento superficial y simulación del plasma. Mexico, Distrito Federal: Universidad Autónoma Metropolitana; 2001. 
67. Juan Morales Corona, Elizabeth Pérez Tejada, R. Montiel Campos, Humberto Vázquez Torres, Roberto Olayo González, L. E. Gómez Quiróz, et al. Modificación superficial por plasma aplicada a biomateriales. In: Leopoldo G-CS, Leonardo D, Michel P, Vázquez $E$, editors. La física biológica en México: Temas selectos 2. México: El Colegio Nacional; 2008. p. 225-47.

68. Cruz GJ, Morales J, Olayo R. Films obtained by plasma polymerization of pyrrole. Thin Solid Films. 1999;342:119-26.

69. Chu PK, Chen JY, Wang LP, Huang N. Plasma-surface modification of biomaterials. Materials Science and Engineering: R: Reports. 2002;36(5, Äi6):143-206.

70. Ramırez-Fernandez O, Godınez R, Morales J, Gomez-Quiroz L, Gutierrez-Ruiz MC, Zuniga-Aguilar E, et al. Superficies Modificadas Mediante Polimerizacion por Plasma para Cocultivos de Modelos Hepaticos. Revista mexicana de ingeniería biomédica. 2012;33(2):127-35.

71. Sastre R, Aza Sd, Roman JS. Biomateriales. España: Faenza Editrice Ibérica; 2004.

72. Basso DM, Beattie MS, Bresnahan JC. A sensitive and reliable locomotor rating scale for open field testing in rats. J Neurotrauma. 1995 Feb;12(1):1-21.

73. Olayo R, Ríos C, Salgado-Ceballos H, Cruz GJ, Morales J, Olayo MG, et al. Tissue spinal cord response in rats after implants of polypyrrole and polyethylene glycol obtained by plasma. J Mater Sci Mater Med. 2008 Feb 1;19(2):817-26.

74. Karl EM. Spehlmann's Evoked potential primer: Visual, auditory, and somatosensory evoked potentials in clinical diagnosis: Butterworth-Heinemann; 1994.

75. Nevo U, Hauben E, Yoles E, Agranov E, Akselrod S, Schwartz M, et al. Diffusion anisotropy MRI for quantitative assessment of recovery in injured rat spinal cord. Magn Reson Med. 2001 Jan 1;45(1):1-9.

76. Bozzo A, Marcoux J, Radhakrishna M, Pelletier J, Goulet B. The role of magnetic resonance imaging in the management of acute spinal cord injury. J Neurotrauma. 2011 Aug;28(8):1401-11.

77. Weishaupt D, Köchli VD, Marincek B. How Does MRI work? An introduction to the physics and function of Magnetic Resonance Imaging. 2 ed: Springer; 2006.

78. Brown AM, Semelka CR. MRI basic principles and applications. 3 ed. United States: Wiley-Liss; 2003.

79. Brown R. A brief account of microscopical observations made in the months of June, July, and August, 1827, on the particles contained in the pollen of plants; and on the general existence of active molecules in organic and inorganic bodies. Phil Mag. 1828;4:161-173.

80. Le Bihan D, Mangin JF, Poupon C, Clark CA, Pappata S, Molko N, et al. Diffusion tensor imaging: concepts and applications. J Magn Reson Imaging. 2001 Apr;13(4):534-46.

81. Einstein A. Investigations on the Theory of the Brownian Movement. New York: Dover Publications, Inc. 1926.

82. Stejskal EO, E.Tanner J. Spin diffusion measurements: spin echoes in the presence of a time-dependent field gradient. J Chem Phys. 1965; 42(1):288-292.

83. Zufiría LO, Martínez JL. Aprendiendo los fundamentos de la resonancia magnética. España: Médica Panamericana; 2006. 
84. Gili J, Alonso J. Introducción biofísica a la resonancia magnética en neuroimagen. Barcelona2000.

85. W. McRobbie D, A. Moore E, J. Graves M, R. Prince M. MRI from Picture to Proton. 2007 Jan 1:394.

86. Fraidakis $M$, Klason $T$, Cheng $H$, Olson L, Spenger C. High-resolution MRI of intact and transected rat spinal cord. Exp Neurol. 1998 Oct 1;153(2):299-312.

87. Fukuoka M, Matsui N, Otsuka T, Murakami M, Seo Y. Magnetic resonance imaging of experimental subacute spinal cord compression. Spine (Phila Pa 1976). 1998 Jul 15;23(14):1540-9.

88. Narayana PA, Grill RJ, Chacko T, Vang R. Endogenous recovery of injured spinal cord: longitudinal in vivo magnetic resonance imaging. J Neurosci Res. 2004 Dec $1 ; 78(5): 749-59$.

89. Weber T, Vroemen M, Behr V, Neuberger T, Jakob $\mathrm{P}$, Haase A, et al. In vivo highresolution $\mathrm{MR}$ imaging of neuropathologic changes in the injured rat spinal cord. American journal of neuroradiology. 2006;27(3):598-604.

90. Sandner B, Pillai DR, Heidemann RM, Schuierer G, Mueller MF, Bogdahn U, et al. In vivo high-resolution imaging of the injured rat spinal cord using a 3.0T clinical MR scanner. J Magn Reson Imaging. 2009 Mar 1;29(3):725-30.

91. Andrew VS, Hollis GP. Use of Magnetic Resonance Imaging in Spinal Trauma: Indications, Techniques, and Utility. Journal of the American Academy of Orthopaedic Surgeons. 1998;6:134-145.

92. Carneiro AAO, Vilela GR, Araujo DBd, Baffa O. MRI Relaxometry: Methods and Applications. Brazilian Journal of Physics. 2006;36.

93. Cohen-Adad J, Wheeler-Kingshott CAM. Quantitative MRI of the Spinal Cord: Academic Press; 2014.

94. Hagmann P, Jonasson L, Maeder P, Thiran JP, Wedeen VJ, Meuli R. Understanding diffusion MR imaging techniques: from scalar diffusion-weighted imaging to diffusion tensor imaging and beyond. Radiographics. 2006 Oct;26 Suppl 1:S205-23.

95. Fenyes DA, Narayana PA. In vivo diffusion characteristics of rat spinal cord. Magn Reson Imaging. 1999 Jun 1;17(5):717-22.

96. Lorke D. A new approach to practical acute toxicity testing. Arch Toxicol. 1983 Dec 1;54(4):275-87.

97. Vaquero J, Zurita M, Oya S, Santos M. Cell therapy using bone marrow stromal cells in chronic paraplegic rats: systemic or local administration? Neurosci Lett. 2006 May 1;398(1-2):129-34.

98. Zurita M, Vaquero J. Bone marrow stromal cells can achieve cure of chronic paraplegic rats: functional and morphological outcome one year after transplantation. Neurosci Lett. 2006 Jul 10;402(1-2):51-6.

99. Mondragon-Lozano R, Diaz-Ruiz A, Rios C, Olayo Gonzalez R, Favila R, SalgadoCeballos $\mathrm{H}$, et al. Feasibility of in vivo quantitative MRI with DWI, T2-relaxometry and DTI in a clinical 3T MR scanner for the acute traumatic spinal cord injury of rats: technical note. Spine (Phila Pa 1976). 2013 Jun 11.

100. Mondragon-Lozano R, Rios C, Diaz-Ruiz A, Salgado-Ceballos H, Olay R, Morales J, et al., editors. In vivo diffusion characteristics of the injured rat spinal cord with 
3.0T clinical magnetic resonance equipment. 41st annual meeting, Society for Neuroscience; 2011; Washigton, D. C. .

101. Mondragon-Lozano R, Olayo R, Morales J, Alvarez-Mejia L, Morales A, Salgado-Ceballos $\mathrm{H}$, et al., editors. In vivo diffusion magnetic resonance characteristics of spinal cord injury following polypirrole/iodine treatment in rats. 42nd annual meeting, Society for Neuroscience; 2012; New Orleans.

102. Callot V, Duhamel G, Kober F. Spinal cord - MR of rodent models. Methods Mol Biol. 2011;771:355-83.

103. Basso DM, Beattie MS, Bresnahan JC. Graded histological and locomotor outcomes after spinal cord contusion using the NYU weight-drop device versus transection. Experimental Neurology. 1996 Jun 1;139(2):244-56.

104. Sedı J, Urdzíková L, Jendelová P, Syková E. Methods for behavioral testing of spinal cord injured rats. Neuroscience \& Biobehavioral Reviews. 2008;32(3):550-80.

105. Morales J, Olayo MG, Cruz GJ, Olayo R. Synthesis by plasma and characterization of bilayer aniline-pyrrole thin films doped with iodine. Journal of Polymer Science Part B: Polymer Physics. 2002;40(17):1850-6.

106. Guizar-Sahagun G, Grijalva I, Madrazo I, Franco-Bourland R, SalgadoCeballos $\mathrm{H}$, Ibarra A, et al. Neuroprotection of completely lacerated spinal cord of adult rats by homotopic and heterotopic transplantation. Restor Neurol Neurosci. 1994 Jan 1;7(2):61-70.

107. Beauchamp NJ, Jr., Ulug AM, Passe TJ, van Zijl PC. MR diffusion imaging in stroke: review and controversies. Radiographics. 1998 Sep-Oct;18(5):1269-83; discussion 83-5.

108. Rugg-Gunn FJ, Boulby PA, Symms MR, Barker GJ, Duncan JS. Whole-brain T2 mapping demonstrates occult abnormalities in focal epilepsy. Neurology. 2005 Jan 25;64(2):318-25.

109. Bartlett PA, Symms MR, Free SL, Duncan JS. T2 relaxometry of the hippocampus at 3T. AJNR Am J Neuroradiol. 2007 Jun-Jul;28(6):1095-8.

110. Kamble RB, Venkataramana NK, Naik AL, Rao SV. Diffusion tensor imaging in spinal cord injury. Indian J Radiol Imaging. 2011 Jul;21(3):221-4. 